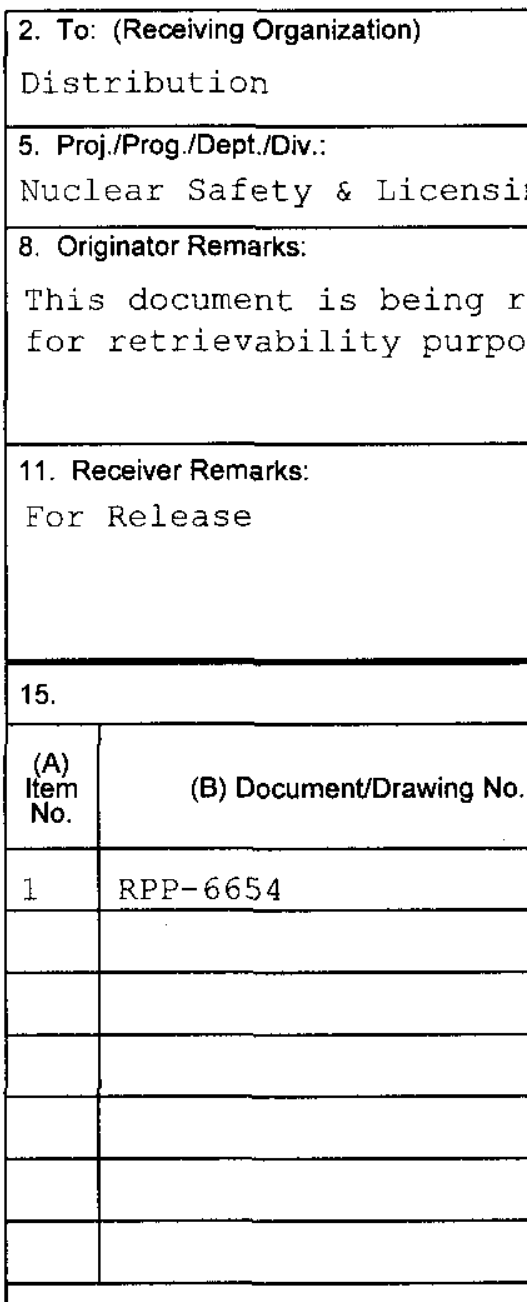

16.
11A. Design Baseline Document? $\square$ Yes $\square$ No

\author{
3. From: (Originating Organization) \\ Nuclear Safety \& Licensing \\ 6. Design Authority/Design Agent/Cog. Engr.: \\ D. R. Bratzel.
}

4. Related EDT No.:
N/A
7. Purchase Order No.:
N/A

9. Equip./Component No.

$\mathrm{N} / \mathrm{A}$

10. System/Bldg./Facility:

$\mathrm{N} / \mathrm{A}$

12. Major Assm. Dwg. No.:

$\mathrm{N} / \mathrm{A}$

13. Permit/Permit Application No.:

N/A

14. Required Response Date:

$\mathrm{N} / \mathrm{A}$

\begin{tabular}{|c|c|c|c|}
\hline$(F)$ & $(G)$ & $(H)$ & $(I)$ \\
\hline $\begin{array}{c}\text { Approval } \\
\text { Desig- } \\
\text { nator }\end{array}$ & $\begin{array}{c}\text { Reason } \\
\text { for Trans- } \\
\text { mittal }\end{array}$ & $\begin{array}{c}\text { Origi- } \\
\text { nator } \\
\text { Dispo- } \\
\text { stion }\end{array}$ & $\begin{array}{c}\text { Receiv- } \\
\text { er } \\
\text { Dispo- } \\
\text { sition }\end{array}$ \\
\hline N/A & 2 & 1 & 1 \\
\hline & & & \\
\hline & & & \\
\hline & & & \\
\hline
\end{tabular}

KEY

\begin{tabular}{|c|c|c|c|c|}
\hline Approval Designator (F) & \multicolumn{2}{|c|}{ Reason for Transmittal (G) } & \multicolumn{2}{|c|}{ Disposition $(H) \&(1)$} \\
\hline $\begin{array}{l}\text { E, S, Q, D OR N/A } \\
\text { (See WHC-CM-3-5, } \\
\text { Sec. 12.7) }\end{array}$ & $\begin{array}{l}\text { 1. Approval } \\
\text { 2. Release } \\
\text { 3. Information }\end{array}$ & $\begin{array}{l}\text { 4. Review } \\
\text { 5. Post-Review } \\
6 \text {. Dist. (Receipt Acknow. Required) }\end{array}$ & $\begin{array}{l}\text { 1. Approved } \\
\text { 2. Approved w/comment } \\
\text { 3. Disapproved w/comment }\end{array}$ & $\begin{array}{l}\text { 4. Reviewed no/comment } \\
\text { 5. Reviewed w/comment } \\
6 \text {. Receipt acknowledged }\end{array}$ \\
\hline
\end{tabular}

17. SIGNATURE/DISTRIBUTION (See Approval Designator for required signatures)

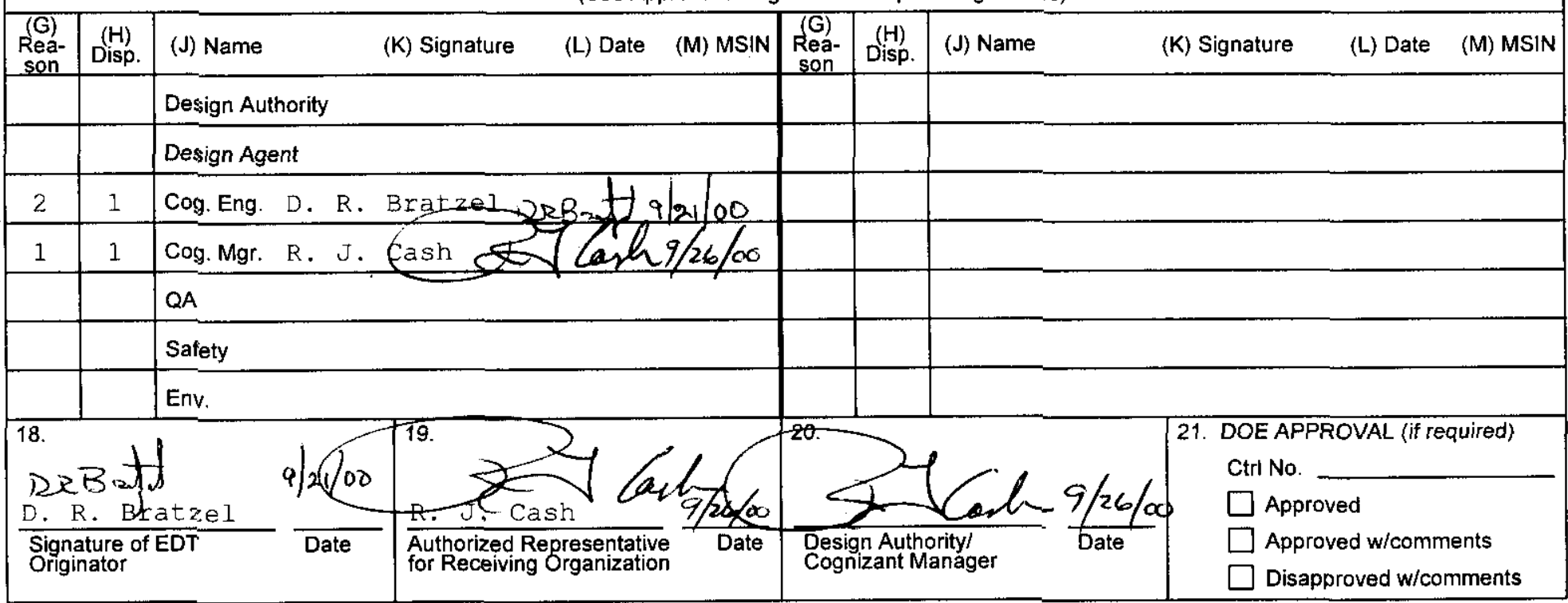




\section{DISTRIBUTION SHEET}

To

Distribution

\section{Project Title/Work Order}

Tank Bump Accident Potential and Consequences During Waste Retrieval, RPP-6654, Rev. 0

\begin{tabular}{|l|}
\hline \multicolumn{1}{|c|}{ Name } \\
\hline CH2M HILI Hanford Group, Inc. \\
\hline D. R. Bratzel copies) \\
\hline R. J. Cash \\
\hline G. W. Gault \\
\hline T. G. Goetz \\
\hline J. M. Grigsby \\
\hline J. P. Harris \\
\hline N. W. Kirch \\
\hline C. E. Leach \\
\hline S. N. Maruvada \\
\hline J. E. Meacham \\
\hline R. G. Stickney \\
\hline \\
\hline Fauske \& Associates, Inc. \\
\hline 16W070 W. 83rd St. \\
\hline Burr Ridge, IL 60521 \\
\hline M. G. Plys \\
\hline B. Malinovic \\
\hline \\
\hline Fluor Federal Services \\
\hline G. W. Ryan \\
\hline \\
\hline \\
\hline \\
\hline
\end{tabular}

From

Nuclear Safety \& Licensing

MSIN

Attach.

$\mathrm{R} 1-44$

$\mathrm{R} 1-44$

$\mathrm{R} 1-44$

R1-49

$\mathrm{R} 1-44$

$\mathrm{R} 1-49$

R2-11

$\mathrm{R} 1-44$

$\mathrm{R} 1-49$

$\mathrm{R} 1-49$

$\mathrm{R} 1-43$ \begin{tabular}{l} 
Page 1 of 1 \\
\hline Date September 20, 2000 \\
\hline EDT No. 625136 \\
ECN No. N/A
\end{tabular}

\section{Text 1 Attach./}

Attach./ Only 


\title{
TANK BUMP ACCIDENT POTENTIAL AND CONSEQUENCES DURING WASTE RETRIEVAL
}

\author{
M. Epstein, B. Malinovic, \& M. G. Plys \\ Fauske \& Associates \\ Richland, WA 99352 \\ U.S. Department of Energy Contract DE-AC06-99RL14047

$\begin{array}{lll}\text { EDT/ECN: } & 625136 & \text { UC: N/A } \\ \text { Cost Center: } & 73 \mathrm{~B} 00 & \text { Charge Code: } 109311 \\ \text { B\&R Code: } & \text { EWO } / 2 \mathrm{~J} 2020 & \text { Total Pages: } 105\end{array}$

D. R. Bratzel

CH2M HILL Hanford Group, Inc.

Key Words: Tank Bump, Accident Analysis, Consequence Analysis

\begin{abstract}
This report provides an evaluation of the Hanford tank bump accident analysis and consequences for incorporation into the Authorization Basis. The analysis scope is for the feed delivery and retrieval of waste from single-shell and double-shell tanks.

*Visual Basic is a registered trademark of Microsoft Corporation.
\end{abstract}

TRADEMARK DISCLAIMER. Reference herein to any specific commercial product, process, or service by trade name, trademark, manufacturer, or otherwise, does not necessarily constitute or imply its endorsement, recommendation, or favoring by the United States Government or any agency thereof or its contractors or subcontractors.

Printed in the United States of America. To obtain copies of this document, contact: Document Control Services, P.O. Box 950, Mailstop H6-08, Richland WA 99352, Phone (509) 372-2420; Fax (509) 376-4989.
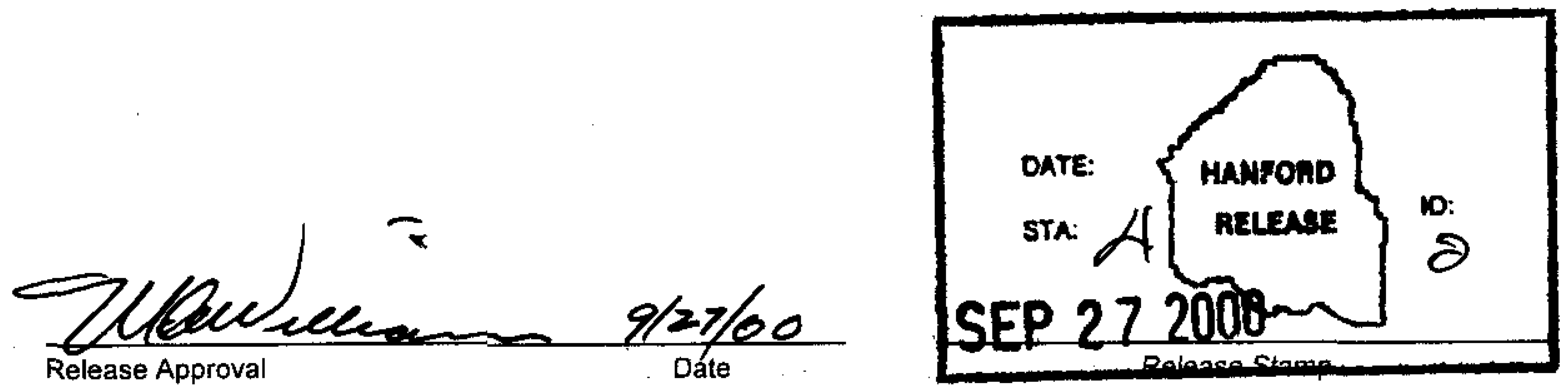

Approved For Public Release 
RPP-6654

Revision 0

\section{Tank Bump Accident Potential and Consequences During Waste Retrieval}

Prepared for the U.S. Department of Energy Assistant Secretary for Environmental Management

\section{CH2MHILL Hanford Group, Inc.}

Richland, Washington

Contractor for the U.S. Department of Energy

Office of River Protection under Contract DE-AC06-99RL14047

Approved for Public Release; Further Dissemination Unlimited 


\section{LEGAL DISCLAIMER}

This report was prepared as an account of work sponsored by an agency of the United States Government. Neither the United States Government nor any agency thereof, nor any of their employees, nor any of their contractors, subcontractors or their employees, makes any warranty, express or implied, or assumes any legal liability or responsibility for the accuracy, completeness, or any third party's use or the results of such use of any information, apparatus, product, or process disclosed, or represents that its use would not infringe privately owned rights. Reference herein to any specific commercial product, process, or service by trade name, trademark, manufacturer, or otherwise, does not necessarily constitute or imply its endorsement, recommendation, or favoring by the United States Government or any agency thereof or its contractors or subcontractors. The views and opinions of authors expressed herein do not necessarily state or reflect those of the United States Government or any agency thereof.

This report has been reproduced from the best available copy.

Available in paper copy and microfiche.

Available electronically at

http://www.doe.gov/bridge. Available for a processing fee to the U.S. Department of Energy and its contractors, in paper, from:

U.S. Department of Energy

Office of Scientific and Technical Information

P.O. Box 62

Oak Ridge, TN 37831-0062

phone: $865-576-8401$

fax: 865-576-5728

email: reports@adonis.osti.gov(423) 576-8401

Available for sale to the public, in paper, from:

U.S. Department of Commerce

National Technical information Service

5285 Port Royal Road

Springfield, VA 22161

Phone: 800-553-6847

fax: 703-605-6900

email: orders@ntis.fedworld.gov

online ordering:

http://www.ntis.gov/ordering.htm 


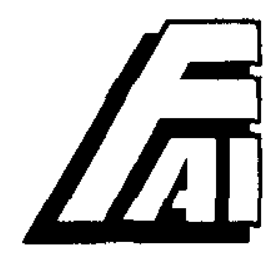

FAL/00-52, Rev. 0

TANK BUMP ACCIDENT POTENTIAL

AND CONSEQUENCES DURING WASTE RETRIEVAL

Submitted To:

CH2M HILL Hanford Group, Inc.

2355 Stevens Center

Richland, Washington 99352

Prepared By:

B. Malinovic, M. Epstein, and M. G. Plys

Fauske \& Associates, Inc.

16W070 West 83rd Street

Burr Ridge, Illinois 60521

Tel: (630) 323-8750 Fax: (630) 986-5481

August 2000 
RPP-6654, REV. 0

This page intentionally left blank.

FAI/00-52, Rev. 0 


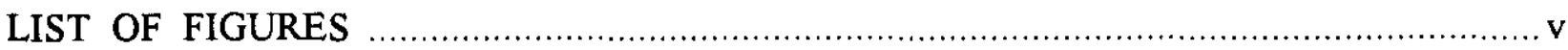

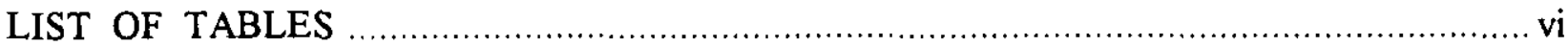

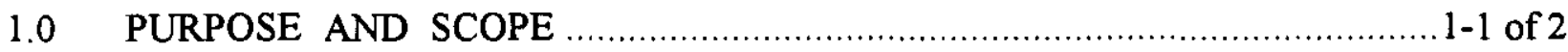

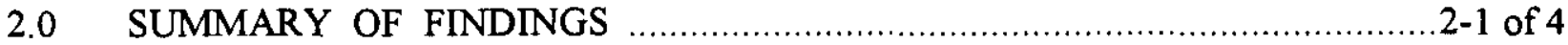

3.0 OPERATIONS, EQUIPMENT, AND WASTE PARAMETERS

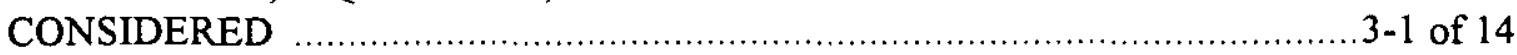

3.1 Tank 241-AZ-101 Feed Delivery Activities ................................................ 3-2

3.2 Feed Delivery Activities for Tanks 241-AN-104 and 241-AN-105 ..................3-2

3.3 Tank Bump Considerations for Feed Delivery Activities …….........................3-5

3.4 Tank Bump Considerations for LAW Feed Delivery Activities .........................3-7

3.5 Tank Bump Considerations for Aging Waste Facility Tank Feed

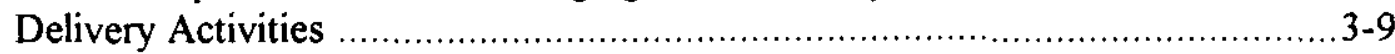

4.0 TANK BUMP PHYSICAL MODELS AND CRITERIA …....................... $4-1$ of 8

5.0 WASTE FEED DELIVERY TANK BUMP SCENARIO
QUANTIFICATION ….............................................................. 16 of 16

5.1 Frequency of Bump Conditions for the Analyzed Scenario ............................5-1

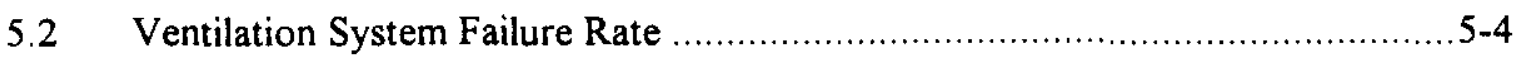

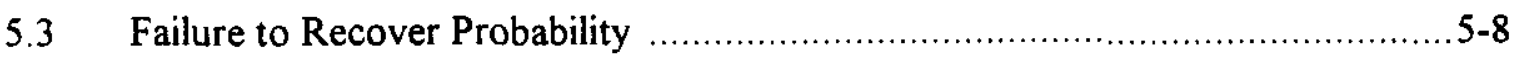

5.4 The Likelihood of Tank Bump Given Saturated Conditions and

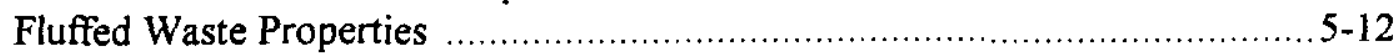

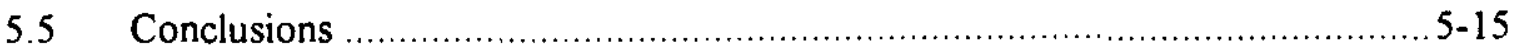

6.0 WASTE FEED DELIVERY TANK BUMP CONSEQUENCE
ANALYSIS

6.1 Bubble and Waste Ascent Model ............................................................ 6-1

6.2 Parametric HADCRT Analysis of a Retrieval Tank Bump for Headspace Pressure and Aerosol Generation .............................................6-4

6.3 HADCRT Input for the Bounding Tank 241-AZ-102 Tank Bump Scenario ......6-6

6.4 Tank 241-AZ-102 Retrieval Tank Bump Bounding Radiological and Toxic Chemical Consequences 
RPP-6654, REV. 0

TABLE OF CONTENTS

(concluded)

Page

6.5 Tank 241-AZ-102 Retrieval Tank Bump Bounding Radiological and

Toxic Chemical Consequences: 12-Hour On-Site Exposure and

24-Hour Off-Site Exposure

7.0 REFERENCES

$.7-1$ of 2

APPENDIX A

APPENDIX B

APPENDIX C

APPENDIX D

APPENDIX E

APPENDIX F
Quantitative Treatment of Transient Conduction Within

the Non-Convective Layer During Settling A-1 of 4

Transient Temperature Calculations for Off-Normal

Retrieval Scenarios

B-1 of 10

Spreadsheets for Accident Frequency Calculation

C-1 of 8

HADCRT Inputs for Tank Bump Consequence Analysis

D-1 of 6

Quality Assurance Documents

E-1 of 4

Checklists for Technical Peer Review

F-1 of 4 


\section{LIST OF FIGURES}

Figure

$\underline{\text { Page }}$

3-1 Simplified Logic Diagram for Tank 241-AZ-101 Feed Delivery Activities 3-3

3-2 Tanks 241-AN-105 and 241-AN-104 Feed Delivery Activities $3-4$

3-3 LAW Feed Delivery Tank Bump Event Tree ............................................... 3-8

3-4 AWF Feed Delivery Activity Tank Bump Event Tree ........................................ 3-10

3-5 Tank 241-AZ-102 Case 2 Temperatures with 2,000 SCFM Annulus Flow and Chilled Air

3-6 Tank 241-AZ-102 Case 2 Temperatures for Loss of Ventilation and Mixer Pump Shut Off at Maximum Mixed Waste Temperature

4-1 Convective Layer Power - Non-Convective Layer Power Map for the Possible Occurrence of Steam Bumps

5-1 Illustration of Time to Tank Bump Conditions as a Function of Ventilation System Failure Time During Mixer Pump Operation ...................................................... 5-2

5-2 Schematic Diagram of the Primary Ventilation System for AZ/AY DSTs ............... 5-5

5-3 Schematic Diagram of Tank 241-AZ-102 Annulus Ventilation System ................... 5-6

5-4 Base Case Tank Bump Conditions Frequency as a Function of Mixer Pump Operation

5-5 Uncertainty Analysis for the Mixer Pump Operation Day where Tank Bump Conditions Frequency Becomes Credible

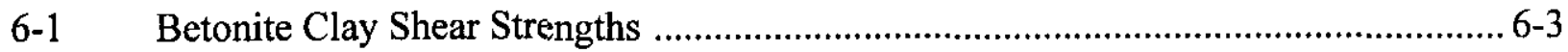

6-2 Tank 241-AZ-102 Retrieval Bump Short-Term Results ...................................... 6-9

6-3 Tank 241-AZ-102 Retrieval Bump Long-Term Results .................................... 6-10

B-1 RETRIEVAL Validation Results ....................................................................

B-2 Results of Case with Primary Ventilation but No Annulus Ventilation ....................B-8 


\section{LIST OF TABLES}

Table

Page

4-1 Parameter Values for Steam Bump Condition Calculations ..................................4-6

5-1 Mixed Waste Temperature as a Function of Time …........................................ $5-9$

5-2 Baseline Inputs for Tank Bump Frequency Evaluation as a Function of Time ........ 5-10

5-3 Evaluation of Meyer and Wells (2000) Criterion for Two Fluffing Factors of 1.4 and 1.7

6-1 Parameter Values for Tank 241-AZ-102 Headspace Overpressure Analysis $6-5$

6-2 Results of Parametric Analysis of a Single Retrieval Bump in Tank 241-AZ-102 ......6-6

6-3 Parameter Values for Tank 241-AZ-102 Bounding Consequence Analysis ..............6-8

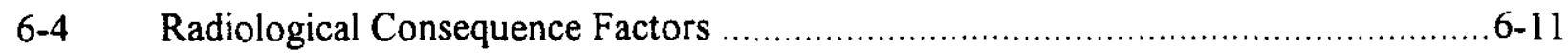

6-5 Sum-of-Fraction of Risk Guidelines for a Unit Release of Chemicals ..................6-13

6-6 Toxic Consequence Evaluation Results for a Single Retrieval Scenario Bump ........6-13

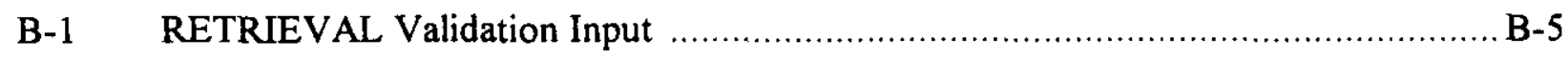

B-2 Inputs for Case with Primary Ventilation but No Annulus Ventilation ................... B-7 


\subsection{PURPOSE AND SCOPE}

This report provides an evaluation of Hanford tank bump accident potential and consequences during waste retrieval operations. The purpose of this report is to consider the best available new information to support recommendations for safety controls. A new tank bump accident analysis for safe storage (Epstein et al. 2000) is extended for this purpose.

A tank bump is a postulated event in which gases, consisting mostly of water vapor, are suddenly emitted from the waste and cause tank headspace pressurization. Tank bump scenarios, physical models, and frequency and consequence methods are fully described in Epstein et al. (2000).

The analysis scope is waste retrieval from double-shell tanks (DSTs) including operation of equipment such as mixer pumps and air lift circulators. The analysis considers physical mechanisms for tank bump to formulate criteria for bump potential during retrieval, application of the criteria to the DSTs, evaluation of bump frequency, and consequence analysis of a bump. The result of the consequence analysis is the mass of waste released from tanks; radiological dose is calculated using standard methods (Cowley et al. 2000). 
RPP-6654, REV. 0

This page intentionally left blank. 


\subsection{SUMMARY OF FINDINGS}

Waste retrieval activities have been evaluated to identify credible tank bump accident scenarios, estimate their frequency, and calculate radiological and toxicological consequences stemming from predicted source terms.

Retrieval operations were reviewed with respect to tank bump phenomena and possible scenarios were presented as logic trees. Based on a set of ventilation system success criteria and the tank bump requirements presented in the safe storage accident analysis (Epstein et al. 2000), a scenario for further analysis was developed. This scenario states that during mixer pump operation, the ventilation system fails and mixer pumps are shut down to minimize heat load. Then, the ventilation system cannot be recovered prior to tank self-heating to bump conditions.

Success criteria assume that the ventilation system will maintain waste temperatures below limiting condition for operation (LCO) 3.3.2 for indefinite mixer pump operation, as in the analysis of Crea et al. (2000). The results of the safe storage accident analysis

(Epstein et al. 2000) can then be used to immediately state that tank bump during retrieval frequency is beyond extremely unlikely for all DSTs, with the exception of the aging waste facility (AWF) tanks. Safe storage results show that starting from the LCO 3.3.2 temperature limits of $195^{\circ} \mathrm{F}$, tank self-heating to bump conditions would require hundreds of days, excepting the AWFs. In addition, this report shows that for DSTs with a total decay heat load of less than $10 \mathrm{~kW}$, tank bumps are impossible, regardless of non-convective layer depth or the fluffing factor.

The AWFs were considered further and Tank 241-AZ-102 was selected as the bounding tank for both frequency and consequence analysis, based on the safe storage results of the analysis (Epstein et al. 2000) and Crea et al. (2000). For the frequency analysis, the duration of mixer pump operation is a key risk metric. A long mixer pump duration increases the likelihood of ventilation system failure during mixer pump operation and heats the waste to reduce the available recovery time. For the planned operations, which have mixer pump operations lasting only a few days, tank bump frequency is beyond extremely unlikely because the available recovery time will be much larger than even the worst corrective maintenance times. Mixer pump operation was studied parametrically, however, to account for prolonged operation caused by schedule delays, procedural errors, and the like. Tank bump frequency becomes credible (greater than $1 \times 10^{-6} /$ demand) if the mixer pumps operate for approximately one month.

Consequences were calculated for Tank 241-AZ-102 in much the same manner as they were calculated in the safe storage accident analysis (Epstein et al. 2000). Only the first batch operation for Tank 241-AZ-102 was considered; subsequent batches will have smaller waste inventories and heat loads. The main difference between consequence analysis in the safe storage scenario and consequence analysis for the retrieval scenario is the waste properties. A fluffing factor of 2.0 was applied to settled waste, per Crea et al. (2000), which means relative to the safe storage scenario, the non-convective layer has a smaller solids mass (or volume) fraction and smaller yield strength. A fluffing factor value of 2.0 proves to be very conservative, in light of mixing test results that indicate best-estimate values of 1.3 or 1.4. Calculations using the Meyer and Wells (2000) criterion described in the safe storage accident analysis 
(Epstein et al. 2000) indicate that a tank bump initiated by retrieval operations is possible only for fluffing factor values greater than 1.7 .

For Tank 241-AZ-102, HADCRT parametric runs were performed to study the range of outcomes for a retrieval bump. The HADCRT code is an integrated model for storage tank thermal-hydraulic and accident phenomena (Malinovic et al. 2000). Code revisions for bump phenomena are described in the safe storage accident analysis (Epstein et al. 2000). The parametric runs considered a range of initial gas volumes and two supernatant temperatures, 94 and $100^{\circ} \mathrm{C}$. The size of the retrieval bump, in terms of headspace overpressure and aerosol generation, is very sensitive to the supernatant temperature. The $94^{\circ} \mathrm{C}$ value is identified as a best-estimate, based on the work of Crea et al. (2000), while $100^{\circ} \mathrm{C}$ is an upper bound assuming pure water properties. The analysis of Crea et al. (2000) shows that when the non-convective layer reaches saturated conditions, the supernatant is not yet saturated and is only $94^{\circ} \mathrm{C}$. (As shown in the safe storage accident analysis (Epstein et al. 2000), the supernatant temperature determines the bubble expansion ratio, which is the bubble gas volume exiting the top surface of the supernatant to the initial gas volume.) This series of parametric runs revealed that for the best-estimate supernatant temperature and the expected initial gas volume(s), retrieval tank bump consequences would be much smaller than the consequences calculated for the safe storage scenario. This is because the retrieval scenario bumps should be weak by comparison and the filters should not fail on overpressure.

A bounding, unmitigated scenario was identified for Tank 241-AZ-102, nevertheless, assuming that the initial gas volume in the bump would be half the initial gas volume in the safe storage bump already analyzed. Parametric runs for the strength of a single bump show that with a fluffing factor of 2.0 , a retrieval scenario bump of $4.0 \mathrm{~m}^{3}$ of initial gas released would be nearly as strong as the safe storage scenario bump with $8 \mathrm{~m}^{3}$ of initial gas released. But halving the initial gas volume means that the total number of bumps is roughly doubled. In the bounding retrieval bump scenario, 29 bumps occur over a span of three weeks. In keeping with the definition of a bounding, unmitigated scenario, HEPA filters were not credited and no account was made of their decontamination factor or pressure drop characteristics.

HADCRT analysis shows that the bumps are spaced so far apart (18 hours) that each individual bump is unaffected by the previous bump. Between bumps, all airborne aerosols are either deposited back to the waste surface or expelled. In other words, the headspace returns to the initial conditions before the next bump occurs. The source term from $n$ bumps is then simply $n$ multiplied by the source term of a single bump. For a single bump, $0.42 \mathrm{~kg}$ of waste are released including 0.01 liters of solid and 0.36 liters of liquid. Note that the solids mass fraction of the released waste is smaller in the retrieval scenario due to fluffing.

As in the safe storage accident analysis (Epstein et al. 2000), radiological consequences were calculated based on methodology identified in Cowley et al. (2000). Radiological and toxicological consequences were calculated for one bump only. The presumption is that after the first bump occurs, mitigating actions would minimize or prevent dose to both the on-site worker and off-site receiver. During an eight-hour shift, total on-site worker dose is $0.003 \mathrm{~Sv}$ for a receiver at $100 \mathrm{~m}$. For an eight-hour event, the off-site dose is $6 \times 10^{-6} \mathrm{~Sv}$. Toxicological consequences were calculated using methodology identified in 


\section{RPP-6654, REV. 0}

WHC-SD-WM-SARR-011 (1996) and found to be within guidelines for continuous release assumptions, but not puff release assumptions. 
RPP-6654, REV. 0

This page intentionally left blank. 


\subsection{OPERATIONS, EQUIPMENT, AND WASTE PARAMETERS CONSIDERED}

This section describes the retrieval activities as planned for double-shell Tanks 241-AZ-101, 241-AN-104, and 241-AN-105. Primary information sources are Carlson (1999a and 1999b). Because retrieval operations are amply described in these references and elsewhere, the focus here is only to summarize them in sufficient detail to understand the accident scenarios evaluated in Sections 5.0 and 6.0. In the references, much of the discussion of waste feed delivery activities (the terms waste feed delivery and retrieval are used interchangeably here) pertains to administrative, waste qualification, and transfer processes that have no bearing on tank bump phenomena.

Because the tank bump criteria from the safe storage accident analysis (Epstein et al. 2000) are used again frequently, they are repeated here for convenience. Criteria are presented and ordered to create a graded approach from the easiest to most difficult to apply, and to leave successively fewer remaining tanks to screen. Individual tanks are excluded from further consideration if any of the following are true:

1. There is an insignificant non-convective layer,

2. Supernatant depth does not exceed $1 \mathrm{~m}$,

3. Total tank heat load can be removed by steady-state conduction through the soil overburden (total tank heat load is less than $8500 \mathrm{~W}$ ),

4. The time to saturated tank conditions exceeds the time needed for ventilation system repairs using a lumped capacitance (single waste temperature) approach,

5. The time to saturated tank conditions exceeds the time needed for ventilation system repairs using separate energy balances for supernatant and non-convective layers, and

6. Neutral buoyancy cannot be attained in the non-convective layer through buildup of noncondensible gases.

The limiting conditions for operation are also referred to repeatedly. They are as follows (HNF-SD-WM-TSR-006 2000):

LCS / LCO 3.3.2 The WASTE temperature shall be either:

a. $\quad \leq 195^{\circ} \mathrm{F}$ in all levels of the waste.

OR

b. $\leq 195^{\circ} \mathrm{F}$ in the top $15 \mathrm{ft}$. of the waste 
RPP-6654, REV. 0

AND

$\leq 215^{\circ} \mathrm{F}$ in the waste below $15 \mathrm{ft}$.

\subsection{TANK 241-AZ-101 FEED DELIVERY ACTIVITIES}

A logic diagram for Tank 241-AZ-101 waste feed delivery activities is shown in Figure 3-1. This figure is a streamlined version of a logic diagram shown in Carlson (1999b).

Feed qualification is the first feed delivery activity. One set of samples will be used for the entire Tank 241-AZ-101 inventory, which will be delivered in nine batch transfers. Feed qualification begins with five days of mixing using two mixer pumps. After the non-convective layer has been mobilized and the waste is homogeneous, samples are obtained, provided to the feed delivery customer, and analyzed. The mixer pumps are stopped and the waste is cooled in Tank 241-AZ-101 while the samples are qualified.

After the $\mathrm{CH} 2 \mathrm{M}$ Hill Hanford Group ( $\mathrm{CHG}$ ) and feed delivery customer concur on the feed qualification, the waste in the tanks is mixed with two mixer pumps for two days to ensure the waste is well mixed. This second mixing process should take less time because the waste should be easier to mobilize. The waste is cooled for five days as preparations take place for the batch transfer. The waste transfer pump transports the waste through the Tank 241-AZ-01A central pump pit, onto the "New AZ Valve Pit," and then to the feed delivery customer. For batch transfers two through nine, the processes of mixing, cooling, and transfer are repeated.

\subsection{FEED DELIVERY ACTIVITIES FOR TANKS 241-AN-104 AND 241-AN-105}

Waste transfers from Tank 241-AN-105 to the feed delivery customer are described in Carlson (1999a and 1999b). Feed delivery activities for Tank 241-AN-105 are more complicated than for Tank 241-AZ-101 feed delivery activities and consist of degassing, settling, decanting, salt cake dissolution, decanting again, and delivery. These steps are shown in Figure 3-2, which also indicates that the activities description for Tank 241-AN-105 applies just as well to Tank 241-AN-104. Each step is described below with attention to tank bump concerns only.

Degassing involves mixing the settled solids to release flammable gases. (This step is optional and the process might begin with decanting immediately.) To limit the flammable gas release rate, mixer pumps will be operated intermittently and sequentially over the course of a few days. This operating mode also limits the amount of mixing; extensive mixing is not especially desirable because the supernatant must be decanted from the salt cake.

After degassing, the tank is allowed to settle for 30 days. This minimizes the amount of solid in the supernatant and keeps the transfer consistent with the feed delivery specification for low activity waste (LAW) transfers. During this period, only the ventilation system and its ancillary functions must operate.

After 30 days of settling, the supernatant will be decanted by transferring it with in-line dilution from Tank 241-AN-105 to Tank 241-AP-102, which is the "interim waste staging tank". 
RPP-6654, REV. 0

Figure 3-1. Simplified Logic Diagram for Tank 241-AZ-101 Feed Delivery Activities.

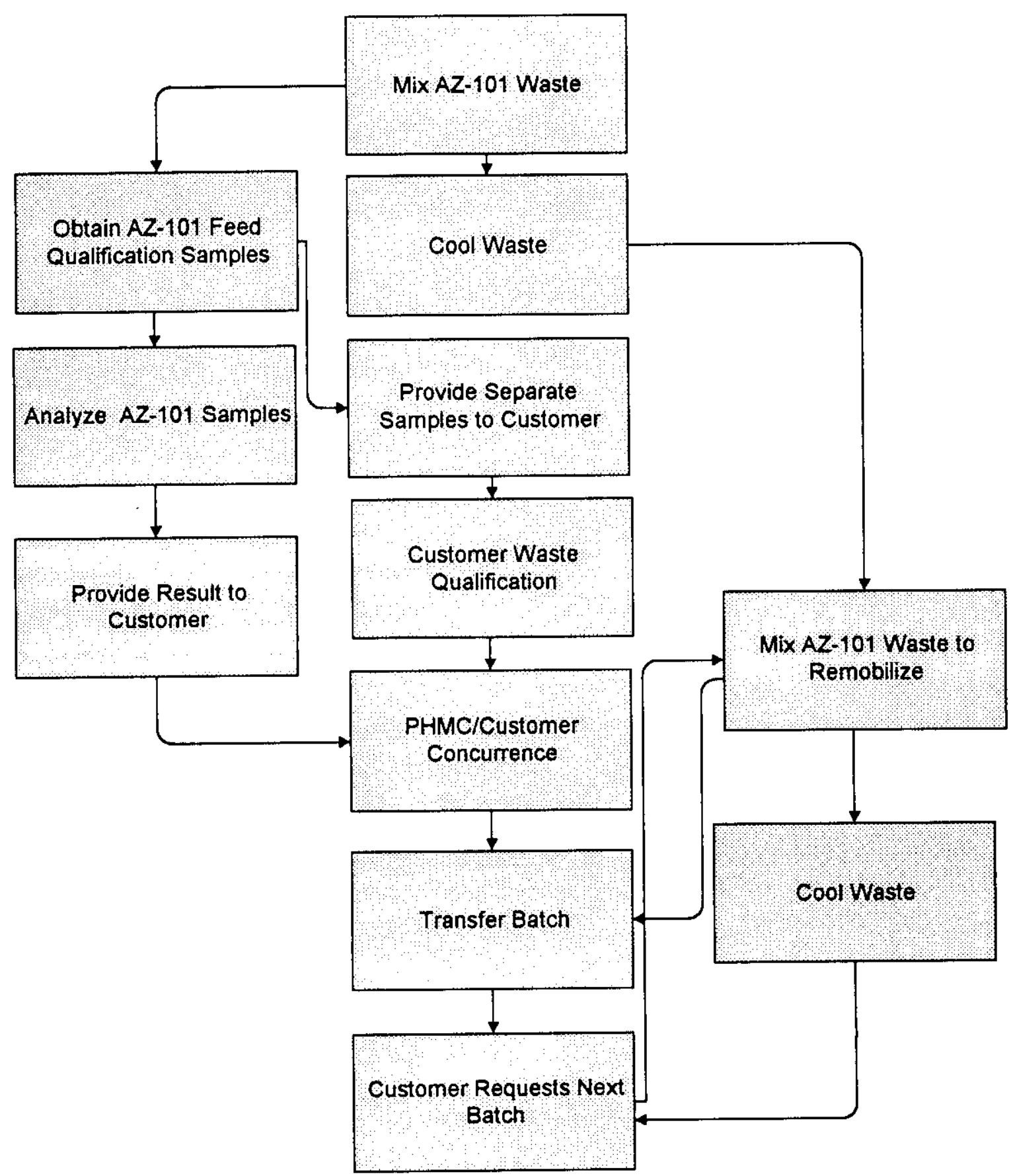


Figure 3-2. Tanks 241-AN-105 and 241-AN-104 Feed Delivery Activities.

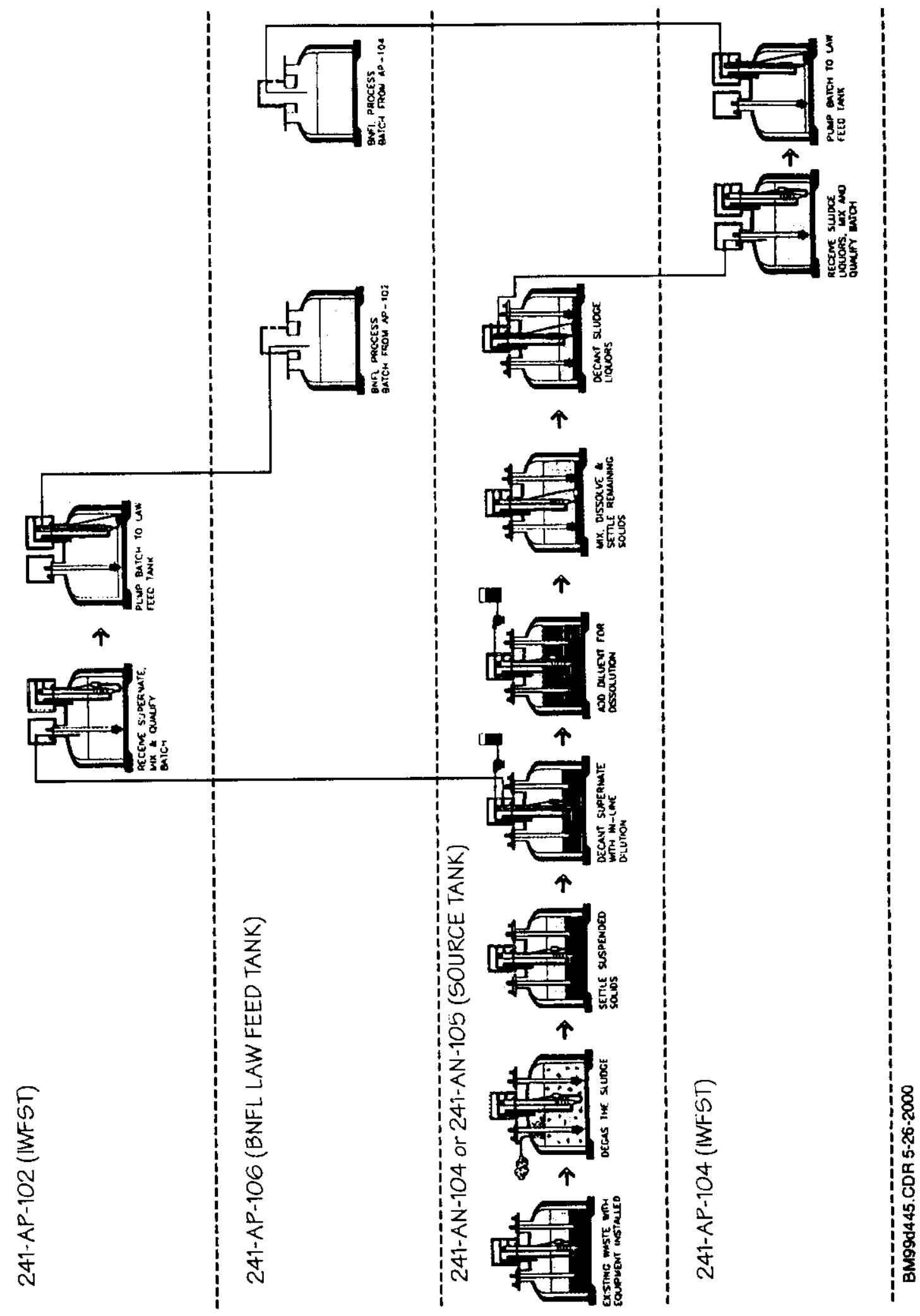


Carlson (1999a and 1999b) states that something like 790,000 gallons $\left(2,991 \mathrm{~m}^{3}\right)$ will be decanted to Tank 241-AP-102, but the actual amount transferred will depend on the effectiveness of settling during the 30 -day interim. The Hu et al. (2000) waste database states that there are $2,441 \mathrm{~m}^{3}$ of supernatant in Tank $241-\mathrm{AN}-105$.

Salt cake remaining after the first decanting process is then dissolved by the addition of raw water and mixed for seven days. The Waste Feed Delivery Reliability, Availability, and Maintainability (WFD RAM) study (Carlson 1999a and 1999b) assumed that the waste temperature does not exceed limiting conditions for operation (LCO)

(HNF-SD-WM-TSR-006 2000). This work makes the same assumption for reasons described below.

A second decanting process will transfer the remaining waste volume in Tank 241-AN-105, except for a heel, to Tank 241-AP-104 for sampling and qualification.

Waste in Tanks 241-AP-102 and 241-AP-104 will be mixed for a short time and sampled for feed delivery qualification.

After meeting feed delivery qualifications, the contents of each tank will be transferred to the customer's low activity waste (LAW) feed tank. This involves one batch transfer for each interim tank.

\subsection{TANK BUMP CONSIDERATIONS FOR FEED DELIVERY ACTIVITIES}

Feed delivery activities are examined for potential tank bump scenarios. The following assumptions are used in combination with the screening criteria presented in the safe storage tank bump accident analysis (Epstein et al. 2000):

1. Feed delivery activities begin with the current safe storage conditions. Waste temperatures are at current, steady-state values and primary and annulus ventilation systems are functional.

2. Normal mixer pump operation prevents a tank bump, assuming that the supernatant is highly sub-cooled at the start of mixing. The safe storage tank bump analysis lists the conditions required for a tank bump. First, the waste must consist of a heat generating non-convective layer with a deep, overlying supernatant. Another condition is that the supernatant must be saturated or nearly so to create significant expansion of the released gas bubble. Bubble expansion is minimal (a factor of 4 for $10 \mathrm{~m}$ of supernatant) for $10^{\circ} \mathrm{C}$ sub-cooling. If the supernatant is highly sub-cooled at the time of mixer pump start-up, gases released by disturbing the waste will not result in significant bubble expansion. Once the mixer pumps have operated for a time and the non-convective layer is fluidized, the configuration for a bump no longer exists.

3. Primary and annulus ventilation are sized to keep waste temperatures below the LCO 3.3.2 temperature limit requirements, even for indefinite 
mixer pump operation. Although the mixing operations described above last for a few days only, the primary and annulus ventilation systems will operate with flow rates to ensure that the LCO 3.3.2 requirements are not exceeded, despite indefinite operation. Crea et al. (2000) shows that this can be accomplished for the aging waste facility tanks by operating the existing primary and annulus ventilation systems within design limits.

4. A success criterion is that primary and annulus ventilation are both needed to maintain waste temperature below tank bump conditions. Success criteria are defined as the minimum sets of equipment needed to maintain a safe, stable state where all waste temperatures meet LCO 3.3.2 and are either steady or declining. Clearly, both the primary and annulus ventilation systems are needed to maintain temperatures below the LCO 3.3.2 requirements, while the mixer pumps are operating indefinitely with a total power of $600 \mathrm{hp}$. This work assumes the same success criterion is needed to prevent bumps, regardless of mixer pump operation. This amounts to assuming that a failure of either system leads to bump conditions.

If the primary ventilation system operates, but the annulus ventilation system does not, bump conditions in the non-convective layer are possible, but the supernatant will remain highly sub-cooled. This does not necessarily lead to a safe, stable state, however, because the nonconvective layer temperature can exceed the local saturation temperature. The annulus ventilation system alone cannot prevent bumps because the supernatant temperature cannot be maintained. The WFD RAM state that air lift circulators (ALCs) will be used to maintain safe storage. This work does not consider operation of the ALCs because there is no thermalhydraulic analysis to support ALC operation as a success criterion for retrieval bump scenarios. Moreover, inadvertent use of the ALC can lead to a bump.

5. Waste feed deliveries in all the aging waste facility tanks are the same as the description above for Tank 241-AZ-101.

6. In the aging waste facility tanks, tank bump risk (frequency times consequences) for the first batch bounds the risk from subsequent batches. Each subsequent batch has a somewhat lower tank heat load, supernatant depth, etc. Since there are nine batches planned, the total tank heat load decreases by about $11 \%$ after the first batch transfer. This assumption removes the need to perform consequence and frequency calculations for each batch transfer because the first one is bounding for both frequency and consequences.

7. Partial mixing scenarios are considered for both the LAW and AWF tanks. In a partial mixing scenario, mixer pump operation causes a non-uniform height distribution in the non-convective waste. This could happen if a single mixer pump operated very briefly, so as to sweep only a small 
portion of the tank and allow the mobilized solids to settle in other parts of the tank.

Tank bump scenarios for feed delivery activities are considered next on the basis of these assumptions and the screening criteria of the safe storage tank bump accident analysis (Epstein et al. 2000)

\subsection{TANK BUMP CONSIDERATIONS FOR LAW FEED DELIVERY ACTIVITIES}

Each of the steps in the LAW feed delivery is considered for tank bump potential. The logic discussed below can be represented by the LAW feed delivery event tree in Figure 3-3.

For the first degassing step, initial mixer operation cannot cause a bump, per assumptions 1 and 2 above. A tank bump caused by indefinite mixer pump operation with operating ventilation can be ruled out on the same basis. If the mixer pump fails or is shut off, but primary and annulus ventilation do not fail, a bump cannot occur on the basis of assumptions 1,3 , and 4 . If the mixer pump is shut off (or fails) prior to or concurrent with primary and annulus ventilation system failure, a tank bump is excluded on the basis of bump criterion 4 from the safe storage accident analysis (Epstein et al. 2000). This branch of the tree results in tank self-heating, with the LCO 3.3.2 limits as bounding initial conditions. Assuming the LCO 3.3.2 as the initial conditions, it takes at least 350 days to reach saturated conditions (Table 6-5 of Epstein et al. (2000)). Some tanks can never bump in this scenario, despite the loss of ventilation, because the total tank heat load can be removed by conduction. Section 4.0 demonstrates that for tanks with a heat load less than roughly $10 \mathrm{~kW}$, bumps cannot occur, regardless of non-convective layer height (the fluffing factor) or non-uniform waste distribution caused by partial mixing.

It can be postulated that mixer pump operation continues after primary and annulus ventilation system failure and heats the waste to saturated conditions. This involves two procedural errors: failing to turn off the mixer pumps immediately and then turning them off when the waste temperature approaches bump conditions. A tank bump is then possible after the waste settles, if the tank total heat load is sufficient and if the ventilation system cannot be recovered in the meantime.

For the first degassing procedure, tank bumps are immediately judged to be beyond extremely unlikely. As already stated, the "Bump Conditions @>350 days" end state is dismissed based on generic corrective maintenance clock times. The "Bump Conditions After Settling" end state is dismissed because it calls for an equipment failure (Ventilation Fails), two operator errors, and a failure to repair ventilation prior to settling. Operators will use the mixer pumps intermittently, which means they will be acutely aware of the need to stop mixer operation in the event of ventilation failure. Settling could be on the order of a few days, as demonstrated by waste transfer for Tanks 241-C-106 to 241-AY-102 (Ogden and Bratzel 2000) and the Tank 241-AZ-101 mixer tests (Carlson et al. 2000). According to the WFD RAM, a few days would still be enough to recover the annulus or primary ventilation system in many instances, provided that relatively simple restoration activities are needed rather than lengthy corrective maintenance functions. 
Figure 3-3. LAW Feed Delivery Tank Bump Event Tree.

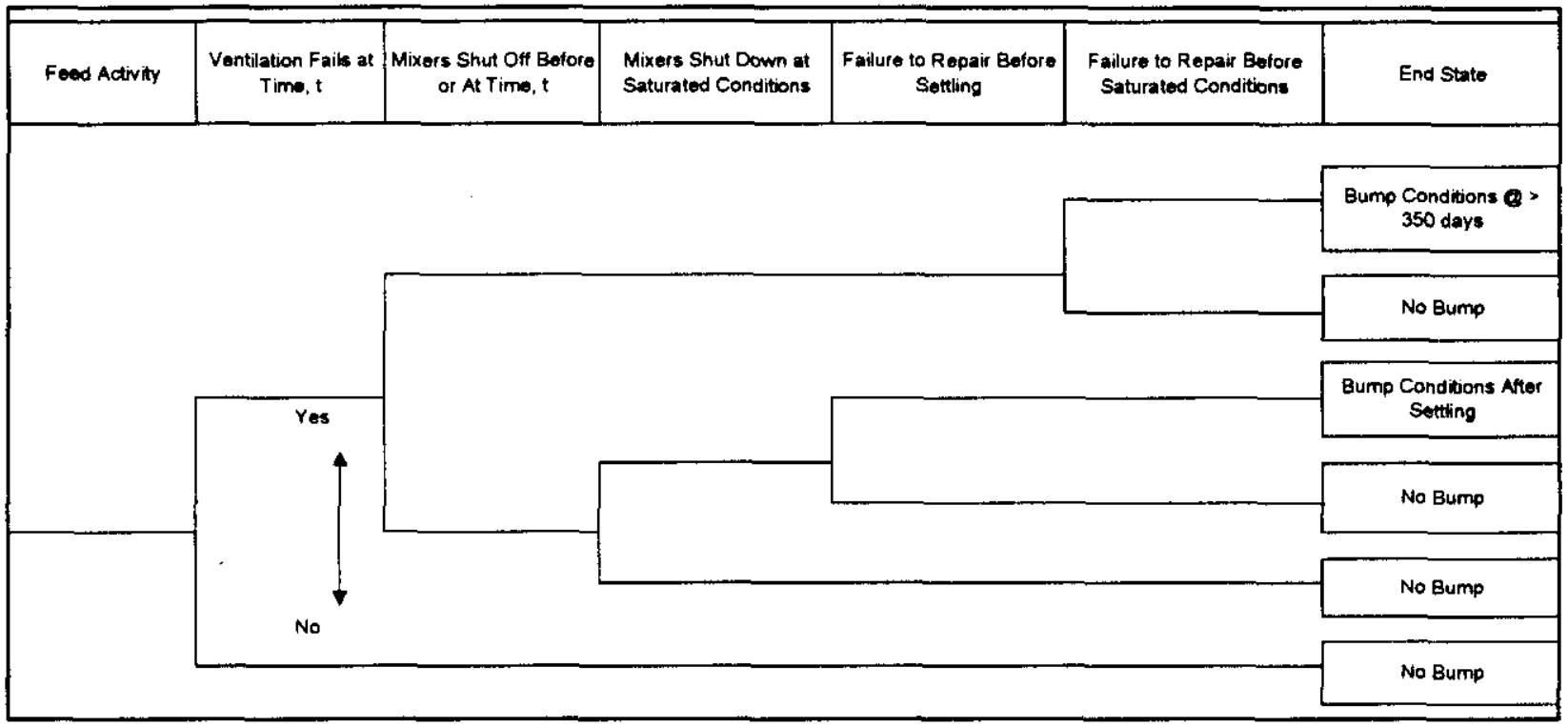


Although the "Bump Conditions After Settling" end state can be dismissed on frequency (probabilistic) grounds, the thermal-hydraulic response to this scenario is worth discussion. This branch of the tree assumes that the mixer pumps continue to operate right up to saturated conditions, at which time the mixer pumps are then turned off. This leaves the waste at saturated conditions, but well-mixed, so a bump does not occur immediately. Two processes begin at this point: the waste settles back to a distinct supernatant atop a non-convective layer, and the temperature approaches the steady-state value dictated by decay heat load, upward conduction through the overlying soil and downward conduction to soil underneath. If this steady-state temperature is below saturation, the tank will cool. If it is not, the tank will continue to boil.

Assuming the first degassing procedure is successful, similar conclusions can be drawn for the 30-day settling process. In fact, once the supernatant is decanted, tank bumps are impossible in the source tank, feed tank, and interim waste feed storage tanks (IWFST), based on the safe storage tank bump criteria 1 and 3. According to Hu et al. (2000), a little more than half the total tank power resides in the supernatant for Tank 241-AN-105, and the total tank heat load is $9,340 \mathrm{~W}(13.4 \mathrm{~kW}$ in the pedigreed database). Once the supernatant has been decanted, about $4,700 \mathrm{~W}$ remain in the source tank and $4,700 \mathrm{~W}$ reside in the IWFST. This can be compared to bump criterion 3 from the safe storage accident analysis (Epstein et al. 2000), which states that $8,500 \mathrm{~W}$ can be removed by steady-state conduction through the soil overburden alone. The same argument applies for the other DSTs, with the exception of the AWFs. After dilution, the source tank can be screened based on bump criterion 1, which states there must be a significant non-convective layer. Bump criterion 1 always applies to the IWFST and the customer feed tank.

\subsection{TANK BUMP CONSIDERATIONS FOR AGING WASTE FACILITY TANK FEED DELIVERY ACTIVITIES}

Figure 3-4 shows an event tree for the AWF feed activities. It is the same as the event tree for the LAW activities, except that "Bump Conditions@ @ 350 Days" is replaced by "Bump Conditions @X Days", where X is to be determined. In a series of parametric GOTH_SNF calculations, Crea et al. (2000) analyzed the thermal-hydraulic response of the AWF during retrieval operations. Tanks 241-AY-102 and 241-AZ-102 were considered and deemed bounding based on tank heat load and sludge inventory. For each DST, the first calculation was to predict the temperature at which the mixed waste heat loads, namely the mixer pump heat dissipation and decay heat, balance the ventilation system heat removal. Once this maximum temperature is attained, the mixer pumps are shut off, but the ventilation system continues to operate.

An example of predicted waste and supernatant temperatures for Tank 241-AZ-102 is shown here as Figure 3-5. Nomenclature is as follows: $T 1$ is the initial supernatant temperature, T2 is the maximum waste temperature, $\mathrm{T} 3$ is the initial mixed-waste temperature, and T4 is the mixed waste temperature as a function of time. Figure 3-5 shows that after the mixer pumps start at 37 days, the waste temperature quickly approaches $\mathrm{T} 3$, initial mixed-waste temperature. Due to the mixer pump heat load, the mixed-waste temperature, $\mathrm{T} 4$, approaches its maximum after 32 days of mixer pump operation, which is about 69 days from time zero; this T4 designator in Figure 3-5 is placed at this maximum value. If the mixer pumps were to continue operating, the 
Figure 3-4. AWF Feed Delivery Activity Tank Bump Event Tree.

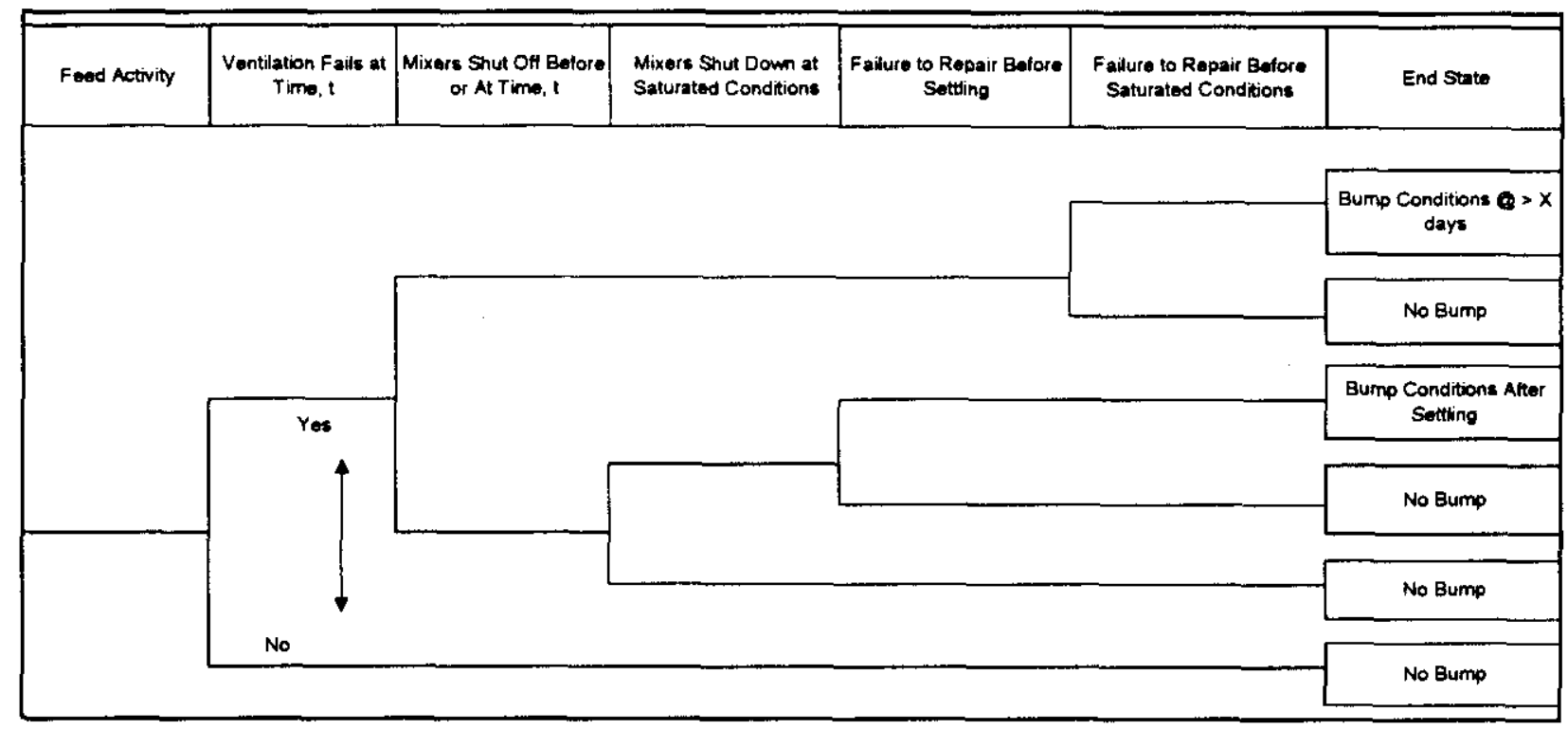


Figure 3-5. Tank 241-AZ-102 Case 2 Temperatures with 2,000 SCFM Annulus Flow and Chilled Air (Crea et al. 2000).

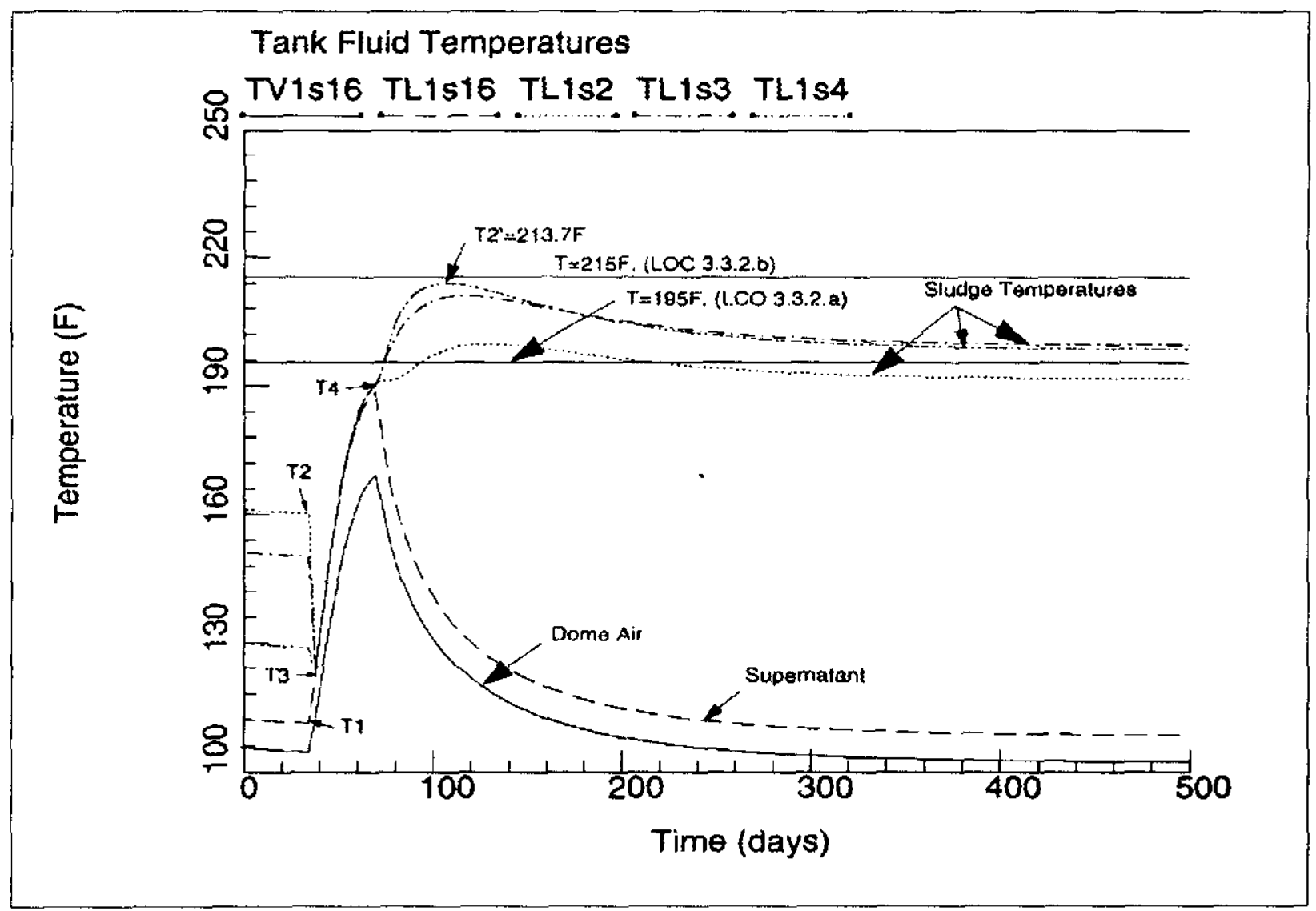


mixed waste temperature would remain at this value, which is just below LCO 3.3.2a. For the run shown in Figure 3-5, the mixer pumps are turned off when T4 reaches its maximum, and the waste begins to settle. The maximum temperature of post-settled waste, $T 2$, is shown to be just under LCO 3.3.2.b. The fluffing factor value of 2.0 explains why T2 is so high. Fluffing increases sludge height and decreases thermal conductivity. Because of the continued operation of the ventilation system, supernatant temperature begins to decline after the mixer pumps are turned off and eventually approaches the condition at time zero.

GOTH_SNF calculations demonstrate several points gleaned indirectly from Figure 3-5. First, if the mixer pumps and ventilation system operate indefinitely, the waste is well-mixed and the temperature remains just below LCO 3.3.2a. In other words, T4 would be a flat line extending from 69 days on. This is the basis for assumptions 2, 3, and 4 in Section 3.3. The worst case then is to lose ventilation when $\mathrm{T} 4$ just reaches its maximum and the mixer pumps are shut off. If the ventilation and mixer pumps are lost/shut down after only a few days of operation, the time to bump conditions is not much different than either of the values listed in Table 6-4 of the safe storage accident analysis (Epstein et al. 2000), which shows values of over 100 days for self-heat to saturation for the current waste conditions.

Crea et al. (2000) have analyzed the loss of ventilation case for both Tanks 241-AY-102 and 241-AZ-102. Tank 241-AZ-102 is limiting in this regard, which is why results are shown in Figure 3-6 are for this tank. In fact, the loss of ventilation analysis for Tank 241-AY-102 shows that bump conditions are not reached after 100 days without ventilation. Figure 3-6 shows that the tank reaches bump conditions at about 120 days after time zero, which is about 50 days after the loss of ventilation and mixer pump shutdown. The maximum waste temperature flattens out at about $254^{\circ} \mathrm{F}$, or $123^{\circ} \mathrm{C}$, which is the local saturation temperature. (The safety limit SL2.1.1 set at $250^{\circ} \mathrm{F}$ is based on chemical reactivity concerns.) When sludge layer temperatures reach saturation, the supernatant is just over $200^{\circ} \mathrm{F}$, or $94^{\circ} \mathrm{C}$.

Partial mixing in the AWF is an unlikely event bounded by the scenario described in Figure 3-6 and the "Ventilation Fails at Time, t, Mixers Shut Off Before or At Time, t, and Failure to Repair Before Saturated Conditions" sequence shown in Figure 3-4. Tank 241-AZ-101 mixing tests (Carlson et al. 2000) demonstrate that even one pump at partial capacity is almost as effective as two pumps at full capacity. Partial mixing would occur only if a lone pump operated very briefly. Tank 241-AZ-101 tests show effective mixing took place in less than 19 hours. A partial mixing scenario leading to bump conditions would require mixer pump(s) failure during some brief interval with concurrent failure of the ventilation system. This partial mixing scenario is far less likely to occur than the one described in Figure 3-6. Moreover, because the mixer pumps fail after only a few hours, waste temperatures are still not much above initial safe, storage temperatures, which means that available recovery times would be very long. 
Figure 3-6. Tank 241-AZ-102 Case 2 Temperatures for Loss of Ventilation and Mixer Pump Shut Off at Maximum Mixed Waste Temperature (Crea et al. 2000).

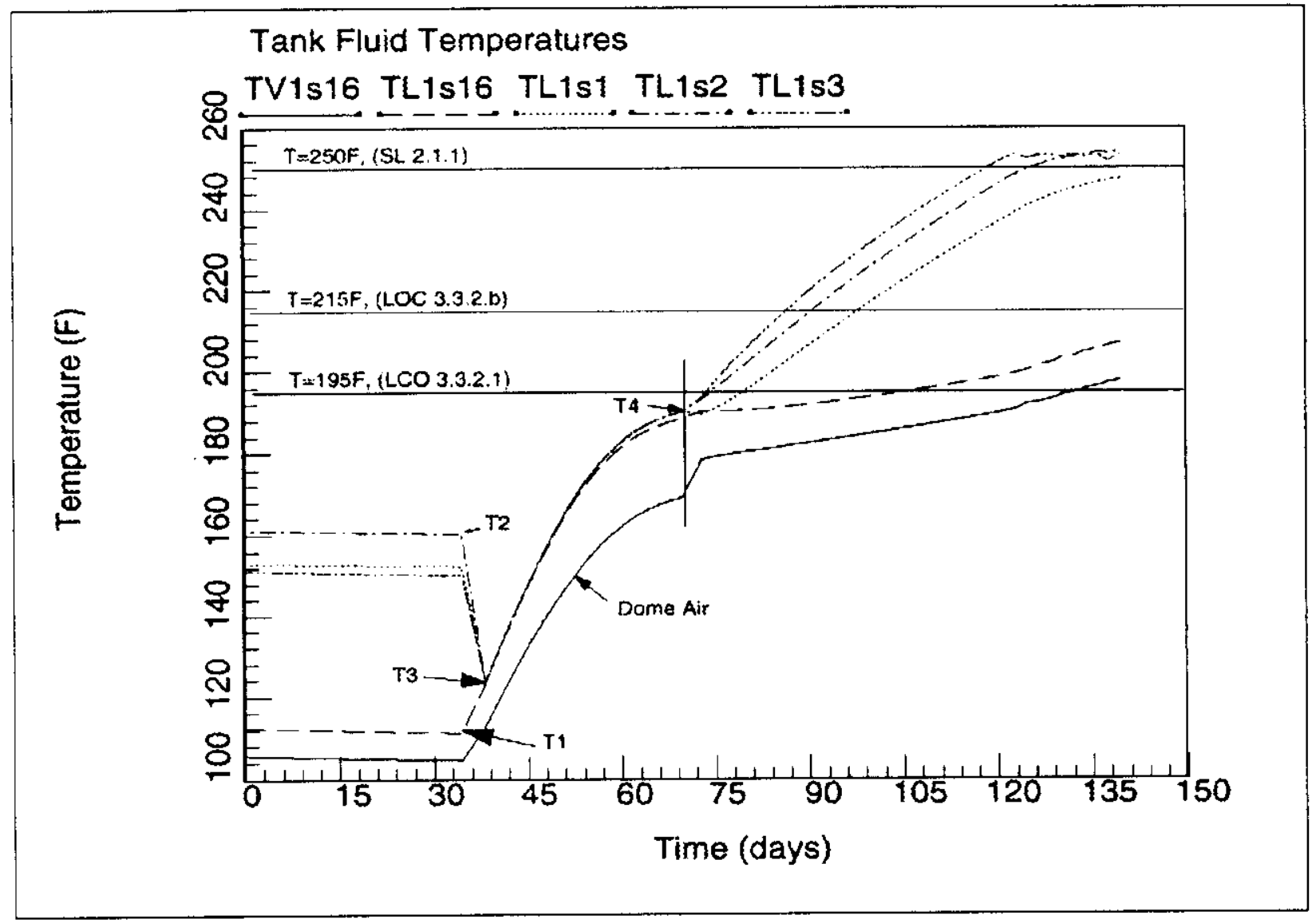


RPP-6654, REV. 0

This page intentionally left blank. 


\subsection{TANK BUMP PHYSICAL MODELS AND CRITERIA}

The previous section identified that the scenario of interest is as follows: ventilation fails at time $t$, mixers shut off at or before time $t$, and failure to repair before saturated conditions. This section develops a general tank bump criterion for this scenario and shows that a tank bump cannot occur for low heat load tanks $(<10 \mathrm{~kW})$ regardless of the non-convective layer depth or partial mixing. For low heat load tanks, the time to repair is infinite, in effect.

A steam bump via gas release from the resettled non-convective layer becomes possible if the supernatant temperature increases after the mixer pump operation is stopped. Obviously if the decay heat production exceeds the heat losses to the surrounding soil, the waste temperature (and supernatant temperature) will increase. The maximum supernatant temperature will be achieved when heat production is completely balanced by heat losses to the surroundings, that is when steady-state is achieved. Thus the criterion we seek is one that ensures that the supernatant temperature remains below the critical temperature $\left(\simeq 90^{\circ} \mathrm{C}\right)$ for steam bumps at steady-state.

To obtain simple results from the time-independent analysis, we make the following basic assumptions:

A1. Because the thicknesses of the non-convective layer and the soil layer above the tank are small in comparison with the tank diameter, heat conduction in the horizontal direction can be ignored in these regions. Also, heat loss to the soil below the tank is given by the solution to the conduction equation with spatially uniform heat flux over the bottom of the tank into a semi-infinite medium (underlying soil).

A2. Owing to turbulent natural convection, the supernatant (convective layer) temperature is spatially uniform.

A3. Because of thermal radiation and natural convection the temperature drop in the vertical direction across the tank headspace may be ignored.

A4. Again because of natural convection, the resistance to heat exchange between the ground and the atmosphere may be ignored and the resistance to heat exchange between the non-convective layer and the convective layer may be ignored.

The conduction equation for the non-convective layer is expressed as

$$
\frac{d^{2} T}{d z^{2}}=-\frac{Q_{N C L}}{k_{N C L}}
$$

where $\mathrm{z}$ is the vertical distance measured from the bottom of the non-convective layer to some arbitrary location within the layer, $T$ is the layer temperature at elevation $z, k_{N C L}$ is the thermal conductivity of the non-convective layer, and $\mathrm{Q}_{\mathrm{NCL}}$ is the layer's volumetric decay-heat generation rate. At the tank floor $(z=0)$, equation (4-1) must satisfy the condition 


$$
-\mathbf{k}_{\mathrm{NCL}} \frac{\mathrm{d} \mathrm{T}}{\mathrm{dz}}(0)=-\frac{\mathbf{k}_{\text {soil }}}{\mathrm{R}}\left[\mathrm{T}(0)-\mathrm{T}_{\infty}\right]
$$

which equates the heat flux in the non-convective with the heat flux in the underlying soil at $z=0$. In equation (4-2), $k_{\text {soil }}$ is the thermal conductivity of the soil, $R$ is the radius of the waste tank, and $T_{\infty}$ is the soil temperature far below the tank.

In accord with the assumptions listed earlier, the conduction heat flux at the top of the nonconvective layer (at $\mathrm{z}=\mathrm{H}_{\mathrm{NCL}}$ ) plus the upward heat flux from the convective layer must equal the conduction heat flux through the overlying soil layer (or soil "overburden") of thickness $\mathrm{H}_{\text {soil }}$. This energy balance is represented mathematically as

$$
-\mathrm{k}_{\mathrm{NCL}} \frac{\mathrm{d} \mathrm{T}}{\mathrm{dz}}\left(\mathrm{H}_{\mathrm{NCL}}\right)+\mathrm{H}_{\mathrm{CL}} \mathrm{Q}_{\mathrm{CL}}=\frac{\mathrm{k}_{\text {soil }}}{\mathrm{H}_{\text {soil }}}\left(\mathrm{T}_{\mathrm{CL}}-\mathrm{T}_{\mathrm{a}}\right)
$$

where $\mathrm{H}_{\mathrm{CL}}, \mathrm{Q}_{\mathrm{CL}}$, and $\mathrm{T}_{\mathrm{CL}}$ are, respectively, the depth, volumetric heat generation rate, and uniform temperature of the convective layer; and $\mathrm{T}_{\mathrm{a}}$ is the temperature of the atmosphere.

It is more convenient to work in terms of dimensionless variables and parameters:

$$
\begin{array}{ll}
\theta=\frac{\mathrm{k}_{\mathrm{NCL}}\left(\mathrm{T}-\mathrm{T}_{\infty}\right)}{\mathrm{Q}_{\mathrm{NCL}} \mathrm{H}_{\mathrm{NCL}}^{2}}, & \mathrm{x}=\frac{\mathrm{z}}{\mathrm{H}_{\mathrm{NCL}}}, \quad \theta_{\mathrm{CL}}=\frac{\mathrm{k}_{\mathrm{NCL}}\left(\mathrm{T}_{\mathrm{CL}}-\mathrm{T}_{\infty}\right)}{\mathrm{Q}_{\mathrm{NCL}} \mathrm{H}_{\mathrm{NCL}}^{2}}, \\
\mathrm{~B}_{1}=\frac{\mathrm{k}_{\mathrm{soil}} \mathrm{H}_{\mathrm{NCL}}}{\mathrm{k}_{\mathrm{NCL}} \mathrm{H}_{\mathrm{soil}}}, & \mathrm{B}_{2}=\frac{\mathrm{k}_{\text {soil }} \mathrm{H}_{\mathrm{NCL}}}{\mathrm{k}_{\mathrm{NCL}} \mathrm{R}}, \\
\Lambda=\frac{\mathrm{k}_{\mathrm{NCL}}\left(\mathrm{T}_{\infty}-\mathrm{T}_{\mathrm{a}}\right)}{\mathrm{Q}_{\mathrm{NCL}} \mathrm{H}_{\mathrm{NCL}}^{2}}, & \mathrm{q}=\frac{\mathrm{H}_{\mathrm{CL}} \mathrm{Q}_{\mathrm{CL}}}{\mathrm{H}_{\mathrm{NCL}} \mathrm{Q}_{\mathrm{NCL}}} .
\end{array}
$$

Inserting these dimensionless quantities into equations (4-1), (4-2), and (4-3), the differential equation becomes

$$
\frac{d^{2} \theta}{d x^{2}}=-1
$$

with boundary conditions

$$
\begin{aligned}
& \frac{d \theta}{d x}(0)=B_{2} \theta(0) \\
& \frac{d \theta}{d x}(1)=q-B_{1}\left(\theta_{C L}+\Lambda\right)
\end{aligned}
$$


where $\theta_{C L}$ is the dimensionless, spatially uniform convective layer temperature. Integrating equation (4-7) twice with respect to $z$ gives

$$
\begin{aligned}
& \frac{d \theta}{d x}=-x+C_{1} \\
& \theta=-\frac{x^{2}}{2}+C_{1} x+C_{2}
\end{aligned}
$$

The constants $C_{1}$ and $C_{2}$ are determined by the boundary conditions, equations (4-8) and (4-9), and the fact that $\theta(1)=\theta_{\mathrm{CL}}$ at $z=\mathrm{H}_{\mathrm{NCL}}$ or, equivalently, at $\mathrm{x}=1$. The results are

$$
\begin{aligned}
& C_{1}=B_{2} \theta(0) \\
& C_{2}=\theta(0) \\
& \theta(0)=\frac{q+1+B_{1}\left(\frac{1}{2}-\Lambda\right)}{B_{1}+B_{1} B_{2}+B_{2}} \\
& \theta_{C L}=\frac{\left(1+B_{2}\right)\left[q+1+B_{1}\left(\frac{1}{2}-\Lambda\right)\right]}{B_{1}+B_{1} B_{2}+B_{2}}-\frac{1}{2}
\end{aligned}
$$

For a sufficiently thick non-convective layer and/or a sufficiently large volumetric heat generation rate within the non-convective layer, the temperature $\mathrm{T}($ or $\theta$ ) will exhibit a maximum. The maximum value $\theta_{\max }$ and the elevation $x_{\max }$ at which it occurs can be found by letting $(d \theta) /(d x)=0$ in equation (4-10) and solving the result for $x_{\max }$. This gives (see equations (4-12) and (4-14))

$$
x_{\max }=B_{2} \theta(0)=\frac{B_{2}\left[q+1+B_{1}\left(\frac{1}{2}-\Lambda\right)\right]}{B_{1}+B_{1} B_{2}+B_{2}}
$$

From equation (4-11)

$$
\theta_{\max }=\theta(0)\left[1+\frac{1}{2} B_{2} \theta(0)\right]
$$

Equation (4-17) yields physical values of $\theta_{\max }$ only when these values occur within the nonconvective layer, that is only when the following inequality is satisfied: 


$$
0<\mathrm{x}_{\max } \leq 1.0
$$

Steam bumps become possible when the supernatant temperature is close to its saturation temperature at atmospheric pressure. A rather conservative value for the critical supernatant temperature $T_{\text {crit }}$ below which steam bumps are impossible is $90^{\circ} \mathrm{C}$ (Epstein et al. 2000). Thus the limits of the non-bumping and bumping regimes can be found by setting the convective layer temperature $T_{C L}$ in equation (4-15) equal to $T_{\text {crit. }}$. This leads to the relation (see also equations (4-4) and (4-6))

$$
\begin{aligned}
& \frac{k_{\mathrm{NCL}}\left(\mathrm{T}_{\text {crit }}-\mathrm{T}_{\infty}\right)}{\mathrm{Q}_{\mathrm{NCL}} \mathrm{H}_{\mathrm{NCL}}^{2}} \\
= & \frac{1+\mathrm{B}_{2}}{\mathrm{~B}_{1}+\mathrm{B}_{1} \mathrm{~B}_{2}+\mathrm{B}_{2}}\left\{\frac{\mathrm{H}_{\mathrm{CL}} \mathrm{Q}_{\mathrm{CL}}}{\mathrm{H}_{\mathrm{NCL}} \mathrm{Q}_{\mathrm{NCL}}}+1+\mathrm{B}_{1}\left[\frac{1}{2}-\frac{\mathrm{k}_{\mathrm{NCL}}\left(\mathrm{T}_{\mathrm{a}}-\mathrm{T}_{\infty}\right)}{\mathrm{Q}_{\mathrm{NCL}} \mathrm{H}_{\mathrm{NCL}}^{2}}\right]\right\}-\frac{1}{2}
\end{aligned}
$$

Equation (4-19) can be used to construct the $\mathrm{Q}_{\mathrm{CL}}$ - $\mathrm{Q}_{\mathrm{NCL}}$ locus which separates the non-bumping and bumping regimes. Alternatively, the volumetric generation rates may be converted to power $\mathrm{W}$ via the definitions

$$
\begin{aligned}
& \mathrm{W}_{\mathrm{NCL}}=\mathrm{AH}_{\mathrm{NCL}} \mathrm{Q}_{\mathrm{NCL}} \\
& \mathrm{w}_{\mathrm{CL}}=\mathrm{AH}_{\mathrm{CL}} \mathrm{Q}_{\mathrm{CL}}
\end{aligned}
$$

where A is the tank cross-sectional area $\left(411 \mathrm{~m}^{2}\right)$. The "boundary" for steam bumps in power parameter space is then

$$
=\frac{\mathrm{B}_{\mathrm{CL}} \mathrm{Ak_{ \textrm {NCL } }}\left(\mathrm{T}_{\infty}-\mathrm{T}_{\mathrm{a}}\right)}{\mathrm{H}_{\mathrm{NCL}}}+\left(\frac{\mathrm{B}_{1}+\mathrm{B}_{1} \mathrm{~B}_{2}+\mathrm{B}_{2}}{1+\mathrm{B}_{2}}\right) \frac{\mathrm{Ak_{ \textrm {NCL } } ( T _ { \mathrm { cit } } - \mathrm { T } _ { \infty } )}}{\mathrm{H}_{\mathrm{NCL}}}-\frac{1}{2}\left(\frac{2+\mathrm{B}_{2}}{1+\mathrm{B}_{2}}\right) \mathrm{W}_{\mathrm{NCL}}
$$

Since the parameters $k_{N C L}, k_{\text {soil }}, R, T_{\infty}$, and $T_{a}$ are nearly the same for all the tanks, the possibility of steam bumps as determined from equation (4-22) depends mainly on the values of $\mathrm{W}_{\mathrm{CL}}, \mathrm{W}_{\mathrm{NCL}}$, and $\mathrm{H}_{\mathrm{NCL}}$. However, a careful examination of equation (4-22) reveals that the power conditions for a steam bump are remarkably insensitive to the depth $\mathrm{H}_{\mathrm{NCL}}$ of the nonconvective layer. Figure 4-1 shows a convective layer power versus non-convective layer power map for steam bump conditions when $\mathrm{H}_{\mathrm{NCL}}=3.5 \mathrm{~m}$. The fixed input parameters for the calculations are given in Table 4-1. The calculations show that the boundary in the figure translates by only $\pm 5.0 \%$ for $\mathrm{H}_{\mathrm{NCL}}$ values as low as $0.5 \mathrm{~m}$ and as high as $6.0 \mathrm{~m}$. Thus, the map shown in Figure 4-1 may be regarded as a universal map for the possibility of steam bumps. Also shown in Figure 4-1 is the region in which boiling occurs in the non-convective layer when the temperature of the convective layer is below $T_{\text {crit }}=90^{\circ} \mathrm{C}$. The lower boundary of this region is defined by the condition $T_{\max }=T_{b p}$, which, from equation (4-17), leads to an explicit relation 
Figure 4-1. Convective Layer Power - Non-Convective Layer Power Map for the Possible Occurrence of Steam Bumps; $\mathrm{T}_{\text {crit }}=90^{\circ} \mathrm{C}$.

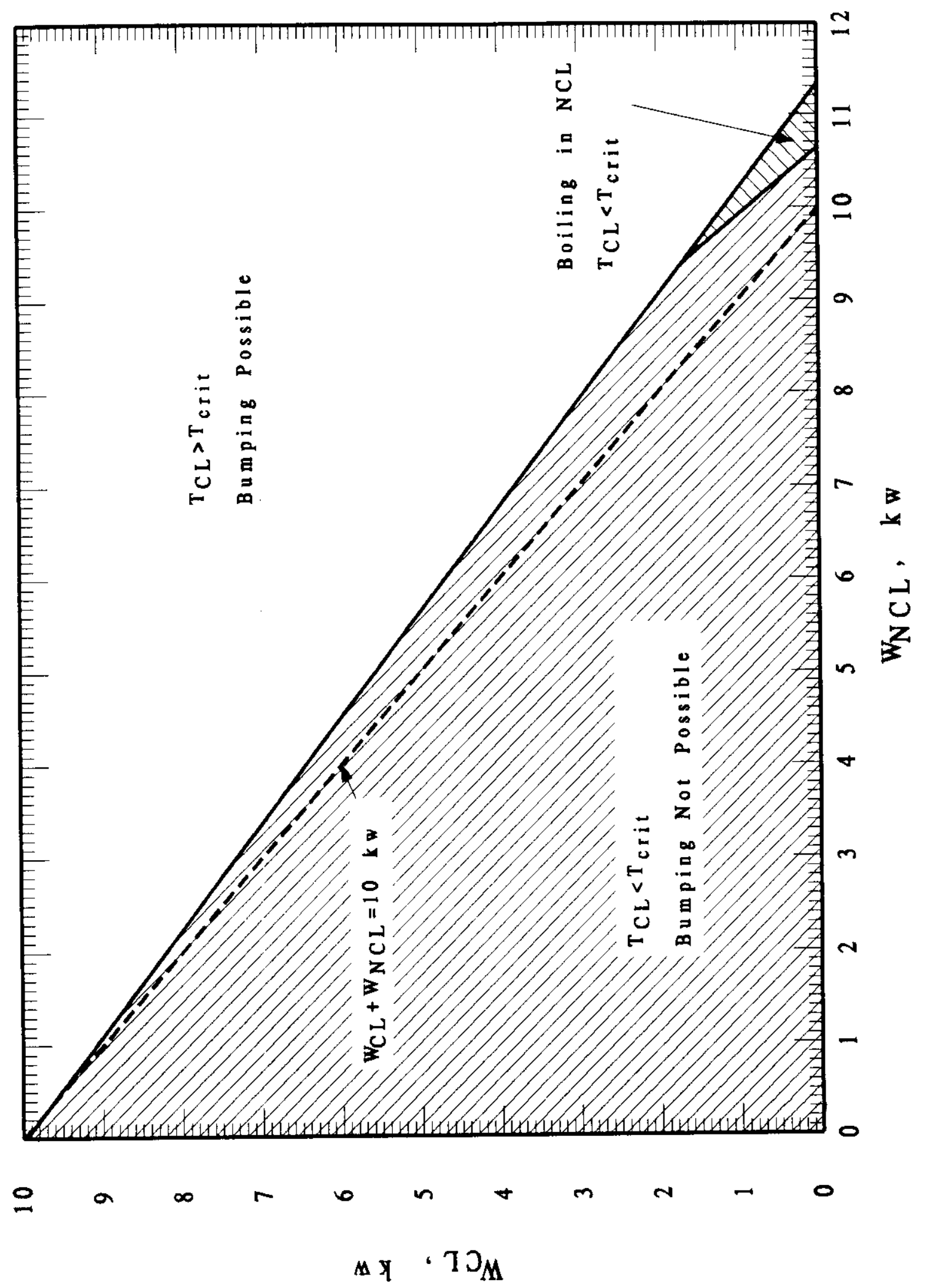


Table 4-1. Parameter Values for Steam Bump Condition Calculations.

\begin{tabular}{|l|l|}
\hline Soil thermal conductivity & $\mathrm{k}_{\text {soil }}=1.0 \mathrm{~W} \mathrm{~m}^{-1} \mathrm{~K}^{-1}$ \\
Non-convective layer thermal conductivity & $\mathrm{k}_{\mathrm{NCL}}=1.0 \mathrm{~W} \mathrm{~m}^{-1} \mathrm{~K}^{-1}$ \\
Tank radius & $\mathrm{R}=11.0 \mathrm{~m}$ \\
Soil Overburden & $\mathrm{H}_{\text {soil }}=4.0 \mathrm{~m}$ \\
Average Hanford air temperature & $\mathrm{T}_{\mathrm{a}}=14^{\circ} \mathrm{C}$ \\
Average Hanford soil temperature & $\mathrm{T}_{\infty}=14^{\circ} \mathrm{C}$ \\
\hline
\end{tabular}

between $\mathrm{W}_{\mathrm{CL}}$ and $\mathrm{W}_{\mathrm{NCL}}$. The parameter $\mathrm{T}_{\text {bp }}$ is the local boiling temperature at the mid-plane of the non-convective layer. The pure conduction theory presented here does not account for boiling in this layer so that the steam bump boundary is not precisely located at high $\mathrm{W}_{\mathrm{NCL}}$ values. Nevertheless, given the small parameter space occupied by the non-convective-layer boiling region, more refined calculations are probably not justified. The present analysis should provide a useful first approximation to the steam bump-boundary when boiling occurs in the non-convective layer.

The dashed curve in Figure 4-1 is an approximate and conservative alternative to the steam bump boundary arrived at by the formal analysis presented in the foregoing. This boundary is represented by the formula

$$
\mathrm{W}_{\mathrm{CL}}+\mathrm{W}_{\mathrm{NCL}}=10 \mathrm{~kW}
$$

and provides the simple rule of thumb that steam bumps are not possible in tanks with total power levels less than $10 \mathrm{~kW}$. If $T_{a}$ is taken to be as high as $28^{\circ} \mathrm{C}$, the predicted boundary is lowered by $15 \%$. In this case, the conservative rule of thumb is $W_{C L}+W_{N C L}=8.5 \mathrm{~kW}$. Since the criterion presented here for steam bumps is insensitive to the depth of the non-convective layer, the criterion is also insensitive to the degree to which the non-convective layer settles to its original volume (i.e., the fluffing factor) or to the degree to which the non-convective layer depth is rendered non-uniform by prior mixing operations.

To defend the conclusion regarding non-uniformity, consider the overall tank energy balance

$$
W_{\mathrm{NCL}}+W_{\mathrm{CL}}=\frac{A \mathbf{k}_{\text {soil }}}{\mathrm{R}}\left[\mathrm{T}(0)-\mathrm{T}_{\infty}\right]+\frac{A \mathbf{k}_{\text {soil }}}{\mathrm{H}_{\text {soil }}}\left(\mathrm{T}_{\mathrm{CL}}-\mathrm{T}_{\infty}\right)
$$

which states that the total tank power is divided between downward heat conduction into the underlying soil and upward heat conduction through the soil overburden. Substituting $\mathrm{T}_{\mathrm{CL}}=90^{\circ} \mathrm{C}$ into equation (4-24) should provide a formula for the steam bump boundary that is identical in form to equation (4-23), provided that the as yet unknown temperature $T(0)$ at the bottom of the tank can be determined. Owing to multi-dimensional conduction effects in a non- 
uniform, non-convective layer and possible boiling of the interstitial liquid, the quantity $\mathrm{T}(0)$ can not be accurately estimated without resorting to a numerical approach. However, a useful lower bound to $T(0)$ may be obtained by writing an energy balance which equates the vertical conduction heat flux through the thickest portion of the non-convective layer (where $\mathrm{H}_{\mathrm{NCL}}=\mathrm{H}_{\mathrm{NCL}, \max }$ ) with the heat flux through the underlying soil; namely,

$$
\frac{k_{\mathrm{NCL}}\left[\mathrm{T}_{\mathrm{CL}}-\mathrm{T}(0)\right]}{\mathrm{H}_{\mathrm{NCL}, \max }}=\frac{\mathrm{k}_{\text {soil }}\left[\mathrm{T}(0)-\mathrm{T}_{\infty}\right]}{\mathrm{R}}
$$

Solving this relation for $\mathrm{T}(0)$ gives

$$
T(0)=T_{\infty}+\frac{T_{C L}-T_{\infty}}{1+B_{2, \max }}
$$

where $\mathrm{B}_{2, \max }=\frac{\mathrm{k}_{\mathrm{soil}} \mathrm{H}_{\mathrm{NCL}, \max }}{\mathrm{R} \mathrm{k}_{\mathrm{NCL}}}$

In deriving equation (4-26), we have neglected decay heat, boiling, and lateral heat conduction. All of these effects would tend to increase the effective value of T(0) at the bottom of the tank, either by increasing $\mathrm{T}(0)$ itself or decreasing the effective depth of the non-convective layer from the local, peak depth $\mathrm{H}_{\mathrm{NCL}}$,max.

It is not likely that a ridge of mixer-blown non-convective material would achieve a depth that exceeds the radius of the tank. Thus $B_{2, \max }$ in equation (4-27) should not be greater than unity and, therefore, $\mathrm{T}(0)$ in equation (4-26) should not be smaller than the arithmetic average $\left(\mathrm{T}_{\infty}+\mathrm{T}_{\mathrm{CL}}\right) / 2$. Thus, from equation (4-24), a rather conservative steam bump boundary for a tank with a non-uniform layer of non-convective material is

$$
\mathrm{W}_{\mathrm{NCL}}+\mathrm{W}_{\mathrm{CL}}=\left(1+\frac{\mathrm{H}_{\text {soil }}}{2 \mathrm{R}}\right) \frac{\left(\mathrm{T}_{\mathrm{CL}}-\mathrm{T}_{\infty}\right) \mathrm{A} \mathrm{k}_{\text {soil }}}{\mathrm{H}_{\text {soil }}}=9.23 \mathrm{~kW}
$$

The above equation is not too different from equation (4-23) that was derived for a uniform nonconvective layer. 
RPP-6654, REV. 0

This page intentionally left blank. 


\subsection{WASTE FEED DELIVERY TANK BUMP SCENARIO QUANTIFICATION}

The purpose of this section is to estimate the frequency of tank bumps caused by a single waste feed delivery (WFD) operation that involves mixer pump operation. Per the discussion in Section 3.0, the only scenario that needs evaluation is as follows: ventilation fails at time $t$, mixers shut off at or before time $t$, and failure to repair before saturated conditions. The event tree shown in Figure 3-4 is stylized in the sense that it applies for only one ventilation failure time $t$, when in fact, there are an infinite number of times at which the ventilation system could fail. The final calculation for tank bump must account for the fact that the time to ventilation failure is a continuous random variable. Only the first batches from Tanks 241-AZ-101 and 241-AZ-102 need consideration.

\subsection{FREQUENCY OF BUMP CONDITIONS FOR THE ANALYZED SCENARIO}

For some mixer pump operation time in the interval between $t$ and $t+\Delta t$, an expression for the frequency of this scenario $\mathrm{FWFD}_{W}$, is given by:

$$
d F_{W F D}(t)=p_{f}(t) P_{n r}(t) d t
$$

where $p_{f}(t)$ is the ventilation system failure probability density as a function of $t$, and $P_{n r}(t)$ is the conditional probability that ventilation cannot be recovered as a function of the failure at time $t$. Probability density $p_{\mathrm{f}}(t)$ has units of $1 / \mathrm{hr}$ or $1 /$ day, and $P_{n r}(t)$ has units of $1 /$ demand ( $1 / d)$, as does $F_{W F D}$. In writing this equation, an assumption is that the mixer pumps are shut off at the same time the ventilation system fails. The total frequency over the entire operation time is then simply:

$$
F_{W F D}=\int_{0}^{t_{o p}} p_{f}(t) P_{n r}(t) d t
$$

where equation (5-1) is integrated over time that the ventilation system must run concurrently with the mixer pumps.

Figure 5-1 illustrates how equations (5-1) and (5-2) arise. If ventilation is lost at a mixer pump operation time $t$ and recovery actions are never taken, the waste will self-heat until the settled waste temperature reaches the bump condition temperature. The time-to-bump conditions (or available recovery time) is determined by the difference between the mixed waste temperature, $\mathrm{T} 4$, at time $t$ and the settled waste temperature criterion of $240^{\circ} \mathrm{F}$. (This $240^{\circ} \mathrm{F}$ value is in keeping with LCO limits, where 25 degrees were subtracted from the sludge saturation temperature (HNF-SD-WM-TSR-006 2000).)

Figure 5-1 shows that the time to bump conditions, $t_{a}$, is a function of $t$, is very long if $t$ is only a few days, and becomes constant after the mixed waste temperature reaches steady-state. A ventilation failure early in the operation, as shown in Figure 5-1 by the designator $t_{1}$, results in 
Figure 5-1. Illustration of Time to Tank Bump Conditions as a Function of Ventilation System Failure Time During Mixer Pump Operation.

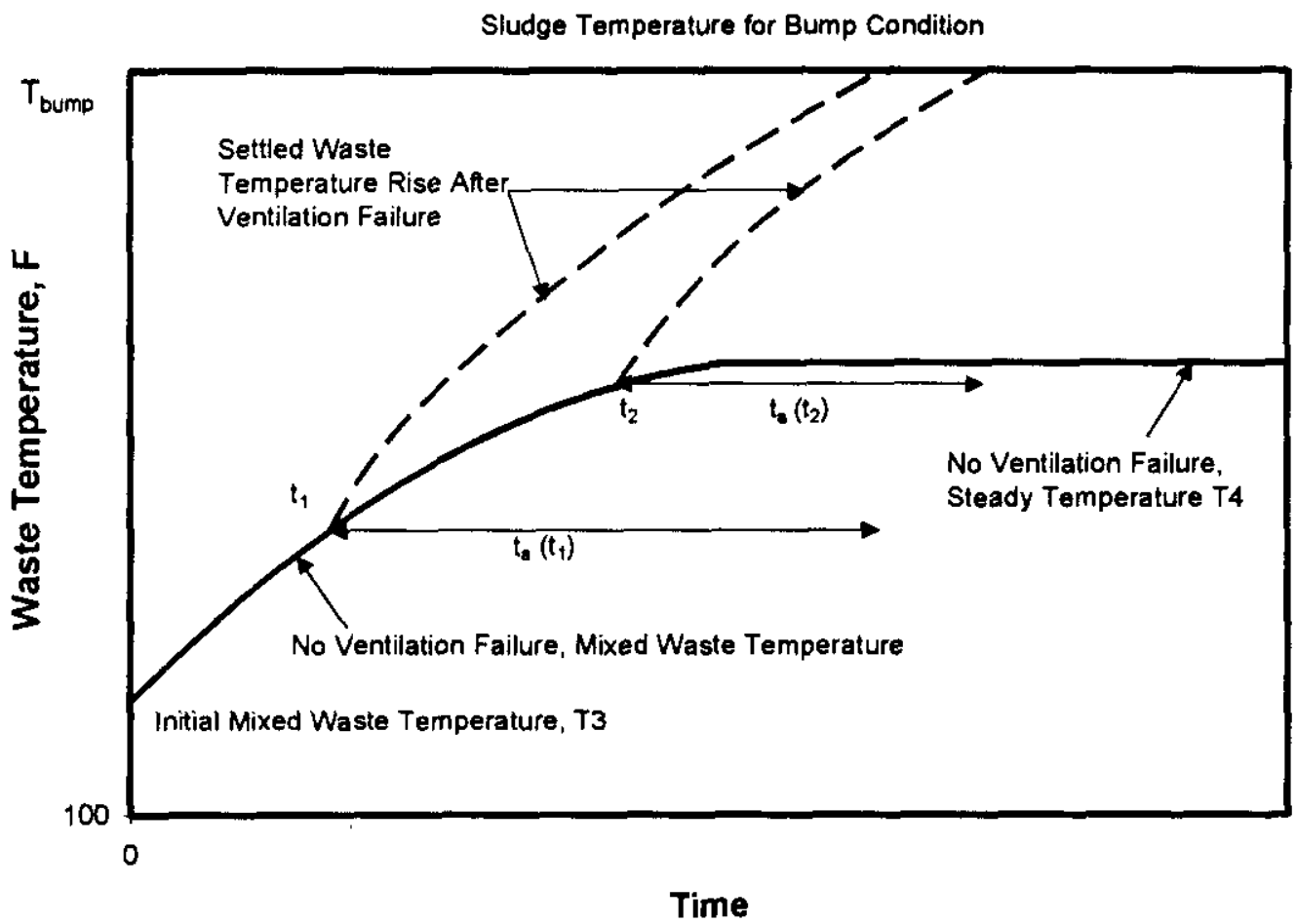


$t_{a}\left(t_{1}\right)$, which is longer than the available recovery time $t_{a}\left(t_{2}\right)$ for a ventilation failure later in the operation. Once the mixed waste temperature reaches steady-state, $t_{a}$ is constant. Figure 3-6 shows that if the ventilation system fails anytime after about 35 days of mixer operation, the available time for recovery is a constant, but the available time is much greater if the ventilation system fails after, say, 10 or 15 days of mixer pump operation. In principle, the calculation shown in Figure 3-6 can be repeated for each possible ventilation failure time, $t$, and the available recovery time approximated by the following function:

$$
\begin{array}{ll}
\text { If }(\mathrm{t}<35 \text { days }) & \mathrm{t}_{\mathrm{a}}=\frac{\left[\mathrm{T}_{\text {bump }}-\mathrm{T} 4(\mathrm{t})\right]}{\alpha} \\
\text { else } & \mathrm{t}_{\mathrm{a}}=\text { cons tan } \mathrm{t}
\end{array}
$$

where $\alpha$ is the temperature rate-of-change in ${ }^{\circ} \mathrm{F} /$ day, $\mathrm{T}_{\text {bump }}$ is the temperature defined for bump conditions, and $T 4(t)$ is the mixed waste temperature from Figure 3-6. This function is evaluated numerically in the next sub-section.

Because there is no conspicuous choice for $t_{\mathrm{op}}$, it will be treated parametrically. The bestestimate is that the mixer pumps will operate for only a few days, in which case the retrieval tank bump accident frequency analysis is academic. Consider Figure 3-6 and assume that the ventilation system fails and mixer pumps are shut off at 45 days with respect to time zero, or about 8 days of mixer pump operation. Figure 3-6 shows that if the ventilation system fails and the mixer pumps are shut down at the peak temperature, T4, 40 days must pass before bump conditions $\left(240^{\circ} \mathrm{F}\right)$ are reached. If the accident sequence starts at 45 days from time zero, however, the time-to-bump conditions is much greater than 40 days because the initial temperature is only $150^{\circ} \mathrm{F}$, or $66^{\circ} \mathrm{C}$. Assuming that the heat up rate is $\left(240^{\circ} \mathrm{F}-191^{\circ} \mathrm{F}\right) / 40$ days, which equals $1.2^{\circ} \mathrm{F} /$ day, the time to heat up to bump condition from $150^{\circ} \mathrm{F}$ would be about 75 days.

The preceding approximation shows that if the mixer pumps operate briefly, the time-to-bump conditions after a retrieval accident scenario is comparable to the time-to-bump conditions calculated for a safe storage scenario with the current conditions. The safe storage analysis shows that for the current conditions, annual tank bump frequency is beyond extremely unlikely. Moreover, the ventilation system failure frequency depends directly on the mission time for mixer pump operation: the smaller the mixer pump operation time, the smaller the probability of ventilation system failure during mixer pump operation. If the mixer pumps operate for only several days, both the probability of ventilation failure and the probability of recovery failure prior to bump conditions are so small that the accident frequency is beyond extremely unlikely for any one operation.

Another assumption is that a lengthy mixer pump interval is possible because it will not violate LCO 3.3.2 as long as the ventilation system functions. Operator errors or schedule delays may cause mixer pump operations to exceed the expected duration. For this reason, the mixer pump mission time will be studied parametrically. 


\subsection{VENTILATION SYSTEM FAILURE RATE}

The probability of a ventilation system failure during the feed activity is considered here. Only random equipment failures are quantified, as failures due to external events have been shown to be unimportant by comparison (Epstein et al. 2000). Loss of off-site power (LOSP) events long enough to initiate bump conditions were judged beyond extremely unlikely as an initiating event. Seismic events of sufficient magnitude to cause ventilation system failure are not incredible, but such events in and of themselves pose greater risk to the site than do tank bumps. Note that severe weather events were considered as part of the WFD RAM (Carlson 1999a and 1999b), but are neglected here. The WFD RAM considered high winds, extreme temperatures, thunderstorms, and precipitation as a source of schedule delays, but not necessarily as a source of ventilation system failure. For example, the WFD RAM considered low temperatures that would make working conditions unbearable as a cause for a schedule delay.

The success criteria defined in Section 3.3 state that both the annulus and primary ventilation systems must operate. Schematic diagrams of the primary and annulus ventilation systems are shown in Figures 5-2 and 5-3, respectively. Simplifying assumptions which allow Figure 3-6 to be applied here are that the two systems are independent of each other and that a failure of either system leads to a complete loss of active heat removal. The probability density function for ventilation system failure during the feed activity is then:

$$
\mathrm{p}_{\mathrm{f}}=\lambda_{\mathrm{p}}+\lambda_{\mathrm{ann}}
$$

where $\lambda_{\mathrm{p}}$ is the primary system failure rate per unit time and $\lambda_{\mathrm{ann}}$ is the annulus ventilation system failure rate per unit time.

Primary system failure rate was estimated in the safe storage accident analysis (Epstein et al. 2000) to have an expected failure rate of $0.04 / \mathrm{yr}$, but distributed log-uniformly between 0.01 and $0.1 / y r$. This estimate was based on limited data for exhaust fan availability and assumes that primary ventilation system failure rate is the same as the failure rate of a subsystem of two exhaust fans. This assumption is reasonable given the operating history and waste temperature surveillance. The safe storage primary ventilation failure rate is in reasonable agreement with the generic failure rate for two motor-driven fans or blowers with one in standby, taking into account common cause failures by the simple beta-factor method. This failure rate is listed as 3E-5/hr (0.26/yr) with an error factor of 3 (Carlson 1999a) and a generic beta-factor for common cause failure is 0.13 for fans (Mosleh et al. 1988). For a system with two fans, one in standby, the annual failure rate of primary ventilation system would be roughly $0.26 \times 0.13 / \mathrm{yr}$, or $0.03 / \mathrm{yr}$, with an error band of 0.09 to $0.01 / \mathrm{yr}$.

For the waste feed delivery operation, the primary ventilation system failure rate will be conservatively evaluated using generic failure rate data for the major components shown in Figure 5-2. The failure rate for the primary ventilation system is then:

$$
\lambda_{\mathrm{p}}=\lambda_{\mathrm{HEME}}+\lambda_{\mathrm{CH}}+\lambda_{\text {CCFFANS }}
$$


Figure 5-2. Schematic Diagram of the Primary Ventilation System for AZ/AY DSTs.

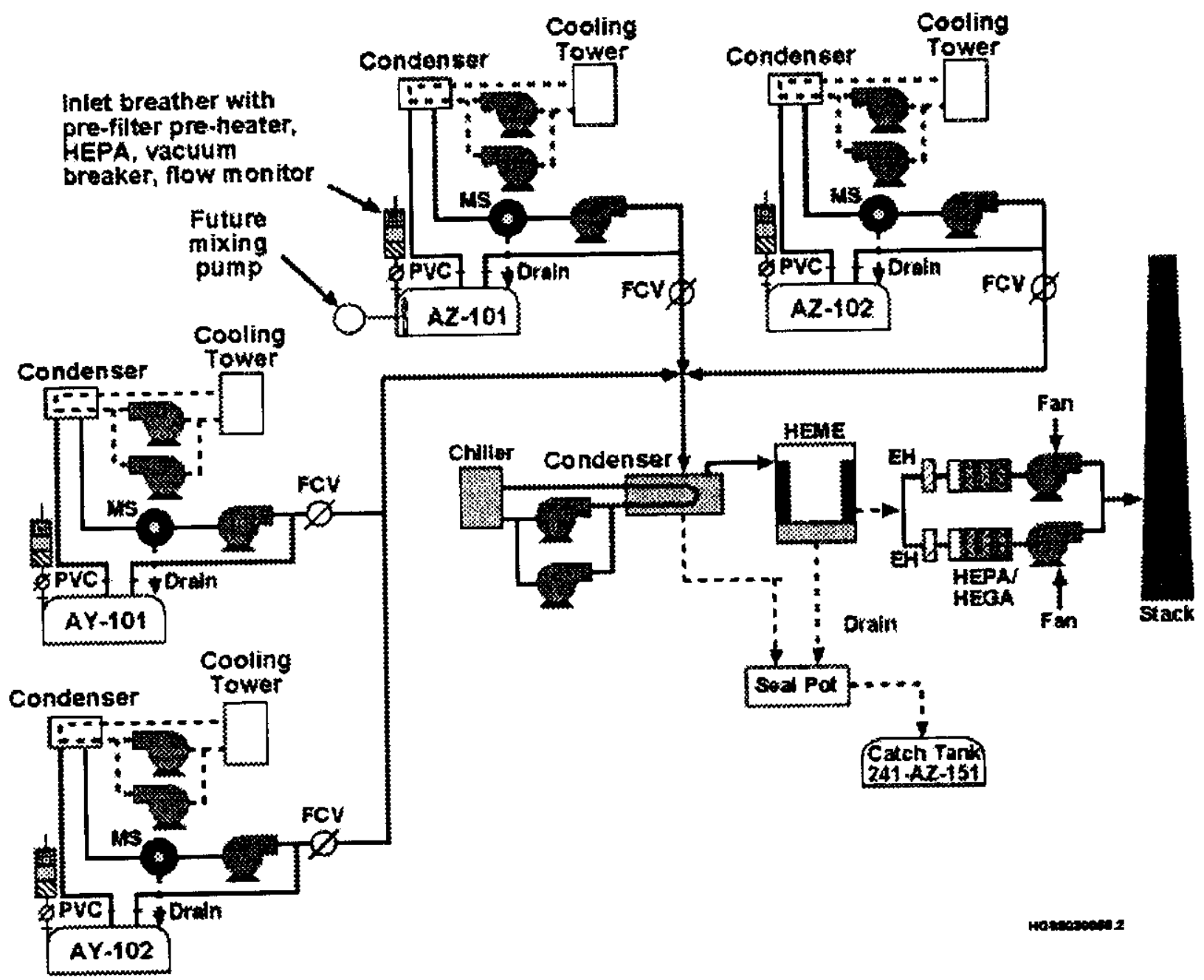


Figure 5-3. Schematic Diagram of Tank 241-AZ-102 Annulus Ventilation System.

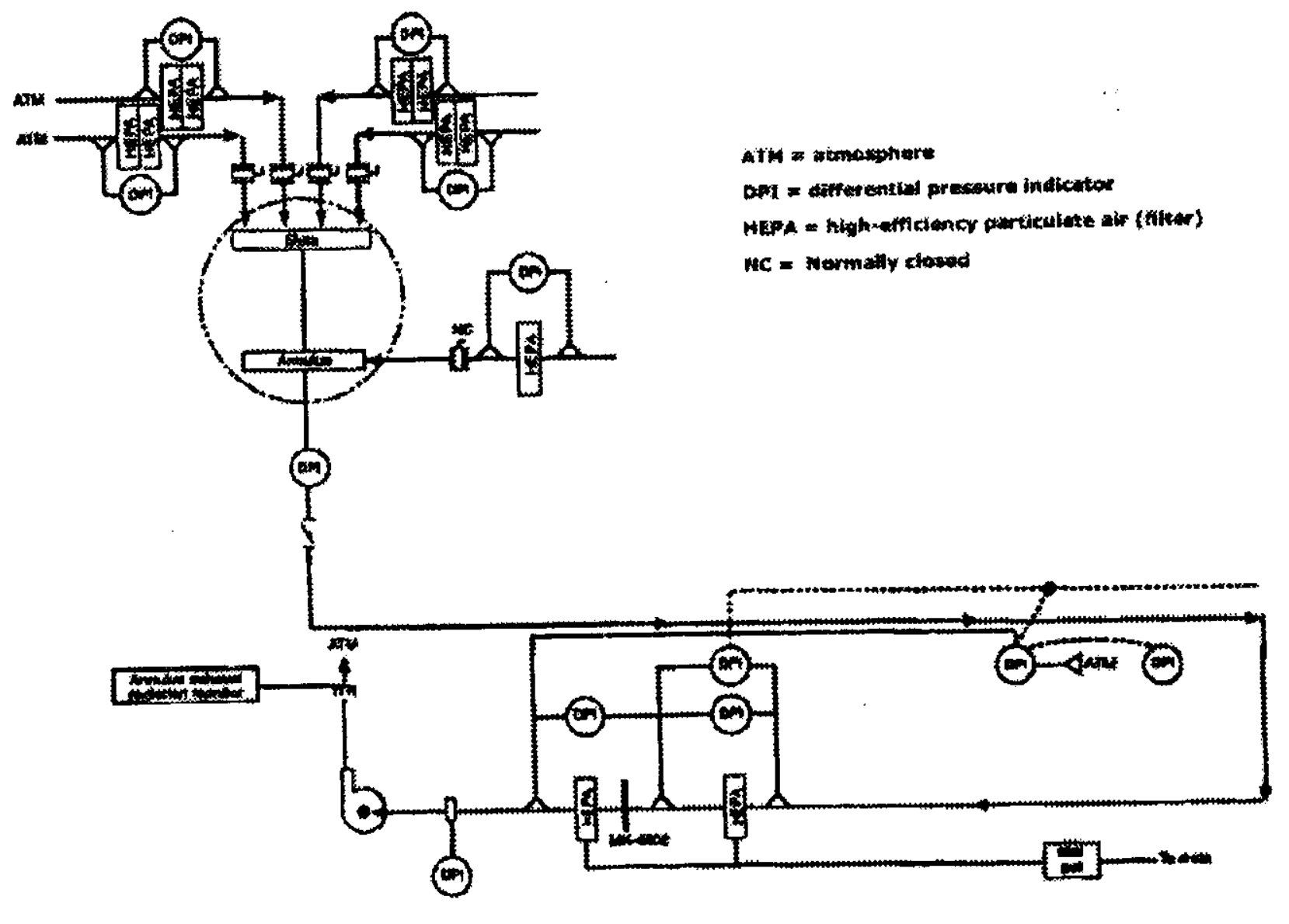


where $\lambda$ is the hourly failure rate, subscript HEME denotes the failure rate for high efficiency mist eliminator, $\mathrm{CH}$ denotes the failure rate for the heat exchanger unit (chiller and condenser), and CCFFANS is the failure rate for the sub-system of exhaust fans, which has already been calculated at $4.5 \mathrm{E}-6 / \mathrm{hr}$. This equation neglects HEPA filters, dampers, and instrumentation subcomponents that have very low failure rates or are not vital to heat removal. The ventilation condenser cooling system, which circulates some air back to the tank headspace, is neglected on the basis of WFD RAM results showing that the number of off-normal events for the ventilation condenser cooling system is much less than the number of off-normal events for either the primary ventilation or annulus ventilation system. The same can be said for support systems, namely electric power, service water, and instrument air. The WFD RAM shows that the number of off-normal events per transfer due to any one of the support systems is two orders of magnitude smaller than the number due to either the primary or annulus ventilation systems.

Figure 5-3 shows that the annulus system is much simpler. By making the same assumptions made for the primary ventilation systems (neglect support systems and HEPA filters), the failure rate for the annulus ventilation system is just the generic failure rate for a motor-driven fan, which is $3 \mathrm{E}-5 / \mathrm{hr}$. That is, $\lambda_{\text {ann }}=\lambda_{\text {FAN }}$, where $\lambda_{\text {FAN }}=3 \mathrm{E}-5 / \mathrm{hr}$.

An expression for ventilation system failure rate is then:

$$
\mathrm{p}_{\mathrm{f}}=\lambda_{\mathrm{HEME}}+\lambda_{\mathrm{CH}}+\lambda_{\mathrm{CCFFANS}}+\lambda_{\mathrm{FAN}}
$$

Data from the WFD RAM are as follows:

- $\quad$ HEME failure rate has a mean of $1 \mathrm{E}-4 / \mathrm{hr}$ with an error factor of 10 ,

- Heat exchanger failure rate has a mean of $4 \mathrm{E}-5 / \mathrm{hr}$ with an error factor of 10 , and

- Annulus fan failure rate has a mean of $3 \mathrm{E}-5 / \mathrm{hr}$ with an error factor of 3

To consider the uncertainty in the ventilation failure rate, a simulation was performed with the following input distributions:

- $\quad$ HEME failure rate is log-uniform on the interval $1 \mathrm{E}-5 / \mathrm{hr}$ to $1 \mathrm{E}-3 / \mathrm{hr}$,

- Heat exchanger failure rate is log-uniform on the interval $4 \mathrm{E}-6 / \mathrm{hr}$ to $4 \mathrm{E}-4 / \mathrm{hr}$,

- Annulus fan failure rate is log-uniform on the interval $1 \mathrm{E}-5 / \mathrm{hr}$ to $9 \mathrm{E}-5 / \mathrm{hr}$, and

- Exhaust fans failure rate is log-uniform on the interval $1.5 \mathrm{E}-6 / \mathrm{hr}$ to $4.5 \mathrm{E}-6 / \mathrm{hr}$

To describe the output distribution, thirty random deviates for ventilation failure rate were used for curve fitting. The Chi-square goodness-of-fit test showed that a log-normal distribution with 
log-mean equal to -8.37 and $\log$-standard deviation equal to 0.806 was a reasonable fit ( $p$ value $=0.57)$. This distribution has a mean of $3,2 \mathrm{E}-4 / \mathrm{hr}$ and standard deviation of $3.1 \mathrm{E}-4 / \mathrm{hr}$.

\subsection{FAILURE TO RECOVER PROBABILITY}

Failure to recover probability consists of two components: failure to restore ventilation within the available time and failure to enact corrective maintenance within the available time. Restoration considers that ventilation system functions can be recovered without repair in many instances by manual switchover for functions with redundant hardware. This was recognized and accounted for in the waste transfer RAM by developing probability density functions for restoration times and determining whether recovery from an off-normal event required a restoration function or a corrective maintenance $(\mathrm{CM})$ function.

Failure to recover probability is considered in the safe storage accident analysis (Epstein et al. 2000) and only important results are repeated here. The probability that ventilation is not recovered in the available time is then:

$$
P_{n r}=\left(1-x_{r s}\right) \sum_{n=1}^{N} x_{n}\left[1-\log -\operatorname{normal}\left(t_{a}, \alpha_{n}, \beta_{n}\right)\right]
$$

where $\mathrm{N}$ is the number of corrective maintenance activities, $\mathrm{x}$ is the fraction of all $\mathrm{CM}$ activities for the $n^{\text {th }} \mathrm{CM}$ activity (the relative frequency such that the sum of all $x_{n}$ values is equal to one), $\log$-normal is the cumulative log-normal distribution function evaluated at the available time, $t_{a}$, for the $\log$-mean $\alpha_{n}$ and $\log$-standard deviation, $\beta_{n}$, of the $n^{\text {th }} C M$ activity. This expression assumes that restoration activities succeed during the available time, which is justifiable because the restoration time is one week at most while the available time is somewhere beyond 40 days. This expression states that the probability that $\mathrm{CM}$ fails is the sum of the probabilities that individual $\mathrm{CM}$ activities fail. The probability that an individual $\mathrm{CM}$ activity will fail in the available time is just the exceedance probability for the log-normal distribution of repair time. Exceedance probability for each individual $\mathrm{CM}$ activity is weighted by the relative frequency of each CM activity.

The available time $t_{a}$ is taken to be the time to heatup to saturated conditions. Restoration or corrective maintenance activities should begin immediately because late waste feed deliveries will result in penalties. Now the time available, $t_{a}$, is a function of the time that the ventilation system fails and the mixer pumps are shut off, $t$. Figure 3-6 shows that if the ventilation system fails anytime after about 35 days of mixer operation, the available time for recovery is 40 days, but the available time is much greater if the ventilation system fails after 10 or 15 days of mixer pump operation. In principle, the calculation shown in Figure 3-6 should be repeated for each possible ventilation failure time, $t$. This is accomplished in Appendices $A$ and $B$, and the available recovery time is approximated by the following function:

$$
\begin{array}{ll}
\text { If }(\mathrm{t}<35 \text { days }) & \mathrm{t}_{\mathrm{a}}=\frac{\left[240^{\circ} \mathrm{F}-\mathrm{T} 4(\mathrm{t})\right]}{\alpha} \\
\text { else } & \mathrm{t}_{\mathrm{a}}=40 \text { days }
\end{array}
$$


where $\alpha$ is the temperature rate-of-change in $\mathrm{F} /$ day and $\mathrm{T} 4(\mathrm{t})$ is the mixed waste temperature from Figure 3-6. Temperature rate-of-change, $\alpha$, is $1.2^{\circ} \mathrm{F} /$ day, based on the results in Appendix B. $T 4(t)$ is found based on a curve fit to the data from Figure 3-6, using the data points between 37 days (T3, the initial mixed waste temperature) and 72 days (peak T4). This data is shown in Table 5-1.

Table 5-1. Mixed Waste Temperature as a Function of Time (see Figure 3-6).

\begin{tabular}{|c|c|c|}
\hline \multicolumn{2}{|c|}{ Time (Days) } & Mixed Waste Temperature, T4, $\left({ }^{\circ} \mathbf{F}\right)$ \\
\hline Relative to Zero & Minus 37 Days & 124 \\
47 & 0 & 148 \\
48 & 8 & 158 \\
51 & 11 & 166 \\
54 & 14 & 173 \\
57 & 17 & 180 \\
60 & 20 & 184 \\
66 & 23 & 189 \\
72 & 29 & 191 \\
\hline
\end{tabular}

A good curve fit $\left(\mathrm{R}^{2}=0.997\right)$ is given by $\mathrm{T} 4=123 .+3.9 \mathrm{t}-0.055 \mathrm{t}^{\circ} \mathrm{F}$, where $\mathrm{t}$ is days minus 37 . The expression for time available before bump conditions is then:

$$
\begin{array}{ll}
\text { If }(\mathrm{t}<35 \text { days }) & \mathrm{t}_{\mathrm{a}}=\frac{\left[240^{\circ} \mathrm{F}-\left(123+3.9 \mathrm{t}-0.055 \mathrm{t}^{2} \circ \mathrm{F}\right)\right]}{\alpha} \\
\text { else } & \mathrm{t}_{\mathrm{a}}=40 \text { days }
\end{array}
$$

Equation (5-2) can now be rewritten as:

$$
F_{W F D}=\left[\lambda_{p}+\lambda_{a n n}\right] \int_{0}^{t_{o p}}\left(1-x_{r s}\right) \sum_{n=1}^{N} x_{n}\left[1-\log -\operatorname{normal}\left(t_{a}, \alpha_{n}, \beta_{n}\right)\right] d t
$$

with $t_{a}$ as specified just above in equation (5-9). This expression is lengthy but is easily evaluated numerically for various mission times $t_{\text {op }}$. Baseline inputs shown in Table 5-2 are taken from the safe storage accident analysis (Epstein et al. 2000).

Corrective maintenance activities are defined as follows: TCNEL refers to Tank Farm (Radiological) Area Access, Non-intrusive, Moderate to Extensive Planning, Long Lead; TCIEL refers to Tank Farm (Radiological) Area Access, Contact Handled/Intrusive, Moderate to Extensive Planning, Long Lead; " 3 " refers to heaters, and " 5 " refers to fans and filters. 
RPP-6654, REV. 0

Table 5-2. Baseline Inputs for Tank Bump Frequency Evaluation as a Function of Time.

\begin{tabular}{|c|l|c|}
\hline Symbol & \multicolumn{1}{|c|}{ Definition } & Value \\
\hline None Here. & Ventilation Failure Rate & $0.0077 /$ day \\
\hline$x_{r s}$ & Restoration Activity Fraction & 0.8 \\
\hline$x_{1}$ & Corrective Maintenance Activity Fraction for 3TCNEL & 0.485 \\
\hline$x_{2}$ & Corrective Maintenance Activity Fraction for 5TCIEL & 0.030 \\
\hline$x_{3}$ & Corrective Maintenance Activity Fraction for 5TCNEL & 0.485 \\
\hline$\alpha_{1}$ & Log-Mean of CM Activity 3TCNEL Distribution & 5.08 \\
\hline$\alpha_{2}$ & Log-Mean of CM Activity 5TCIEL Distribution & 5.56 \\
\hline$\alpha_{3}$ & Log-Mean of CM Activity 5TCNEL Distribution & 4.89 \\
\hline$\beta_{1}$ & Log-St. Dev. Of CM Activity 3TCNEL Distribution & 0.56 \\
\hline$\beta_{2}$ & Log-St. Dev. Of CM Activity 5TCIEL Distribution & 0.56 \\
\hline$\beta_{3}$ & Log-St. Dev. Of CM Activity 5TCNEL Distribution & 0.56 \\
\hline
\end{tabular}

Results of numerical integration of equation (5-10) are shown in Figure 5-4, which shows tank bump conditions frequency as a function of mixer pump operation time. Appendix $\mathrm{C}$ contains computation details. As expected, the curve approaches zero risk for zero operation time, and shows tiny values for mixer pump operation times on the order of a few days. Figure 5-4 shows that tank bump frequency during feed delivery becomes not incredible only after 19 days of continuous mixer pump operation. This greatly exceeds the expected mixer pump operating times mentioned in Section 3.3.

Figure 5-2 also suggests that an interesting risk metric for waste feed delivery activities is the number of mixer pump operation days need to result in a credible frequency of bump conditions per demand (greater than $1 \times 10^{-6} / \mathrm{d}$ ). This metric can be considered with respect to the planned operations to gauge the level of risk involved in a waste activity. To solve for this metric, FWFD is set to $1 \times 10^{-6}$ and the right-hand side of equation $(5-10)$ is integrated over various $t_{\text {op }}$ until the equality is satisfied. This has been accomplished as part of an uncertainty analysis which proceeds as follows:

- Generate respective random samples for $\lambda_{\mathrm{p}}+\lambda_{\mathrm{ann}}, \mathrm{x}_{\mathrm{rs}}$, and $\mathrm{x}_{\mathrm{n}}$,

- Iterate on $t_{o p}$ until equation $(5-10)$ is satisfied with $F_{W F D}=1 \times 10^{-6}$,

- Record $t_{\text {op }}$ is the result of one trial, and

- Repeat for many trials and express results as a probability density function or cumulative distribution function. 
RPP-6654, REV. 0

Figure 5-4. Base Case Tank Bump Conditions Frequency as a Function of Mixer Pump Operation.

WFD Tank Bump Frequency

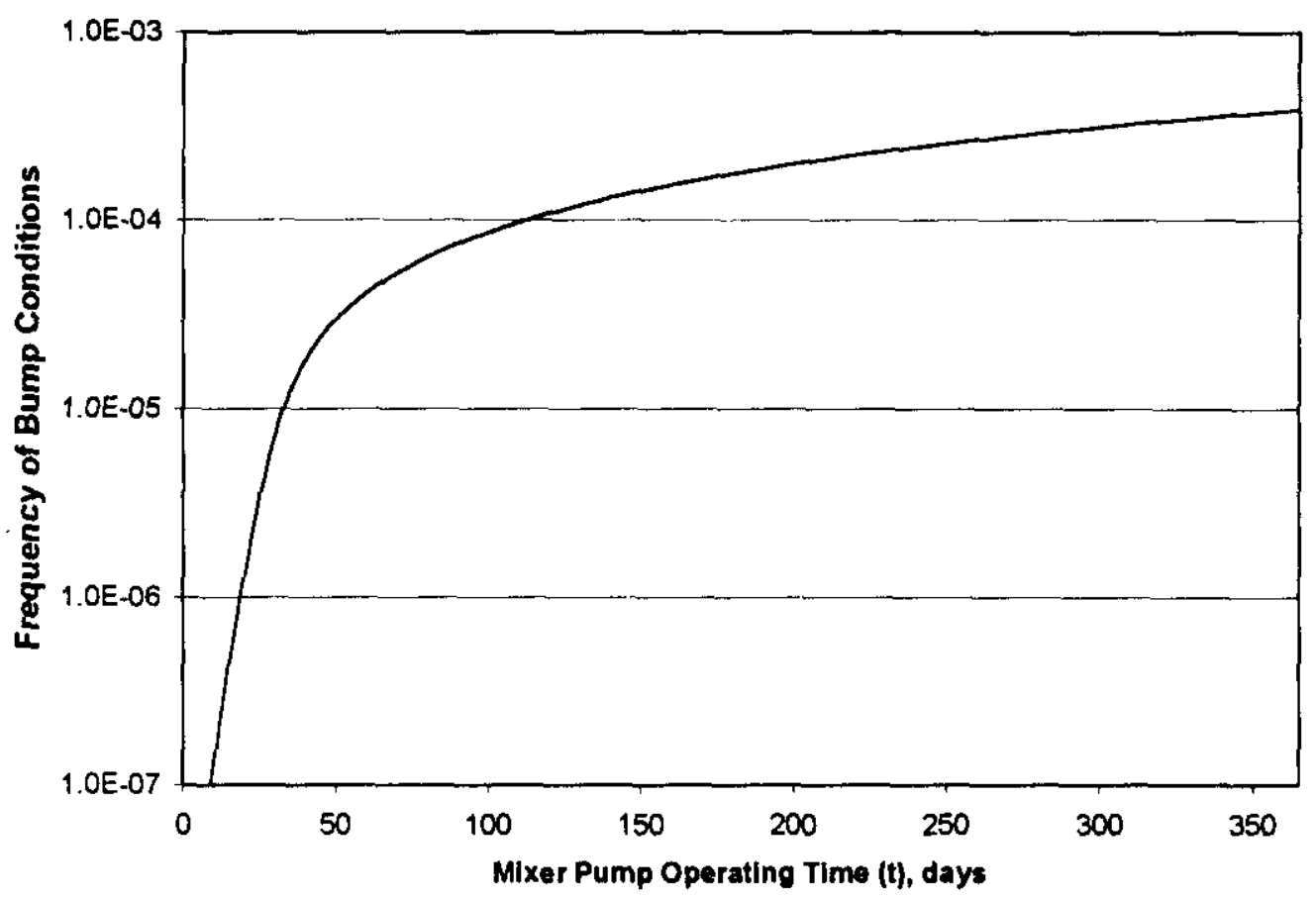


The following distributions were used for the Monte Carlo simulation of the risk metric: the sum $\lambda_{\mathrm{p}}+\lambda_{\text {ann }}$ is log-normally distributed on mean equal to $3.21 \mathrm{E}-4 / \mathrm{hr}$ and standard deviation equal to $3.07 \mathrm{E}-4 / \mathrm{hr}, \mathrm{x}_{\mathrm{rs}}$ is uniformly distributed between $50 \%$ and $80 \%$, and $\mathrm{x}_{2}$, the corrective maintenance activity fraction for 5TCIEL, is uniformly distributed between $1 \%$ and $10 \%$. Distributions for the ventilation failure rate and $x_{2}$ reflect an error factor of roughly 3 about the mean.

Results of the simulation are shown in Figure 5-5. Out of 1000 trials, 7 days is the minimum value and 17 days is the median. These values exceed the planned mixer pump operation times and demonstrate margin for schedule delays.

\subsection{THE LIKELIHOOD OF TANK BUMP GIVEN SATURATED CONDITIONS AND FLUFFED WASTE PROPERTIES}

Up to this point, we have simply determined the frequency of bump conditions based on nonconvective layer and/or supernatant temperature relative to local saturation temperature. As in the safe storage accident analysis (Epstein et al. 2000), tank bump might not occur despite bump conditions, if neutral buoyancy cannot be attained in the non-convective layer through buildup of noncondensible gases. Meyer and Wells (2000) derived criteria that must be satisfied in order for buoyant displacements to occur. These models are evaluated for the fluffed conditions to determine the likelihood of retrieval bumps given saturated conditions in the sludge.

Meyer and Wells (2000) developed an equation for the vertical void fraction profile within the non-convective layer based on a balance between internal gas generation and the rate at which gas is released at the top of the layer. The integrated average of this void fraction profile is compared with the neutral buoyant void fraction to determine whether a buoyant displacement may occur at some point during the transient (quasi-steady) void growth period. Two limiting case solutions were found for the void fraction profile and the corresponding criteria for a buoyant displacement are

$$
\frac{\mathrm{C}_{1} \mathrm{~h}_{\mathrm{NCL}}^{2}}{\rho_{\mathrm{NCL}}-\rho_{\mathrm{Cl}}}\left(\frac{\mathrm{GT}}{\mathrm{P}_{\mathrm{NCL}}}\right)^{1 / 3}>1
$$

for a uniform bubble nucleation rate and a zero initial void fraction, and

$$
\frac{C_{2}}{\rho_{\mathrm{NCL}}-\rho_{\mathrm{CL}}}\left(\frac{\rho_{\mathrm{NCL}}^{2} \mathrm{~h}_{\mathrm{NCL}}^{2} \mathrm{G} \mathrm{T}}{P_{\mathrm{NCL}}}\right)^{1 / 3}>1
$$

for an assumed bubble flux at the lower boundary and zero internal nucleation rate. In equations (5-11) and (5-12), $\rho_{N C L}$ and $\rho_{C L}$ are the density of the non-convective layer and the density of the convective layer $\left(\mathrm{kg} / \mathrm{m}^{3}\right)$, respectively, $\mathrm{G}$ is the molar gas generation rate per unit volume of non-convective layer ( $\mathrm{g}-\mathrm{mole} / \mathrm{m}^{3} /$ day), $\mathrm{T}$ is the average temperature of the non-convective layer $(\mathrm{K}), \mathrm{P}_{\mathrm{NCL}}$ is the average pressure of the non-convective layer (atm), and $\mathrm{h}_{\mathrm{NCL}}$ is the depth of the 
Figure 5-5. Uncertainty Analysis for the Mixer Pump Operation Day where Tank Bump Conditions Frequency Becomes Credible.

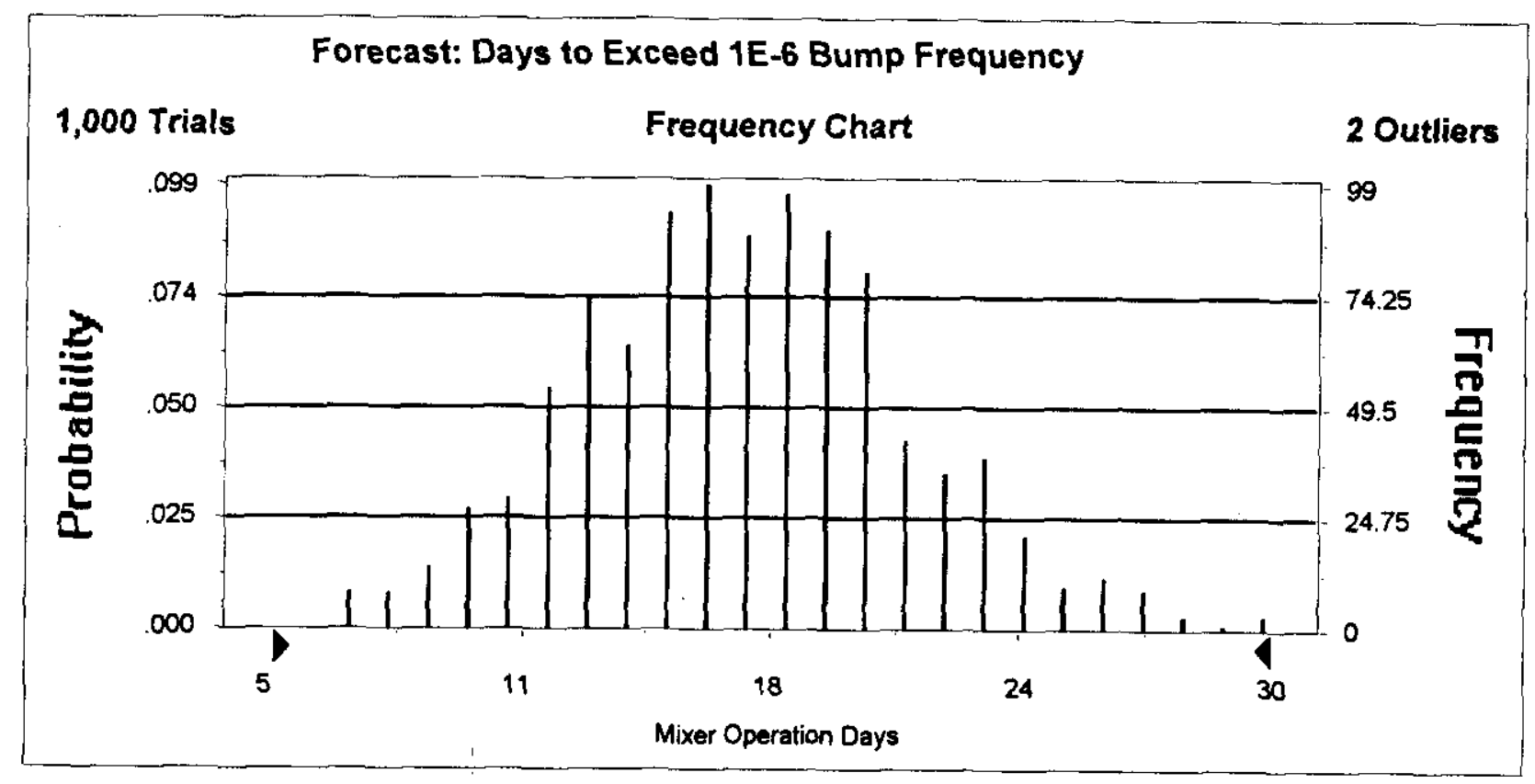


non-convective layer $(m)$. The constants $C_{1}$ and $C_{2}$, each with dimensional units, are empirically adjusted so that all the double-shell tanks with observed buoyant displacements obey the criteria given by equations (5-11) and (5-12).

Equation (5-11) yields a better representation of double-shell tank buoyant displacement behavior (Stewart 2000) and is chosen here for application to Tank 241-AZ-102. The value of the constant in equation (5-11) based on the most recent tank data is $C_{1}=18.5$ (Stewart 2000).

It is of interest to evaluate equation (5-11) when $\mathrm{G}$ is based on noncondensable gas generation only. The noncondensable gas generation rate at some temperature $T$ is obtained by using the Arrhenius equation to extrapolate the known gas generation rate at the current non-convective layer temperature $T_{0}$ to its value at $T$ :

$$
G_{g}(T)=G_{g}\left(T_{0}\right) \exp \left(-\frac{T_{a c t}}{T}+\frac{T_{a c t}}{T_{o}}\right)
$$

where the activation temperature $\mathrm{T}_{\mathrm{act}}(=\mathrm{E} / \mathrm{R})$ is $1.074 \times 10^{4}(\mathrm{Hu} 1999)$. For simplicity and conservatism, $\mathrm{T}$ is taken to be the non-convective layer maximum temperature.

Gas generation rate $G_{g}\left(T_{0}\right)$ for Tank 241-AZ-102 is known for the current conditions (Epstein et al. 2000), but the fluffed conditions are of interest here. A general expression for noncondensable gas generation is not available, but $\mathrm{Hu}$ et al. (2000) gives empirical expressions for hydrogen generation rates due to thermolysis and radiolysis. These expressions show that both thermolytic and radiolytic hydrogen generation are directly proportional to liquid wt. fraction and occur mainly in the liquid phase. Fluffing increases sludge liquid wt. fraction.

The Tank 241-AZ-102 sludge has an initial liquid wt. fraction of $58 \%$ and initial solids volume fraction of $17 \%$ (Crea et al. 2000). A fluffing factor of two cuts the solids volume fraction in half and increases the liquid wt. fraction to $76 \%$. This suggests that for a given temperature, fluffing increases hydrogen generation in the sludge by up to $30 \%$. Current noncondensable gas generation rate is multiplied by 1.3 to account for this possibility. Results are relatively insensitive to this uncertainty because the gas generation rate is raised to the $1 / 3$ power.

Equation (5-11) was evaluated with the following Tank 241-AZ-102 inputs:

- Particle density, $\rho_{\mathrm{s}}=3.8 \mathrm{gm} / \mathrm{ml}$ (Crea et al. 2000),

- Liquid density, $\rho_{1}=1.1 \mathrm{gm} / \mathrm{ml}$ (Crea et al. 2000),

- Fluffing factor, $\mathrm{f}=1.4$ and 1.7 , by assumption,

- Initial sludge depth, $\mathrm{h}_{\mathrm{NCL} 0}=96 \mathrm{~cm}$,

- Initial supernatant depth, $\mathrm{h}_{\mathrm{sup} 0}=761 \mathrm{~cm}$,

- $\quad$ Mixed-waste average density, $\rho_{\mathrm{w}}=1.14 \mathrm{gm} / \mathrm{ml}$ (Hu et al. 2000), 
- $\quad$ Current temperature $=355 \mathrm{~K}($ Epstein et al. 2000),

- Current noncondensable gas generation $=1.3 \times 1.26 \times 10^{-2} \mathrm{~mole} / \mathrm{m}^{3}$-day (Epstein et al. 2000), and

- Waste temperature, $\mathrm{T}_{\max }=396 \mathrm{~K}\left(254^{\circ} \mathrm{F}\right.$ from Figure 3-6).

Auxiliary relationships needed are:

$$
\begin{aligned}
& \alpha_{s}=\frac{\left(h_{\mathrm{NCL} 0}+h_{\text {supo }}\right)\left(\rho_{\mathrm{w}}-\rho_{1}\right)}{f h_{\mathrm{NCLO}}\left(\rho_{\mathrm{s}}-\rho_{1}\right)} \\
& \rho_{\mathrm{NCL}}=\alpha_{\mathrm{s}} \rho_{\mathrm{s}}+\left(1-\alpha_{\mathrm{s}}\right) \rho_{\mathrm{l}} \\
& \mathrm{P}_{\mathrm{NCL}}=\frac{101350+\rho_{\mathrm{CL}} \mathrm{g}\left(\mathrm{h}_{\mathrm{NCL}}+\mathrm{h}_{\text {sup } 0}-\mathrm{f} \mathrm{h}_{\mathrm{NCL} 0}\right)+\frac{1}{2}\left(\rho_{\mathrm{NCL}} \mathrm{gf} \mathrm{h}_{\mathrm{NCLO}}\right)}{101350}
\end{aligned}
$$

where $\alpha_{\mathrm{S}}$ is the solids volume fraction.

Evaluation of equation ( $5-11$ ) with $\mathrm{f}=1.4$ yields 0.6 for the left-hand side, but evaluation with $\mathrm{f}=1.7$ yields 1.0 for the left-hand side. Table $5-3$ shows inputs, intermediate values, and results.

The likelihood of tank bump; given bump conditions, is then roughly the likelihood that the fluffing factor exceeds 1.7. This work begins by identifying 2.0 as a very conservative, perhaps bounding, value used by Crea et al. (2000) and adopted here for consistency. Based on laboratory settling data used for the Project W-320 waste transfer into Tank 241-AY-102, 1.4 is a best-estimate value and 1.8 is a two standard-deviation upper bound (Numatec 1998). Tank 241 -SY-101 settling data provide a best-estimate fluffing factor of 1.5 and bounding value of 1.75 .

A fluffing factor greater than 1.7 can be characterized as unlikely, but not incredible, and the same can be said for the probability of a bump given bump conditions. In principle, equation (5-1) could be modified to reflect this. This right-hand side of the equation could be multiplied by the probability of fluffing factor exceeding 1.7 to obtain the frequency of a bump rather than merely bump conditions.

\subsection{CONCLUSIONS}

The frequency analysis above shows that a tank bump induced by the planned retrieval operations is beyond extremely unlikely. Available recovery times would be very long relative to the time needed for corrective maintenance activities. Given bump conditions, a bump in Tank 241-AZ-102 could only occur if the fluffing factor greatly exceeds the expected value. 
Table 5-3: Evaluation of Meyer and Wells (2000) Criterion for Two Fluffing Factors of 1.4 and 1.7 .

\begin{tabular}{|c|c|c|c|c|c|c|}
\hline $\begin{array}{l}\text { Particle } \\
\text { Density }\end{array}$ & $\begin{array}{l}\text { Liquid } \\
\text { Density }\end{array}$ & $\begin{array}{l}\text { Fluffing } \\
\text { Factor }\end{array}$ & $\begin{array}{l}\text { Initial Sludge } \\
\text { Depth }\end{array}$ & $\begin{array}{c}\text { Initial } \\
\text { Supernatant } \\
\text { Depth }\end{array}$ & $\begin{array}{l}\text { Average } \\
\text { Density }\end{array}$ & $\begin{array}{l}\text { Fluffed } \\
\text { Alpha }\end{array}$ \\
\hline 3800 & 1100 & 1.4 & 0.96 & 7.61 & 1140 & 0.094466 \\
\hline Const & $\begin{array}{c}\text { Sludge } \\
\text { Depth, } m\end{array}$ & $\begin{array}{l}\text { Sludge } \\
\text { Density }\end{array}$ & $\begin{array}{l}\text { Supernatant } \\
\text { Density }\end{array}$ & $\begin{array}{l}\text { Hydrostatic } \\
\text { Pressure, atm }\end{array}$ & & \\
\hline 18.5 & 1.344 & 1355 & 1100 & 1.86 & & \\
\hline $\begin{array}{c}\mathbf{G}_{\mathbf{g}} \mathbf{0} \\
1.64 \mathrm{E}-02 \\
\end{array}$ & $\begin{array}{c}\mathbf{T}_{\text {act }}, \mathbf{K} \\
1.07 \mathrm{E}+04 \\
\end{array}$ & $\begin{array}{l}T_{0}, K \\
355\end{array}$ & $\begin{array}{c}\mathbf{G}_{\mathrm{g}} \\
0.38\end{array}$ & $\begin{array}{l}\mathrm{T}, \mathrm{K} \\
396\end{array}$ & & \\
\hline $\begin{array}{c}\text { LHS } \\
0.56491 \\
\end{array}$ & $\begin{array}{c}\text { Bump? } \\
0 \\
\end{array}$ & & & & & \\
\hline $\begin{array}{l}\text { Particle } \\
\text { Density }\end{array}$ & $\begin{array}{l}\text { Liquid } \\
\text { Density }\end{array}$ & $\begin{array}{l}\text { Fluffing } \\
\text { Factor }\end{array}$ & $\begin{array}{l}\text { Initial Sludge } \\
\text { Depth }\end{array}$ & $\begin{array}{l}\text { Initial } \\
\text { Supernatant } \\
\text { Depth }\end{array}$ & $\begin{array}{l}\text { Average } \\
\text { Density }\end{array}$ & $\begin{array}{l}\text { Fluffed } \\
\text { Alpha }\end{array}$ \\
\hline 3800 & 1100 & 1.7 & 0.96 & 7.61 & 1140 & 0.077796 \\
\hline Const & $\begin{array}{l}\text { Sludge } \\
\text { Depth, } m\end{array}$ & $\begin{array}{l}\text { Sludge } \\
\text { Density }\end{array}$ & $\begin{array}{l}\text { Supernatant } \\
\text { Density }\end{array}$ & $\begin{array}{l}\text { Hydrostatic } \\
\text { Pressure, atm }\end{array}$ & & \\
\hline 18.5 & 1.632 & 1310 & 1100 & 1.84 & & \\
\hline $\begin{array}{c}G_{g} 0 \\
1.64 \mathrm{E}-02\end{array}$ & $\begin{array}{c}T_{\text {act }}, K \\
1.07 E+04\end{array}$ & $\begin{array}{l}\mathrm{T}_{0}, \mathrm{~K} \\
355\end{array}$ & $\begin{array}{c}\mathbf{G}_{\mathrm{g}} \\
0.38\end{array}$ & $\begin{array}{l}T, K \\
396\end{array}$ & & \\
\hline $\begin{array}{c}\text { LHS } \\
1.014242\end{array}$ & $\begin{array}{c}\text { Bump? } \\
1\end{array}$ & & & & & \\
\hline
\end{tabular}

Tank bump conditions brought on by retrieval operations become credible only after extended mixer pump operation for, say, 20 days. This result means that if mixer pump operation time can be doubled or tripled if need be, yet still pose a tank bump frequency less than $1 \times 10^{-6} / \mathrm{d}$. This result also shows that input and underlying assumptions used by Crea et al. (2000) are very conservative. In particular, the demand that peak (or steady-state) temperature not exceed the LCO 3.3.2 temperature is a stringent one. 


\subsection{WASTE FEED DELIVERY TANK BUMP CONSEQUENCE ANALYSIS}

The scenario described in Sections 3.0 and 5.0 is evaluated for consequences even though there is high confidence that the planned operations result in a tank bump frequency that is beyond extremely unlikely. A first step is to compare the post-mixing tank bump conditions to the current safe storage tank bump conditions. The respective tank bump conditions for the postmixing and safe storage cases define a crucial initial condition: the volume of gas released to the headspace during a buoyant displacement. Because post-mixing waste properties are uncertain, a single retrieval tank bump is studied parametrically to determine the range of expected headspace overpressures, bubble expansion ratios, and aerosol generation values. From the results of the parametric study, a bounding case for the wor $u$ combination of initial gas volume and supernatant temperature is identified. Source term and radiological/toxicological doses are presented for this bounding case.

\subsection{BUBbLE AND WASTE ASCENT MODEL}

An important initial condition in the waste ascent model described in the safe storage accident analysis (Epstein et al. 2000) is the volume of gas released to the headspace during a buoyant displacement. Meyer et al. (1997) recommend the following dimensional formula:

$$
V_{b}(0)=750 \frac{\alpha_{\mathrm{NB}} h_{\mathrm{NCL}} \tau_{\mathrm{y}}}{\mathrm{P}_{\mathrm{NCL}} \rho_{\mathrm{CL}}}
$$

where $\alpha_{N B}$ is the neutral buoyant void fraction, $\mathrm{h}_{\mathrm{NCL}}$ is the non-convective layer height in meters, $\mathrm{P}_{\mathrm{NCL}}$ is the hydrostatic pressure in the non-convective layer in atm, $\tau_{\mathrm{y}}$ is the yield stress of the non-convective layer in $\mathrm{Pa}$, and $\rho_{C L}$ is the convective layer density in $\mathrm{kg} / \mathrm{m}^{3}$. For Tank 241-AZ-102, this equation was evaluated for the safe storage scenario using the following values: $P_{\mathrm{NCL}}=2 \mathrm{~atm}, \alpha_{\mathrm{NB}}=0.262, \mathrm{~h}_{\mathrm{NCL}}=96 \mathrm{~cm}, \rho_{\mathrm{CL}}=1100 \mathrm{~kg} / \mathrm{m}^{3}$, and $\tau_{\mathrm{y}}=100 \mathrm{~Pa}$. These values result in $\mathrm{V}_{\mathrm{b}}(0)=8 \mathrm{~m}^{3}$.

The post-mixed scenario value of $\mathrm{V}_{b}(0)$ is now found for Tank 241-AZ-102. From Crea et al. (2000) the non-convective layer has a "fluffing factor" of about 2.0 for post-mixed conditions; i.e., after mixing stops, the waste settles so that in the short term, the non-convective layer is twice its initial height. This means that the post-mixing non-convective layer density is less than the current value, as is the neutral buoyant fraction. Relative to the current conditions, the post-mixing non-convective layer $(\mathrm{NCL})$ has a higher liquid volume fraction, $\mathrm{L}_{\mathrm{f}}$, owing to the fluffing factor.

An expression for the liquid volume fraction as a function of NCL height can be found by using the definition of waste density averaged over the entire height of waste:

$$
L_{\mathrm{f}}=\frac{h_{w} \rho_{\text {avg }}-h_{\mathrm{NCL}} \rho_{\mathrm{s}}-\mathrm{h}_{\mathrm{CL}} \rho_{\mathrm{l}}}{h_{\mathrm{NCL}} \rho_{1}-h_{\mathrm{NCL}} \rho_{\mathrm{s}}}
$$


where $h$ is height, $\rho$ is density, subscript $w$ denotes the total waste height, NCL denotes the fluffed NCL height, avg denotes an average over the entire waste height $\left(h_{w}\right)$, s denotes solid, 1 denotes liquid supernatant, and CL denotes post-mixed convective layer. For Tank $241-\mathrm{AZ}-102$, the following values are taken from Crea et al. $(2000)$ : solid density $=3.8 \mathrm{gm} / \mathrm{cm}^{3}$, liquid density $=1.1 \mathrm{gm} / \mathrm{cm}^{3}$, and fluffed NCL height $=192 \mathrm{~cm}(2.0 \cdot 96 \mathrm{~cm})$. From

Hu et al (2000), total waste height is $8.57 \mathrm{~m}$ and waste average density is $1.14 \mathrm{gm} / \mathrm{cm}^{3}$. Postmixed convective layer height is then $6.65 \mathrm{~m}(8.57-1.92 \mathrm{~m})$. Substituting these values into equation (6-2) gives $L_{f}=93.4 \%$.

Fluffed NCL density is given by,

$$
\rho_{\mathrm{NCL}}^{\prime}=\frac{1}{\mathrm{~F}}\left(\rho_{\mathrm{NCL}}+(\mathrm{F}-1) \rho_{\mathrm{L}}\right)
$$

where $\mathrm{F}$ is the fluffing factor, $\rho_{\mathrm{NCL}}^{\prime}$ is the fluffed non-convective layer density, and $\rho_{\mathrm{NCL}}$ is the non-convective layer density before mixing. From $\mathrm{Hu}$ et al. (2000), the initial non-convective layer density is $1.49 \mathrm{gm} / \mathrm{cm}^{3}$. The fluffed non-convective layer density is then $1.3 \mathrm{gm} / \mathrm{cm}^{3}$. Post-mixed neutral buoyant fraction, $\alpha_{\mathrm{NB}}$, is then $15 \%(1-1.1 / 1.3)$.

Equation (6-1) can now be considered to see how $V_{b}(0)$ changes between the current and postmixed states. Although the NCL height increases by a factor of two, the neutral buoyant fraction is almost halved and the product $\alpha_{\mathrm{NB}} h_{\mathrm{NCL}}$ does not change much. In the denominator, $\mathrm{PCL}$ remains unchanged and $\mathrm{P}_{\mathrm{NCL}}$ changes only slightly because the NCL density decreases while the NCL height increases. Yield strength decreases, however, in response to the increased void fraction, which means that $V_{b}(0)$ in the post-mixed case is somewhat less than $V_{b}(0)$ for the safe storage case.

Gauglitz et al. (1996) measured the yield strength of bentonite-clay simulants as a function of clay/water ratio and reported order of magnitude decreases in shear strength for modest decreases in the clay weight fraction. Data plotted here as Figure 6-1 show that in decreasing clay weight fraction from $20 \%$ to $15 \%$, measured shear strength falls from about $1300 \mathrm{~Pa}$ to a little less than $200 \mathrm{~Pa}$. For Tank $241-\mathrm{AZ}-102$, the solid wt. fraction in the NCL is now $38 \%$, but would be $18 \%$ in the post-mixed scenario. Figure 6-1 cannot be directly applied to the Tank 241-AZ-102 waste. Nevertheless, fluffed shear strength must be regarded as less than current waste shear strength because the trends shown in Figure 6-1 have been observed in waste simulants. An absolute change in solids weight fraction of a few percentage points can change shear strength by an order of magnitude.

Clearly, a tank bump occurring under fluffed conditions is likely to be weaker than a tank bump emanating from safe storage conditions. Yield strength under fluffed conditions is a fraction of the current yield strength, which means that the post-mixing scenario $V_{b}(0)$ is less than the safe storage $V_{b}(0)$. In addition, for Tank 241-AZ-102, the convective layer height is reduced by a meter or so, which also reduces the strength of the post-mixed bump. Yield strength as a function of solids mass fraction is not available for the DST waste. For the retrieval scenario, the consequences of a single tank bump are studied parametrically in the next section. 
RPP-6654, REV. 0

Figure 6-1. Bentonite Clay Shear Strengths.

Bentonite Clay Shear Strengths

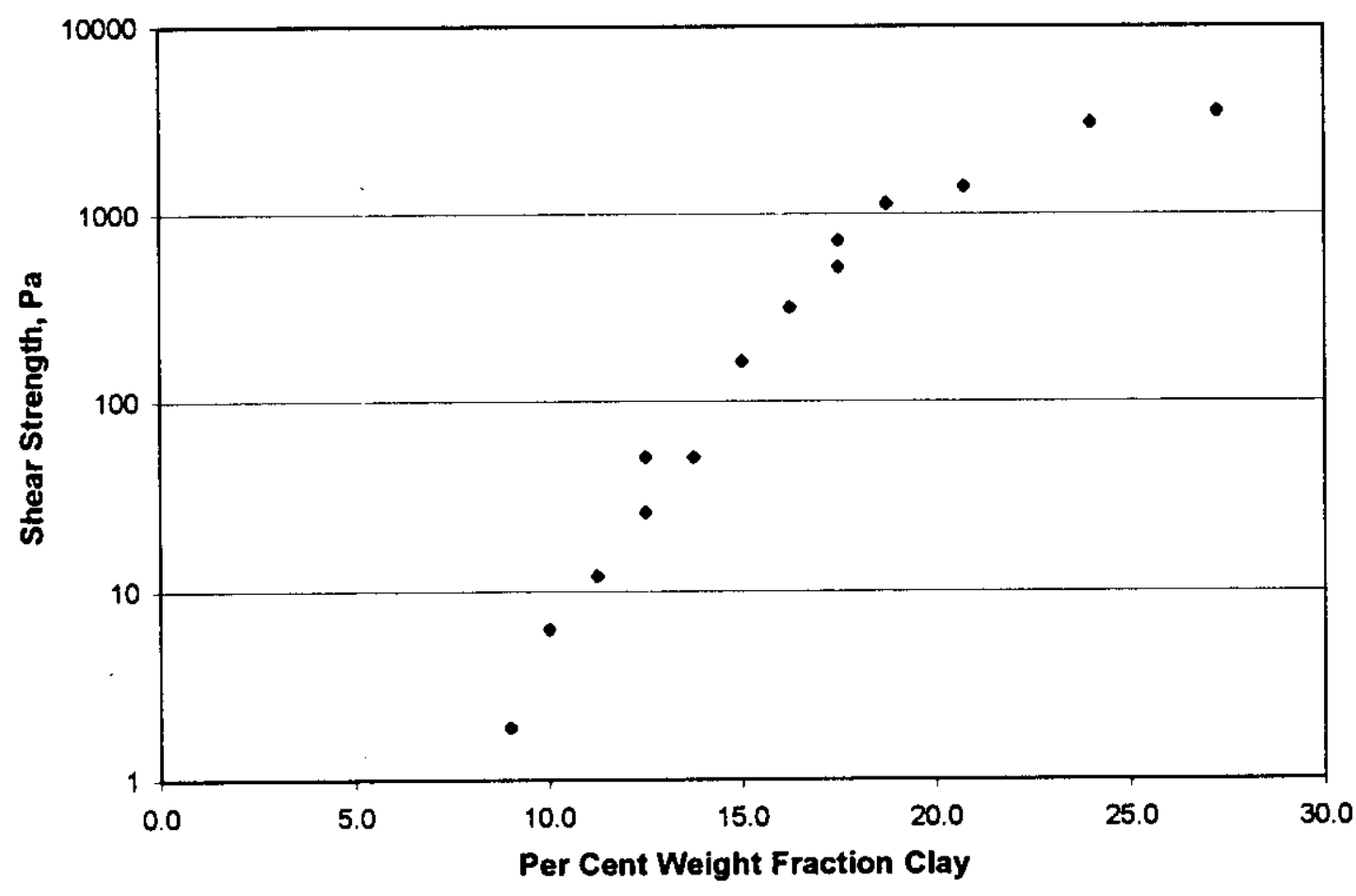




\subsection{PARAMETRIC HADCRT ANALYSIS OF A RETRIEVAL TANK BUMP FOR HEADSPACE PRESSURE AND AEROSOL GENERATION}

The discussion in the previous section qualitatively described the differences between a safe storage tank bump and a retrieval tank bump. Using the HADCRT code, this section parametrically considers the peak headspace pressure and aerosol generation resulting from a single retrieval bump. The HADCRT code and base case inputs for the safe storage bump are described in Epstein et al. (2000) and the details are not repeated here.

Tank 241-AZ-102 is again selected for analysis with two sets of inputs. The first set has a bounding supernatant temperature of $100^{\circ} \mathrm{C}$, with $\mathrm{V}_{b}(0)=8 \mathrm{~m}^{3}, 4 \mathrm{~m}^{3}$, and $1 \mathrm{~m}^{3}$; a second set has supernatant temperature equal to $94^{\circ} \mathrm{C}$, with $\mathrm{V}_{\mathrm{b}}(0)=8 \mathrm{~m}^{3}, 4 \mathrm{~m}^{3}$, and $1 \mathrm{~m}^{3}$. For the sake of comparison, the cases with $\mathrm{V}_{\mathrm{b}}(0)=8 \mathrm{~m}^{3}$ use a fluffing factor of 1.0 and represent the safe storage scenario. The previous section showed that $V_{b}(0)$ is directly proportional to the sludge shear strength. The two cases presented here assume that the fluffed sludge yield strength is somewhere between $1 / 2$ the original value and $1 / 8^{\text {th }}$ the original value. A supernatant temperature of $100^{\circ} \mathrm{C}$ is bounding for pure water properties and $94^{\circ} \mathrm{C}$ is the best-estimate value from Figure 3-6. To bound uncertainties in headspace pressurization, the closed, adiabatic case is considered. Headspace overpressure can also be compared to the HEPA failure overpressure ( 5 psig or $35,600 \mathrm{~Pa}$ ) to show that weak bumps will not cause failure. Relative to the safe storage case, the convective layer depth is reduced by $1 \mathrm{~m}$ (from 7.6 to $6.6 \mathrm{~m}$ ) to account for fluffing. Table 6-1 summarizes inputs for the eight cases. Appendix D contains HADCRT input decks.

In each case, only one bump event was considered. Headspace overpressure, gas volume expansion ratio, and the mass of aerosol generated are reported in Table 6-2. Case 8FF1-100, the first row in this table, essentially reproduces the results from the safe storage accident analysis (Epstein et al. 2000). For Case 4FF2-100, the initial mass of liquid is about the same as in Case 8FF1-100 because neutral buoyancy is now about half the non-fluffed value of 0.26 ; this offsets the fact that $V_{b}(0)$ decreases to $4 \mathrm{~m}^{3}$ from $8 \mathrm{~m}^{3}$. The initial liquid mass is found from Epstein et al. (2000):

$$
m_{\ell}(0)=\rho_{\mathrm{NCL}} \mathrm{V}_{\mathrm{b}_{i}}(0)\left[\frac{1}{\alpha_{\mathrm{NB}}}-1\right]
$$

For Case 1FF2-100 (or Case IFF2-94), the initial mass of liquid is reduced relative to the initial mass for Case 4FF2-100 (or 4FF2-94) in direct proportion to the reduction in $V_{b}(0)$.

Cases 8FF 1-100 and 4FF2-100 produce similar results for overpressure and aerosol generation per bump, with the reduction in initial gas volume offset by an increased expansion ratio for Case 4FF2-100. Although Case 4FF2-100 should result in roughly twice the number of bumps as Case 8FF1-100 (assuming the run is continued for several hours), Case 4FF2-100 also has about one-half the solids fraction in the non-convective layer that Case 8FF1-100 does. 
Table 6-1. Parameter Values for Tank 241-AZ-102 Headspace Overpressure Analysis.

\begin{tabular}{|c|c|}
\hline & Waste and Headspace Parameters \\
\hline$V_{b}(0)=6.54 \times 10^{-8} \mathrm{~m}^{3}$ & Initial volume of representative bubble based on $5.0 \mathrm{~mm}$ bubble diameter. \\
\hline$V_{b}(0)=8,4$, or $1.0 \mathrm{~m}^{3}$ & $\begin{array}{l}\text { Initial total volume of bubbles released from sludge and used in ratio } \\
\mathrm{V}_{\mathrm{b}} / \mathrm{V}_{\mathrm{b}}(0) \text {, parameter variation. }\end{array}$ \\
\hline$V_{\ell}=2712 \mathrm{~m}^{3}$ & Volume of convective layer. \\
\hline$V_{h s}(0)=1800 \mathrm{~m}^{3}$ & Initial volume of headspace. \\
\hline $\mathrm{H}(0)=6.6 \mathrm{~m}$ & Initial depth of convective layer. \\
\hline $\begin{array}{l}\mathrm{M}_{\ell}(0)=34,000,30,000, \text { and } \\
7,500 \mathrm{~kg}\end{array}$ & Initial non-convective layer mass in parcel. \\
\hline $\mathrm{T}_{\ell}(0)=115^{\circ} \mathrm{C}$ & Initial parcel temperature. \\
\hline$P_{\text {hs }}(0)=1.012 \times 10^{5} \mathrm{~Pa}$ & Initial headspace pressure. \\
\hline $\mathrm{T}_{\mathrm{CL}}(0)=100$ or $94^{\circ} \mathrm{C}$ & Supernatant temperature. \\
\hline$X_{\text {st }}(0)=95 \%$ & Headspace steam mole fraction. \\
\hline & B. Flow Path Parameters \\
\hline$A_{\text {in }}=0.00 \mathrm{~m}^{2}$ & Neglect 8" inlet line. \\
\hline$A_{\text {out }}=0.00 \mathrm{~m}^{2}$ & Neglect 20 " outlet line. \\
\hline$A_{\text {leak }}=0.00 \mathrm{~m}^{2}$ & Neglect leakage around $42 "$ risers. \\
\hline$\Delta \mathrm{P}_{\mathrm{HEPA}}=35,600 \mathrm{~Pa}$ & HEPA failure $\Delta \mathrm{P}$, crediting vent path pressure losses. \\
\hline $\mathrm{C}_{\mathrm{e}}=0.5$ & Flow coefficient for inlet and outlet paths. \\
\hline $\begin{aligned} V_{\text {pit }}= & 4 \times 10 \mathrm{~m}^{3} \\
+ & 1 \times 20 \mathrm{~m}^{3}\end{aligned}$ & Sluice pit and center pit volumes. \\
\hline $\mathrm{T}_{\text {pit }}(0)=75^{\circ} \mathrm{C}$ & Pit initial temperature. \\
\hline$P_{\text {pit }}(0)=1.012 \times 10^{5} \mathrm{~Pa}$ & Pit initial pressure. \\
\hline$\therefore \therefore$ & C. Property Values \\
\hline$\rho_{\mathrm{CL}}=1100 \mathrm{~kg} \mathrm{~m}^{-3}$ & Density of convective layer. \\
\hline$\mu_{\mathrm{g}}=1.2 \times 10^{-5} \mathrm{~kg} \mathrm{~m}^{-1} \mathrm{~s}^{-1}$ & Viscosity of bubble gas (vapor). \\
\hline$\rho_{\mathrm{g}}=0.6 \mathrm{~kg} \mathrm{~m}^{-3}$ & Density of bubble gas (vapor). \\
\hline$\sigma=0.059 \mathrm{~kg} \mathrm{~s}^{-2}$ & Surface tension of supernatant. \\
\hline $\mathrm{D}=9.2 \times 10^{-5} \mathrm{~m}^{2} \mathrm{~s}^{-1}$ & Bubble gas/water vapor diffusion coefficient. \\
\hline
\end{tabular}


Table 6-2 shows that only Cases $8 F F 1-100$ and 4FF2-100 conceivably threaten HEPA filter integrity by way of overpressure. Cases $8 F F 1-100$ and 4FF2-100 result in an overpressure of about 2.5 psig, which is still less than the 5 psig value for failure. The balance of the cases result in smaller overpressures.

Table 6-2. Results of Parametric Analysis of a Single Retrieval Bump in Tank 241-AZ-102.

\begin{tabular}{|c|c|c|c|c|c|c|c|}
\hline Case ID & $\begin{array}{c}\text { Initial } \\
\text { Gas } \\
\text { Volume, } \\
\mathbf{m}^{\mathbf{3}}\end{array}$ & $\begin{array}{c}\text { Initial } \\
\text { Liquid } \\
\text { Mass, kg }\end{array}$ & $\begin{array}{c}\text { Fluffing } \\
\text { Factor }\end{array}$ & $\begin{array}{c}\text { Supernatant } \\
\text { Temperature, } \\
{ }^{\circ} \mathbf{C}\end{array}$ & $\begin{array}{c}\text { Expansion } \\
\text { Ratio }\end{array}$ & $\begin{array}{c}\text { Overpressure, } \\
\mathbf{k P a}\end{array}$ & $\begin{array}{c}\text { Mass of } \\
\text { Aerosol } \\
\text { Generated, } \\
\mathbf{k g}\end{array}$ \\
\hline 8 FF1-100 & 8 & 34,000 & 1 & 100 & 23 & 17.4 & 1.24 \\
\hline 4FF2-100 & 4 & 30,000 & 2 & 100 & 43 & 16.9 & 1.15 \\
\hline IFF2-100 & 1 & 7,500 & 2 & 100 & 100 & 8.9 & 0.44 \\
\hline 8 FF1-94 & 8 & 34,000 & 1 & 94 & 9.5 & 6.4 & 0.31 \\
\hline 4FF2-94 & 4 & 30,000 & 2 & 94 & 16 & 5.5 & 0.23 \\
\hline 1FF2-94 & 1 & 7,500 & 2 & 94 & 3 & 0.1 & $2.0 \times 10^{-3}$ \\
\hline
\end{tabular}

For a given initial gas volume and liquid mass, the $94^{\circ} \mathrm{C}$ supernatant temperature cases result in a smaller overpressure and aerosol generation. This is because the bubble expansion ratio is very sensitive to the amount of supernatant sub-cooling. For the $94^{\circ} \mathrm{C}$ case with weak non-convective layer (Case 1FF2-94), overpressure and aerosol generation are small. In this case, even a large number of bumps will result in source term and radiological/toxicological doses that are small relative to those for the safe storage scenario. HEPA filter failure is unlikely, although the aerosol loading could be much larger than design values.

In summary, parametric calculations show that the best-estimate position is that the retrieval tank bump scenario is likely to result in much smaller source terms and radiological/toxicological doses than the safe storage bump scenario. This conclusion is supported by the results shown in Table $6-2$ of the $94^{\circ} \mathrm{C}$ case. A best-estimate position is that HEPA filter failure would not be expected on overpressure, although aerosol loading could exceed design values. A bounding analysis view states that in light of the results for Case 4FF2-100, the retrieval tank bump scenario could result in consequences similar to those of the safe storage scenario. As a result, Case 4FF2-100 is considered in further detail below. In particular, the entire series of tank bump transients is evaluated, rather than just a single bump.

\subsection{HADCRT INPUT FOR THE BOUNDING TANK 241-AZ-102 TANK BUMP SCENARIO}

Case 4FF2-100 is evaluated for source term and radiological/toxicological consequences. The tank configuration is the same as that used in Epstein et al. (2000) for the safe storage scenario. The HADCRT model for this case contains four volumes or regions: the tank headspace, a 
region representing four sluice pits, the center pump pit, and the environment. Normal flowpaths between the environment and the headspace are the filtered 8 " diameter inlet and the filtered 20 " diameter. Sluice pit covers lift at a pressure differential of $13.8 \mathrm{kPa}$ and pump pit covers lift at a pressure differential of $17 \mathrm{kPa}$. Other inputs are shown in Table 6-3. HEPA filters are not credited.

Other parameters important to consequences are the initial mass of liquid in the buoyant parcel, the time between bumps, and the number of bumps. With the volume of gas assumed to be $4 \mathrm{~m}^{3}$, a non-convective layer density of $1300 \mathrm{~kg} / \mathrm{m}^{3}$ and neutral buoyancy fraction of 0.15 , the initial amount of liquid plus suspended solids in the buoyant parcel is $30,000 \mathrm{~kg}$ $(1300 \cdot 4 \cdot[1 / 0.15-1])$. Average time between bumps is given by Epstein et al. (2000):

$$
t_{\mathrm{BD}}=\frac{\mathrm{V}_{\mathrm{b}}(0)}{\mathrm{G}_{\mathrm{g}} \mathrm{A}_{\mathrm{T}} \mathrm{h}_{\mathrm{NCL}}}
$$

With $G_{g}=0.38 \mathrm{~mole} / \mathrm{m}^{3} /$ day, or $0.007 \mathrm{~m}^{3} / \mathrm{m}^{3} /$ day, (see Table $5-3$ ), $A_{T}=411 \mathrm{~m}^{2}$, and $\mathrm{h}_{\mathrm{NCL}}=1.92 \mathrm{~m}, \mathrm{t}_{\mathrm{BD}}=1100$ minutes $(18 \mathrm{hrs})$. The total number of bumps is equal to the total amount of gas in the non-convective layer divided by the volume of gas in one bump:

$$
\mathrm{N}_{\mathrm{BD}}=\frac{\alpha_{\mathrm{NB}} \mathrm{A}_{\mathrm{T}} \mathrm{h}_{\mathrm{NCL}}}{\mathrm{V}_{\mathrm{b}}(0)}
$$

which is 29 for $\alpha_{\mathrm{NB}}=0.15$

Results of the Tank 241-AZ-102 tank bump calculation are shown in Figures 6-2 and 6-3, which provide short- and long-term histories for headspace temperature and pressure, and the aerosol distribution. Figure 6-2 shows the short-term response for one bump. Figure 6-3 shows the response during the interval between the first and second bump, which is 1100 minutes or 66,000 seconds.

Peak overpressure and temperature are $17,000 \mathrm{~Pa}$ and $122^{\circ} \mathrm{C}$, respectively. Headspace temperature and pressure return to the initial conditions of $100^{\circ} \mathrm{C}$ and 1 atmosphere after roughly 1000 seconds. The first bump generates $1.22 \mathrm{~kg}$ of aerosol, which is slightly higher than the $1.15 \mathrm{~kg}$ reported in Table 6-2. The slight difference can be explained by the fact that Table 6-2 was generated using a closed headspace.

Figure $6-3$ shows that about $0.42 \mathrm{~kg}$ are removed by natural circulation during the interval between bumps. The temperature difference between the tank headspace and the environment creates a flow pattern whereby ambient air enters through the 8 " diameter inlet line and headspace gas leaves through the $20^{\prime \prime}$ diameter outlet line. Airborne aerosols leak out the headspace in this manner. Figure 6-3 also shows that there is practically no airborne aerosol in the tank after about 40,000 seconds. About $0.8 \mathrm{~kg}$ are deposited at that point and $0.42 \mathrm{~kg}$ have escaped. Time constant for aerosol settling in the DST headspace is ten hours at most, which is consistent with experimental data such as the AB-5 test (Hilliard et al. 1983), as compared to the time between bumps of 18 hours. This means that the interval between bumps is long enough 
Table 6-3. Parameter Values for Tank 241-AZ-102 Bounding Consequence Analysis.

\begin{tabular}{|c|c|}
\hline & Waste and Headspace Parameters \\
\hline$V_{b}(0)=6.54 \times 10^{-8} \mathrm{~m}^{3}$ & Initial volume of representative bubble based on $5.0 \mathrm{~mm}$ bubble diameter. \\
\hline $\mathrm{V}_{\mathrm{b}}(0)=4 \mathrm{~m}^{3}$ & $\begin{array}{l}\text { Initial total volume of bubbles released from sludge and used in ratio } V_{b} / \\
V_{b}(0) \text {, parameter variation. }\end{array}$ \\
\hline $\mathrm{V}_{\ell}=2712 \mathrm{~m}^{3}$ & Volume of convective layer. \\
\hline $\mathrm{V}_{\mathrm{hs}}(0)=1800 \mathrm{~m}^{3}$ & Initial volume of headspace. \\
\hline $\mathrm{H}(0)=6.6 \mathrm{~m}$ & Initial depth of convective layer. \\
\hline$m_{\ell}(0)=30,000 \mathrm{~kg}$ & Initial non-convective layer mass in parcel. \\
\hline $\mathrm{T}_{\ell}(0)=115^{\circ} \mathrm{C}$ & Initial parcel temperature. \\
\hline $\mathrm{P}_{\text {hs }}(0)=1.012 \times 10^{5} \mathrm{~Pa}$ & Initial headspace pressure. \\
\hline $\mathrm{T}_{\mathrm{CL}}(0)=100^{\circ} \mathrm{C}$ & Supernatant temperature. \\
\hline $\mathrm{X}_{\mathrm{st}}(0)=95 \%$ & Headspace steam mole fraction. \\
\hline & B. Flow Path Parameters \\
\hline$A_{\text {in }}=0.03 \mathrm{~m}^{2}$ & Neglect $8 "$ inlet line. \\
\hline$A_{\text {out }}=0.20 \mathrm{~m}^{2}$ & Neglect $20 "$ outlet line. \\
\hline$A_{\text {leak }}=5 \times 0.00133 \mathrm{~m}^{2}$ & Neglect leakage around $42 "$ risers. \\
\hline$\Delta \mathrm{P}_{\mathrm{HEPA}}=35,600 \mathrm{~Pa}$ & HEPA failure $\Delta \mathrm{P}$, crediting vent path pressure losses. \\
\hline$C_{e}=0.5$ & Flow coefficient for inlet and outlet paths. \\
\hline $\begin{aligned} V_{\text {pit }}= & 4 \times 10 \mathrm{~m}^{3} \\
& +1 \times 20 \mathrm{~m}^{3}\end{aligned}$ & Sluice pit and center pit volumes. \\
\hline $\mathrm{T}_{\text {pit }}(0)=75^{\circ} \mathrm{C}$ & Pit initial temperature. \\
\hline$P_{\text {pit }}(0)=1.012 \times 10^{5} \mathrm{~Pa}$ & Pit initial pressure. \\
\hline & C. Property Values \\
\hline$\rho_{C L}=1100 \mathrm{~kg} \mathrm{~m}^{-3}$ & Density of convective layer. \\
\hline$\mu_{\mathrm{g}}=1.2 \times 10^{-5} \mathrm{~kg} \mathrm{~m}^{-1} \mathrm{~s}^{-1}$ & Viscosity of bubble gas (vapor). \\
\hline$\rho_{\mathrm{g}}=0.6 \mathrm{~kg} \mathrm{~m}^{-3}$ & Density of bubble gas (vapor). \\
\hline$\sigma=0.059 \mathrm{~kg} \mathrm{~s}^{-2}$ & Surface tension of supernatant. \\
\hline $\mathrm{D}=9.2 \times 10^{-5} \mathrm{~m}^{2} \mathrm{~s}^{-1}$ & Bubble gas/water vapor diffusion coefficient. \\
\hline
\end{tabular}


Figure 6-2. Tank 241-AZ-102 Retrieval Bump Short-Term Results.

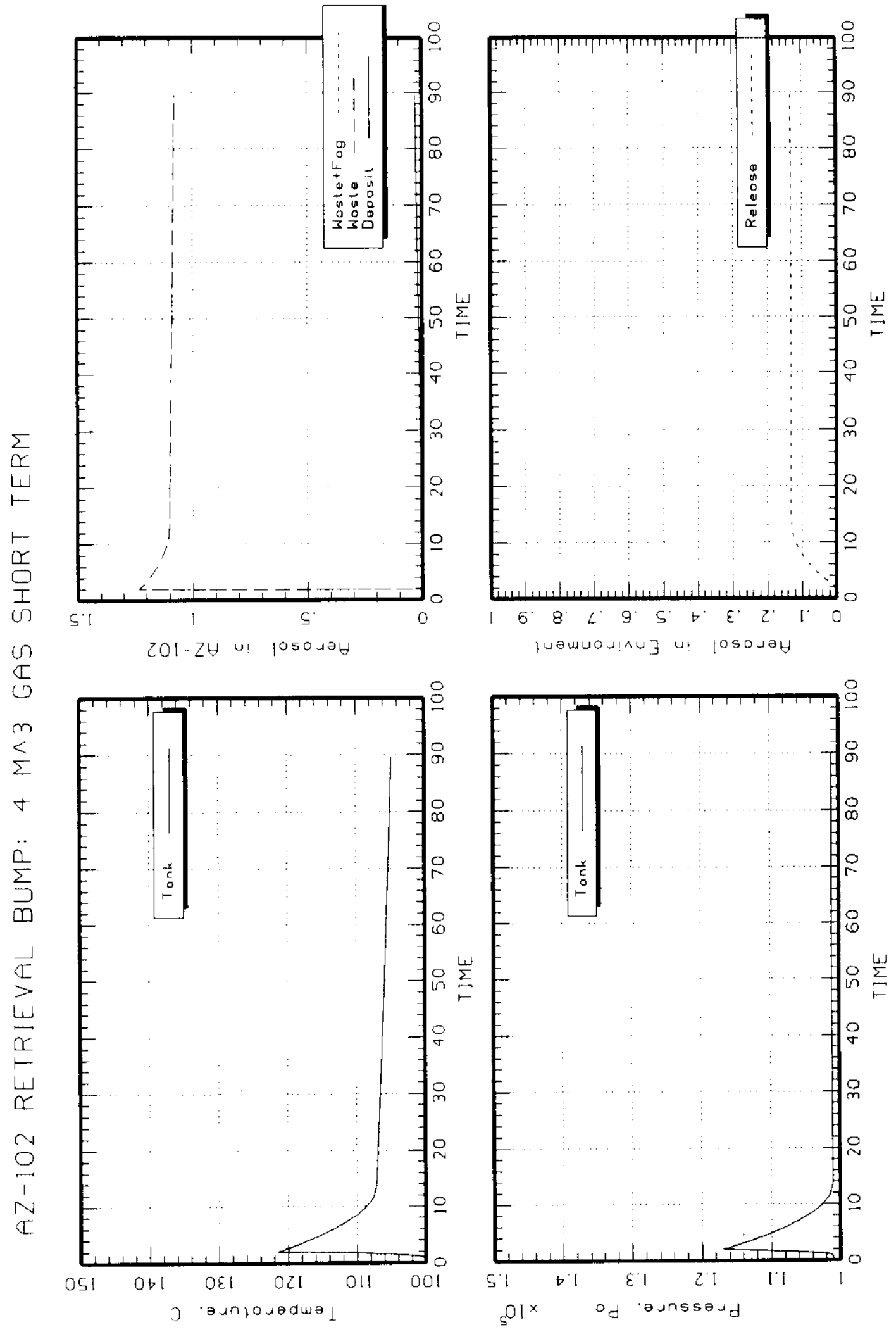


Figure 6-3. Tank 241-AZ-102 Retrieval Bump Long-Term Results.

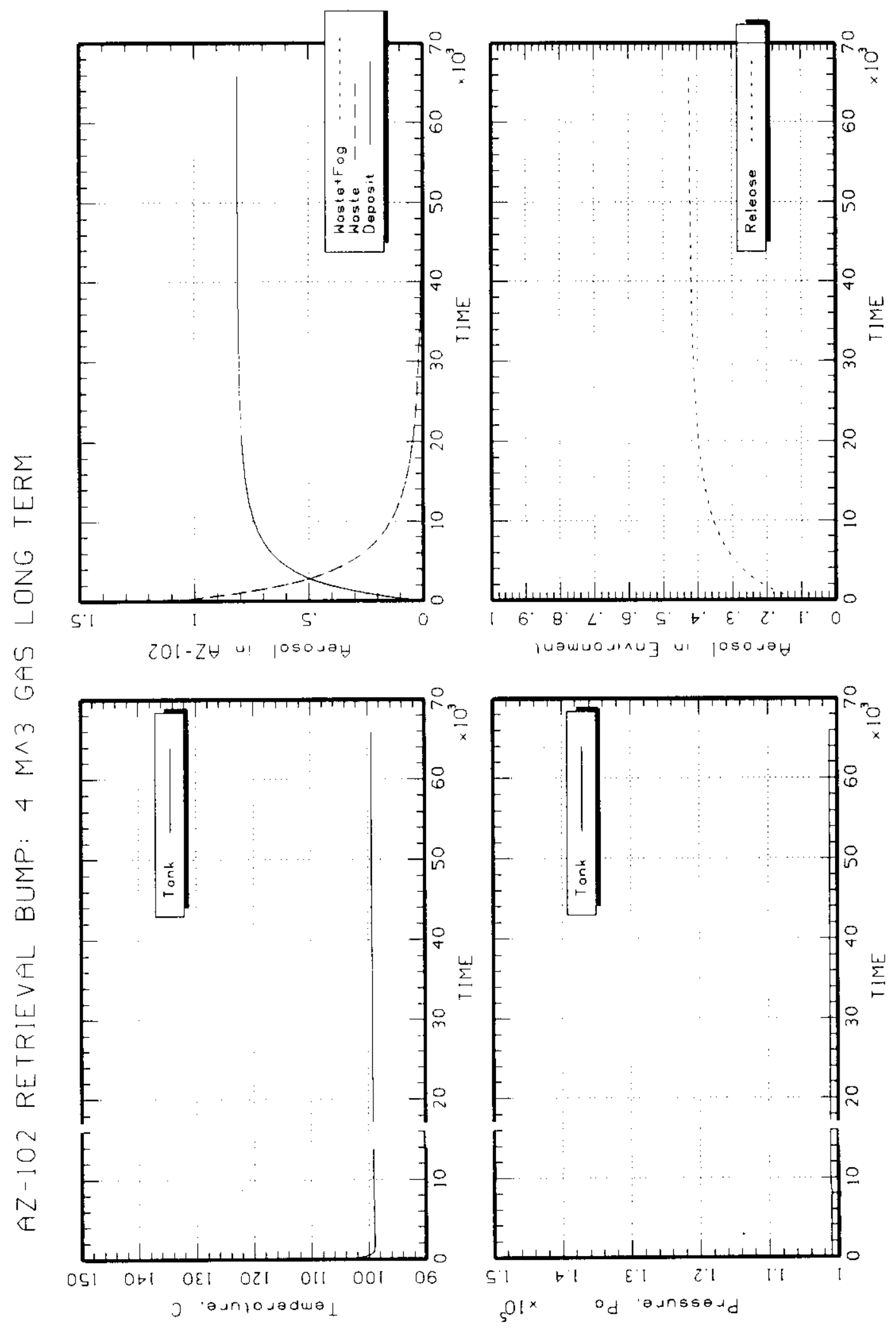


that each successive bump knows nothing about the one before it. An integral analysis for many bumps is not necessary. The consequences of $n$ bumps are simply $n$ times the consequences of one bump.

The present calculation considers one sequence of bumps that eventually displaces all nonconvective material. Sedimentation, noncondensable gas retention, and attainment of neutral buoyancy are required for a subsequent bump sequence. Another sequence of successive bumps can therefore repeat later in time after neutral buoyancy is again achieved, on a timescale consistent with buoyant displacement events.

\subsection{TANK 241-AZ-102 RETRIEVAL TANK BUMP BOUNDING RADIOLOGICAL AND TOXIC CHEMICAL CONSEQUENCES}

Mass of entrained material is converted to dose using the following method from Cowley et al. (2000):

$$
\mathrm{D}=(\mathrm{Q})(\mathrm{ULD})\left(\frac{\mathrm{X}}{\mathrm{Q}}\right)(\mathrm{BR})
$$

where $\mathrm{D}=$ Dose, $\mathrm{Sv}$,

$\mathrm{Q} \quad=$ Released quantity, $\mathrm{L}$,

ULD = Unit Liter Dose, Sv/L,

$\mathrm{X} / \mathrm{Q}=$ Atmospheric dispersion coefficient, $\mathrm{s} / \mathrm{m}^{3}$, and

BR = Breathing rate, $\mathrm{m}^{3} / \mathrm{s}$.

The released mass, $\mathrm{kg}$, calculated above can be converted into volume, $\mathrm{L}$, for waste solids and liquids. Then, parameter values from Cowley et al. (2000) as summarized in Table 6-4 may be applied.

Table 6-4. Radiological Consequence Factors (Cowley et al. 2000).

\begin{tabular}{|l|l|l|}
\hline Factor & On-Site & Off-Site \\
\hline ULD, Sv/L & & \\
DST Solids & $1.07 \times 10^{5}$ & $1.84 \times 10^{5}$ \\
DST Liquids & $7.97 \times 10^{2}$ & $8.45 \times 10^{2}$ \\
\hline $\mathrm{X} / \mathrm{Q}, \mathrm{s} / \mathrm{m}^{3}$ & $5.58 \times 10^{-3}$ & $8 \times 10^{-6}(1)$ \\
\hline $\mathrm{BR}, \mathrm{m}^{3} / \mathrm{s}$ & $3.33 \times 10^{-4}$ & $3.33 \times 10^{-4}$ \\
\hline
\end{tabular}

For on-site dose, worker exposure at $100 \mathrm{~m}$ is taken for an 8-hour shift, so the $\mathrm{X} / \mathrm{Q}$ value of $5.58 \times 10^{-3} \mathrm{~s} / \mathrm{m}^{3}$ from Section 5.2 .3 of Cowley et al. (2000) applies. Similarly, the breathing rate is specified in Section 3.7 of the reference for light work. 
For off-site dose, the methods of Section 5.2.3 of Cowley et al. (2000) are applied using values from Table 5-2 of the reference and approximating the release as an 8-hour event because nearly all of the release occurs over an 8-hour interval. Performing this evaluation,

$$
\frac{\log \left(1.74 \times 10^{-5}\right)-\log \left(\mathrm{X} / \mathrm{Q}^{8 \mathrm{hrs} .}\right)}{\log \left(1.74 \times 10^{-5}\right)-\log \left(1.47 \times 10^{-7}\right)}=\frac{\log (2 \mathrm{hrs} .)-\log (8 \mathrm{hrs} .)}{\log (2 \mathrm{hrs} .)-\log (8,760 \mathrm{hrs} .)}
$$

yielding $X / Q=8 \times 10^{-6} \mathrm{~s} / \mathrm{m}^{3}$. The light work breathing rate also applies off-site due to the short release duration.

Next, liters of solid and liquids released must be derived. In the first bump, non-convective solids are substantially diluted by supernatant: an initial release of $30,000 \mathrm{~kg}$ (liquid + solid) is increased to about $115,000 \mathrm{~kg}$ total in the rising parcel after entrainment (a calculation detail not plotted). But in later bumps, some solids now present in the supernatant are entrained as well, so that in the last bump of the series, the tank mixed-mean solid fraction applies. From Section 6-2, waste properties are:

$\begin{array}{lccc} & \text { Density }\left(\mathbf{k g} / \mathbf{m}^{\mathbf{3}}\right) & \text { Volume (kL) } & \mathbf{H}_{2} \mathbf{O} \text { (wt. \%) } \\ \text { Convective } & 1.10 & 2,712 & 84 \% \\ \text { Non-Convective } & 1.30 & 789 & \end{array}$

where dissolved salts are responsible for an $\mathrm{H}_{2} \mathrm{O} \%<100 \%$ in the convective layer. From the results in Section 6-2, the solids fraction in the fluffed non-convective layer is $6.6 \%$. Thus, the overall mixed mean solids volume fraction is $(6.6)(789) /(789+2712)=1.5 \%$. Noting that the released non-convective volume is $30,000 \mathrm{~kg} / 1.3(\mathrm{~kg} / \mathrm{L})=23.1 \mathrm{~kL}$ and the entrained volume is $85,000 \mathrm{~kg} /(1.1 \mathrm{~kg} / \mathrm{L})=77 \mathrm{~kL}$, the maximum fraction of entrained solids at the final bump is approximately

$$
\frac{(1.5)(77)+(6.6)(23.1)}{77+23.1}=2.7 \%
$$

The average density of released material is simply $(30,000+85,000) /(26,800+74,000)$ $=1.14 \mathrm{~kg} / \mathrm{L}$, which is precisely the waste average density noted in Hu et al. (2000). Therefore, the $0.42 \mathrm{~kg}$ release is equivalent to $0.37 \mathrm{~L}$ total, of which $2.7 \%$ or $0.01 \mathrm{~L}$ are solid, and $0.36 \mathrm{~L}$ are liquid. Note that exact volume fractions and densities could be derived for conversions above, but the amount of solids entrained varies with each bump, so a somewhat conservative approach was taken.

The overall $Q$ * ULD for waste is found by weighting Table 6-4 values by the volume released,

$$
\begin{array}{ll}
\text { On-Site } & Q^{*} \text { ULD }=\left(1.07 \times 10^{5}\right)(0.01)+(797)(0.36)=1,357 \mathrm{~Sv} \\
\text { Off-Site } & Q^{*} \text { ULD }=\left(1.84 \times 10^{5}\right)(0.01)+(845)(0.36)=2,144 \mathrm{~Sv}
\end{array}
$$

Therefore, total on-site worker dose is 


$$
\text { On-Site } \quad D=(1,357 \mathrm{~Sv})\left(5.58 \times 10^{-3} \mathrm{~s} / \mathrm{m}^{3}\right)\left(3.33 \times 10^{-4} \mathrm{~m}^{3} / \mathrm{s}\right)=0.003 \mathrm{~Sv}
$$

and off-site receiver dose is:

$$
\text { Off-Site } \quad D=(2,144 \mathrm{~Sv})\left(8.0 \times 10^{-6} \mathrm{~s} / \mathrm{m}^{3}\right)\left(3.33 \times 10^{-4} \mathrm{~m}^{3} / \mathrm{s}\right)=6.0 \times 10^{-6} \mathrm{~Sv}
$$

Toxic chemical consequences are found using the methods of WHC-SD-WM-SARR-011 (1996). Table 3-8 of the reference provides the toxic limit sum-of-fractions for toxic chemical dose relative to allowed thresholds. Pertinent sum-of-fraction data from Table 3-8 of the reference are summarized in Table 6-5. Values are given for continuous release consistent with the radiological evaluation.

Table 6-5. Sum-of-Fraction of Risk Guidelines for a Unit Release of Chemicals (WHC-SD-WM-SARR-011 1996).

\begin{tabular}{|l|c|c|c|}
\hline \multicolumn{4}{|c|}{ Continuous Release, units $\mathbf{~} / \mathbf{L}$} \\
\hline \multirow{2}{*}{ Waste Type } & \multirow{2}{*}{ Receptor Location } & \multicolumn{2}{|c|}{ Accident Frequency $\mathbf{1 / y r}$. } \\
\cline { 3 - 4 } & & $\mathbf{1 0}^{-\mathbf{2}}$ to $\mathbf{1 0}^{-\mathbf{4}}$ & $\mathbf{1 0}^{-\mathbf{4}}$ to $\mathbf{1 0}$ \\
\hline DST Liquids & On-Site & 750 & 210 \\
DST Solids & On-Site & 3300 & 630 \\
DST Liquids & Off-Site & 8.4 & 0.62 \\
DST Solids & Off-Site & 15 & 2.8 \\
\hline
\end{tabular}

When viewed as a continuous release, values in the table are applied to the released volumes of $0.01 \mathrm{~L}$ solid and $0.36 \mathrm{~L}$ liquid over a duration of 28,800 seconds. A puff evaluation is made for a single release, with a duration of 60 seconds per Cowley et al. (2000). This means the puff release result is a factor of $28,800 / 60=480$ times larger than the continuous release result. The puff evaluation is made because the release history for the tank bump accident presented earlier has aspects of both a continuous and a puff release, and because toxic chemical consequences are sensitive to peak concentration. An evaluation is made for frequency bins of $10^{-2} / \mathrm{yr}$ to $10^{-4} / \mathrm{yr}$ and $10^{-4} / \mathrm{yr}$ to $10^{-6} / \mathrm{yr}$. A release duration of $28,800 \mathrm{~s}$ and volumes of $0.01 \mathrm{~L}$ solid and $0.36 \mathrm{~L}$ liquid are applied for both the puff and continuous release. The result of the evaluation is given in Table 6-6.

Table 6-6. Toxic Consequence Evaluation Results for a Single Retrieval Scenario Bump.

\begin{tabular}{|c|c|c|c|}
\hline Releases & $\begin{array}{c}\text { Receptor } \\
\text { Location }\end{array}$ & $\begin{array}{c}\text { Accident Frequency } \\
1 / \mathbf{y r}=10^{-2} \text { to } 10^{-4}\end{array}$ & $\begin{array}{c}\text { Accident Frequency } \\
1 / \mathbf{y r}=\mathbf{1 0}^{-4} \text { to }^{-6}\end{array}$ \\
\hline \multirow{2}{*}{ Continuous } & On-Site & $1.05 \times 10^{-2}$ & $2.84 \times 10^{-3}$ \\
& Off-Site & $1.10 \times 10^{-4}$ & $8.72 \times 10^{-6}$ \\
\hline \multirow{2}{*}{ Puff } & On-Site & 5.1 & 1.4 \\
& Off-Site & $5.29 \times 10^{-2}$ & $4.19 \times 10^{-3}$ \\
\hline
\end{tabular}

Continuous release results are within guidelines, but puff releases are not. 


\subsection{TANK 241-AZ-102 RETRIEVAL TANK BUMP BOUNDING RADIOLOGICAL AND TOXIC CHEMICAL CONSEQUENCES: 12-HOUR ON-SITE EXPOSURE AND 24-HOUR OFF-SITE EXPOSURE}

The calculations in Section 6.4 were repeated using the standard practice of a 12-hour exposure to on-site receptor and a 24-hour exposure to the off-site receptor.

Consider the 12-hour on-site radiological exposure first. The atmospheric dispersion coefficient, $\mathrm{X} / \mathrm{Q}$, must be calculated anew because the 8-hour values no longer apply. For an on-site receptor (Cowley et al. 2000):

$$
\frac{\log \left(9.40 \times 10^{-3}\right)-\log \left(\mathrm{X} / \mathrm{Q}^{12 \mathrm{hrs} .}\right)}{\log \left(9.40 \times 10^{-3}\right)-\log \left(4.03 \times 10^{-4}\right)}=\frac{\log (2 \mathrm{hrs} .)-\log (12 \mathrm{hrs.})}{\log (2 \mathrm{hrs} .)-\log (8,760 \mathrm{hrs} .)}
$$

which yields $\mathrm{X} / \mathrm{Q}=4.8 \times 10^{-3} \mathrm{~s} / \mathrm{m}^{3}$, which is only slightly different than the value shown in Table 6-4 $\left(5.6 \times 10^{-3} \mathrm{~s} / \mathrm{m}^{3}\right)$. ULD and breathing rate do not change. Figure 6-3 shows that releases between the period of 8 -hours $(28,800$ seconds) and 12 -hours $(43,200$ seconds) are negligible. Therefore, the $0.003 \mathrm{~Sv}$ value calculated in Section 6.4 applies here as well.

Consider the 24-hour off-site radiological exposure next. Two bumps occur during a 24-hour period, so doubling the value reported in Section $6.4\left(6 \times 10^{-6} \mathrm{~Sv}\right)$ is appropriate. Total radiological dose is then $1.2 \times 10^{-5} \mathrm{~Sv}$ for a 24 -hour off-site receptor.

Similarly, the on-site values listed in Table 6.6 are valid for a 12-hour duration, and the off-site values must be doubled. The general conclusion remains unchanged: continuous release calculations are within guidelines, puff release calculations are not. 


\subsection{REFERENCES}

Carlson, A. B., 1999a, Waste Feed Delivery Technical Basis, Volume IV: Waste Feed Delivery Operations and Maintenance Concept, HNF-1939-Vol. IV, Rev. 0, Numatec Hanford Corporation, Richland, WA.

Carlson, A. B., 1999b, Waste Feed Delivery System Phase 1 Preliminary Reliability, Availability, Maintainability Analysis, HNF-2863, Rev. 1, Numatec Hanford Corporation, Richland, WA.

Carlson, A. B. (Numatec Hanford Corp.); J. R. Bellomy, III, K. G. Carothers, J. M. Conner, B. K. Everett, R. J. Fogg, J. D. Guberski, E. I. Husa, D. J. McCain, G. W. Reddick, Jr., G. R. Tardiff, A. M. Templeton, M. S. Tiffany, and S. M. Werry, (CH2M Hill Hanford Group, Inc.); P. J. Fuller, R. E. Mendoza, Jr., T. W. Staehr, and W. H. Ulbricht, Jr., (COGEMA); M. M. Jennings, and D. M. Stenkamp, (Maintenance Concepts); and D. G. Douglas, (Vista Engineering Technologies), 2000, Preliminary Test Report, 241-AZ-101 Mixer Pump Test, RPP-6548, Rev. 0, CH2M HILL Hanford Group, Inc., Richland, WA.

Cowley, W. L., K. R. Sandgren, and J. C. VanKeuren, 2000, Radiological Source Terms for Tank Farm Safety Analysis, RPP-5294, Rev. 0, CH2M HILL Hanford Group, Inc., Richland, WA.

Crea, B. A., K. Sathyanarayana, and D. Ogden, 2000, Parametric Analyses of Heat Removal from High-Level Waste Tanks, RPP-5637, Rev. 0, CH2M HILL Hanford Group, Inc., Richland, WA.

Epstein, M., B. Malinovic, M. G. Plys, and G. M. Hauser, 2000, Hanford Waste Tank Bump Accident and Consequence Analysis, FAI/00-14, Fauske \& Associates, Inc., RPP-6213, Rev. 0, CH2M HILL Hanford Group, Inc., Richland, WA.

Gauglitz, P. A., S. D. Rasat, P. R. Bredt, J. H. Konynenbelt, S. M. Tingey, and D. P. Mendoza, 1996, Mechanisms of Gas Bubble Retention and Release: Results for Hanford Waste Tanks 241-S-102 and 241-SY-103 and Single-Shell Tank Simulants, PNNL-11298, Pacific Northwest National Laboratory, Richland, WA.

Hilliard, R. K., J. D. McCormack, and A. K. Postma, 1983, Results and Code Predictions for ABCOVE Aerosol Code Validation - Test AB5, HEDL-TME 83-16, Hanford Engineering Development Laboratory, Richland, WA.

HNF-SD-WM-TSR-006, 2000, Tank Waste Remediation System Technical Safety Requirements, Rev. 1, as amended, CH2M HILL Hanford Group, Inc., Richland, WA.

Hu, T. A., 1999, Empirical Rate Equation Model and Rate Calculations of Hydrogen Generation for Hanford Tank Waste, HNF-3851, Rev. 0, Lockheed Martin Hanford Corporation, Richland, WA. 
Hu, T. A., S. A. Barker, J. D. Bingham, and M. A. Kufahl, 2000, Steady State Flammable Gas Release Rate Calculation and Lower Flammability Level Evaluation for Hanford Tank Waste, RPP-5926, Rev, 0, CH2M HILL Hanford Group, Inc., Richland, WA.

Malinovic, B., M. G. Plys, and M. Epstein, 2000, Hanford Waste Tank Source Term Model HADCRT I.I: User's Manual, FAI/00-3, Fauske \& Associates, Inc., Burr Ridge, IL.

Meyer, P. A., M. E. Brewster, S. A. Bryan, G. Chen, L. R. Pederson, C. W. Stewart, and G. Terrones, 1997, Gas Retention and Release Behavior in Hanford Double-Shell Waste Tanks, PNNL-11539, Rev. 1, Pacific Northwest National Laboratory, Richland, WA.

Meyer, P., and B. Wells, 2000, Understanding Gas Release Events in Hanford Double Shell Tanks, in WM'00 Proceeding of the Symposium on Waste Management, Tucson, AZ.

Mosleh, A., K. N. Fleming, G. W. Parry, H. M. Paula, D. H. Worledge, and D. M. Rasmuson, 1988, Procedures for Treating Common Cause Failures in Safety and Reliability Studies, NUREG/CR-4780, EPRI NP-5613, PLG-0547, Vol. 1, Pickard, Lowe, and Garrick, Inc., Newport Beach, CA.

Numatec Hanford Corporation, 1998, Project W-320 SAR and Process Control Thermal Analyses, HNF-SD-W320-ER-004, Rev. 1, Prepared for Fluor Daniel Hanford, Inc., Richland, WA.

Ogden, D. M., and D. R. Bratzel, 2000, Thermal Analyses for Tanks 241-AY-102 and 241-C-106, RPP-6463, Rev. 0, CH2M HILL Hanford Group, Inc., Richland, WA.

Stewart, C. W., 2000, personal communication.

WHC-SD-WM-SARR-011, 1996, Toxic Chemical Considerations for Tank Farm Releases, Rev. 2, Westinghouse Hanford Company, Richland, WA. 


\section{A.0 QUANTITATIVE TREATMENT OF TRANSIENT CONDUCTION WITHIN THE NON-CONVECTIVE LAYER DURING SETTLING}

To predict the thermal behavior of a growing non-convective waste layer during settling, a timedependent conduction analysis is required. Again, conduction in the horizontal direction is ignored (see Assumption Al in Section 4.0). In keeping with our objective of developing an accurate but simple mathematical representation of waste self-heat accident scenarios during retrieval activities, we sidestep a direct numerical attack of the partial differential equation of heat conduction. Instead, we exploit the integral profile method. Rather than demanding that the temperature $T(z, t)$ satisfy the transient heat conduction equation everywhere (locally), we only impose the global conservation condition:

$$
\begin{aligned}
& \rho_{\mathrm{NCL}} c_{\mathrm{NCL}} \frac{\mathrm{d}}{\mathrm{dt}} \int_{0}^{\mathrm{H}_{\mathrm{NCl}}(t)} \mathrm{T}(\mathrm{z}, \mathrm{t}) \mathrm{dz}-\rho_{\mathrm{NCL}} \mathrm{c}_{\mathrm{NCL}} \mathrm{T}\left(\mathrm{H}_{\mathrm{NCL}}, \mathrm{t}\right) \frac{\mathrm{d} \mathrm{H}_{\mathrm{NCL}}}{\mathrm{dt}} \\
= & \mathrm{k}_{\mathrm{NCL}} \frac{\partial \mathrm{T}}{\partial \mathrm{z}}\left(\mathrm{H}_{\mathrm{NCL}}, \mathrm{t}\right)-\mathrm{k}_{\mathrm{NCL}} \frac{\partial \mathrm{T}}{\partial \mathrm{z}}(0, \mathrm{t})+\mathrm{Q}_{\mathrm{NCL}} \mathrm{H}_{\mathrm{NCL}}(\mathrm{t})
\end{aligned}
$$

where $\mathrm{H}_{\mathrm{NCL}}(\mathrm{t})$ is the instantaneous thickness of the non-convective layer, $t$ is time, $z$ is vertical distance measured from the bottom of the tank, $Q_{N C L}$ is the volumetric decay heat rate, and $\rho_{\mathrm{NCL}}, \mathrm{c}_{\mathrm{NCL}}, \mathrm{k}_{\mathrm{NCL}}$ are, respectively, the density, specific heat, and thermal conductivity of the non-convective layer.

At the bottom of the tank equation (A-1) is subject to the heat loss condition

$$
k_{\mathrm{NCL}} \frac{\partial \mathrm{T}}{\partial \mathrm{z}}(0, \mathrm{t})=\mathrm{h}_{\mathrm{av}}\left[\mathrm{T}(0, \mathrm{t})-\mathrm{T}_{\mathrm{av}}\right]+\mathrm{h}_{\text {soil }}\left[\mathrm{T}(0, \mathrm{t})-\mathrm{T}_{\infty}\right]
$$

where $h_{a v}$ is the coefficient of heat transport to the annulus ventilation system at temperature $T_{a v}$ and $h_{\text {soil }}$ is the coefficient of heat transport to the soil $\left(k_{\text {soil }} / R\right.$, see equation (4-2)) at temperature $T_{\infty}$. Note that quasi-steady heat conduction is assumed to be a reasonable approximation within the underlying soil. At the top of the non-convective layer, the upward conduction heat flux is equal to the natural convection heat transport rate at the bottom of the convective layer

$$
-\mathrm{k}_{\mathrm{NCL}} \frac{\partial \mathrm{T}}{\partial \mathrm{z}}\left(\mathrm{H}_{\mathrm{NCL}}, \mathrm{t}\right)=\mathrm{h}_{\mathrm{CL}}\left[\mathrm{T}\left(\mathrm{H}_{\mathrm{NCL}}, \mathrm{t}\right)-\mathrm{T}_{\mathrm{Cl}}(\mathrm{t})\right]
$$

where $T_{C L}(t)$ is the instantaneous temperature of the convective layer and $h_{C L}$ is the coefficient for turbulent natural convection heat transfer off the top of the non-convective layer. 
The instantaneous average temperature $\overline{\mathrm{T}}(\mathfrak{t})$ of the non-convective layer is

$$
\overline{\mathrm{T}}(\mathrm{t})=\frac{1}{\mathrm{H}_{\mathrm{NCL}}(\mathrm{t})} \int_{0}^{\mathrm{H}_{\mathrm{NCL}}(t)} \mathrm{T}(\mathrm{z}, \mathrm{t}) \mathrm{dz}
$$

Substituting equations (A-2) to (A-4) into equation (A-1) yields

$$
\begin{aligned}
& \rho_{N C L} c_{N C L} H_{N C L}(t) \frac{d \bar{T}}{d t} \\
= & -\rho_{N C L} c_{N C L}\left[\bar{T}(t)-T\left(H_{N C L}, t\right)\right] \frac{d H_{N C L}}{d t}-h_{C L}\left[T\left(H_{N C L}, t\right)-T_{C L}(t)\right] \\
& -h_{a v}\left[T(0, t)-T_{a v}\right]-h_{\text {soil }}\left[T(0, t)-T_{\infty}\right]+Q H_{N C L}(t)
\end{aligned}
$$

To close the problem, it remains to relate the two dependent variables $T\left(\mathrm{H}_{\mathrm{NCL}}, \mathrm{t}\right)$ and $\mathrm{T}(0, \mathrm{t})$ to the average temperature $\overline{\mathrm{T}}$. The thickness (depth) of the non-convective layer is obtained from a separate analysis of the waste solids settling process. Here it is assumed that $\mathrm{H}_{\mathrm{NCL}}(\mathrm{t})$ is a known function of time. A reasonable functional form for the temperature profile in the non-convective layer is now postulated. The following second-degree polynomial is chosen because it provides the exact solution of the problem in the limit of steady-state heat transfer:

$$
\frac{T(z, t)-T(0, t)}{T\left(H_{N C L}, t\right)-T(0, t)}=\frac{z}{H_{N C L}}[1-x(t)]+x(t)\left(\frac{z}{H_{N C L}}\right)^{2}
$$

where $x(t)$ is a time-dependent profile shape factor. Substituting equation (A-6) into equations $(\mathrm{A}-2),(\mathrm{A}-3)$, and $(\mathrm{A}-4)$ yields the algebraic system

$$
\begin{aligned}
& \frac{(1-x) k_{N C L}}{H_{N C L}}\left[T\left(H_{N C L}, t\right)-T(0, t)\right]=h_{a v}\left[T(0, t)-T_{a v}\right]+h_{\text {soil }}\left[T(0, t)-T_{\infty}\right](A- \\
& -\frac{(1+x) k_{N C L}}{H_{N C L}}\left[T\left(H_{N C L}, t\right)-T(0, t)\right]=h_{C L}\left[T\left(H_{N C L}, t\right)-T_{C L}(t)\right] \\
& \bar{T}(t)=T(0, t)+\frac{1}{6}(3-x)\left[T\left(H_{N C L}, t\right)-T(0, t)\right]
\end{aligned}
$$

After some lengthy algebra, equations (A-7), (A-8), and (A-9) yield the following solutions for the three unknowns $\mathrm{T}(0, \mathrm{t}), \mathrm{T}\left(\mathrm{H}_{\mathrm{NCL}}, \mathrm{t}\right)$, and $\mathrm{x}(\mathrm{t})$ : 


$$
\begin{aligned}
& \mathrm{T}(0, \mathrm{t})=\mathrm{T}_{\mathrm{av}}+ \\
& \frac{3\left(2+\mathrm{B}_{\mathrm{CL}}\right)\left[\overline{\mathrm{T}}(\mathrm{t})-\mathrm{T}_{\mathrm{av}}\right]-\mathrm{B}_{\mathrm{CL}}\left[\mathrm{T}_{\mathrm{CL}}(\mathrm{t})-\mathrm{T}_{\mathrm{av}}\right]-\frac{1}{2} \mathrm{~B}_{\text {soil }}\left(\mathrm{B}_{\mathrm{CL}}+4\right)\left(\mathrm{T}_{\mathrm{av}}-\mathrm{T}_{\infty}\right)}{6+2\left(\mathrm{~B}_{\mathrm{av}}+\mathrm{B}_{\mathrm{CL}}+\mathrm{B}_{\text {soil }}\right)+\frac{1}{2} \mathrm{~B}_{\mathrm{CL}}\left(\mathrm{B}_{\mathrm{av}}+\mathrm{B}_{\text {soil }}\right)} \\
& \begin{aligned}
& \mathrm{T}\left(\mathrm{H}_{\mathrm{NCL}}, \mathrm{t}\right)= \mathrm{T}_{\mathrm{av}}+\frac{2+\mathrm{B}_{\mathrm{av}}+\mathrm{B}_{\text {soil }}}{2+\mathrm{B}_{\mathrm{CL}}}\left[\mathrm{T}(0, \mathrm{t})-\mathrm{T}_{\mathrm{av}}\right]+\frac{\mathrm{B}_{\text {soil }}}{2+\mathrm{B}_{\mathrm{CL}}}\left(\mathrm{T}_{\mathrm{av}}-\mathrm{T}_{\infty}\right) \\
&+\frac{\mathrm{B}_{\mathrm{CL}}}{2+\mathrm{B}_{\mathrm{CL}}}\left[\mathrm{T}_{\mathrm{CL}}(\mathrm{t})-\mathrm{T}_{\mathrm{av}}\right] \\
& \mathrm{x}(\mathrm{t})=\mathrm{B}_{\mathrm{CL}} \frac{\mathrm{T}\left(\mathrm{H}_{\mathrm{NCL}}, \mathrm{t}\right)-\mathrm{T}_{\mathrm{CL}}(\mathrm{t})}{\mathrm{T}(0, \mathrm{t})-\mathrm{T}\left(\mathrm{H}_{\mathrm{NCL}}, \mathrm{t}\right)}-1
\end{aligned}
\end{aligned}
$$

where the B parameters are time-varying Biot numbers defined as

$$
B_{a v}=\frac{h_{a v} H_{N C L}(t)}{k_{N C L}}, \quad B_{C L}=\frac{h_{C L} H_{N C L}(t)}{k_{N C L}}, \quad B_{\text {soil }}=\frac{h_{\text {soil }} H_{\mathrm{NCL}}(t)}{k_{N C L}}(A-1)
$$

Under certain conditions the vertical temperature profile in the non-convective layer will exhibit a maximum. The location $z_{\max }$ of the peak temperature is found by differentiating equation (A-6) and setting the result equal to zero to obtain

$$
z_{\max }(t)=\frac{H_{N C L}(t)}{2}\left[1-\frac{1}{x(t)}\right]
$$

Substituting this result into equation (A-6) gives the maximum temperature

$$
\frac{T_{\max }(t)-T(0, t)}{T\left(H_{N C L}, t\right)-T(0, t)}=\frac{1}{4}\left[2-x(t)-\frac{1}{x(t)}\right]
$$

A physical maximum temperature occurs only when $\mathrm{z}_{\max }$ lies within the interval

$$
0<z_{\max }<H_{\mathrm{NCL}}(t)
$$

Equations (A-5), (A-10) to (A-12), and (A-15) are sufficient to determine the temperature histories at the bottom and top of the non-convective layers. 
RPP-6654, REV. 0

This page intentionally left blank.

FAI/00-52, Rev. 0 


\section{B.0 TRANSIENT TEMPERATURE CALCULATIONS FOR OFF-NORMAL RETRIEVAL SCENARIOS}

The model described in Appendix A was used to develop a code for calculating temperature transients during postulated off-normal retrieval scenarios. In particular, the code was used to calculate five temperatures during loss of ventilation scenarios: supernatant temperature, nonconvective layer (NCL) (or sludge) average temperature, NCL maximum temperature, NCL top temperature, and NCL bottom temperature. The RETRIEVAL code was written in the Visual Basic for Applications language and is executed as a macro in an Excel 7.0 spreadsheet.

\section{B.1 CODE DESCRIPTION}

The integral profile method described in Appendix A requires a model for NCL height during mixing and settling. Since the mixing process is not important to the scenarios of interest, RETRIEVAL simply ramps the NCL thickness to zero in two timesteps and imposes a supernatant and average NCL temperature equal to the waste instantaneous mixing temperature. In the case of $\mathrm{H}_{\mathrm{NCL}} \rightarrow 0$,

$$
\begin{array}{ll}
\text { - } & \left.\mathrm{B}_{\mathrm{CL}}, \mathrm{B}_{\mathrm{av}} \text {, and } \mathrm{B}_{\text {soil }} \text { approach zero (equation }(\mathrm{A}-13)\right), \\
\text { - } & \mathrm{x}(\mathrm{t})=-1(\text { equation }(\mathrm{A}-12)) \\
\text { - } & \mathrm{z}_{\max }(\mathrm{t})=\mathrm{H}_{\mathrm{NCL}}(\mathrm{t})(\text { equation }(\mathrm{A}-14)), \\
\text { - } & \mathrm{T}_{\max }(\mathrm{t})=\mathrm{T}\left(\mathrm{H}_{\mathrm{NCL}}, \mathrm{t}\right)(\text { equation }(\mathrm{A}-15)) \text {, and } \\
\mathrm{T}(0, \mathrm{t})=\mathrm{T}\left(\mathrm{H}_{\mathrm{NCL}}, \mathrm{t}\right)(\text { equation }(\mathrm{A}-11))
\end{array}
$$

which shows that the model approaches the expected uniform temperature profile for a thin NCL.

The settling model is simply:

$$
\mathrm{H}_{\mathrm{NCL}}(\mathrm{t})=\mathrm{H}_{\mathrm{NCL}}(0) \mathrm{F}[1-\exp (-\mathrm{t} / \tau)]
$$

where $\mathrm{H}_{\mathrm{NCL}}(0)$ is the initial NCL (sludge) height, $\mathrm{F}$ is the fluffing factor ( 2.0 here), and $\tau$ is the waste settling time in days. Results plotted for Tank 241-AY-102 show that 5 days is a reasonable estimate for settling time constant (Sathyanarayana 2000). RETRIEVAL tracks NCL thickness based on the settling model above and calculates fluffed properties of density, specific heat, and thermal conductivity.

Sludge properties are calculated by determining appropriate mass and/or volume fractions and then weighting the individual values for liquid and solid constituents to find mixture values. Initial sludge particle volume fraction is an input. The initial particle volume fraction, solid properties, and liquid properties are from Crea et al. (2000) for Tank 241-AZ-102, and are 
presented below. Based on fluffing factor, input for mixer pump operation, and settling time, the code calculates the appropriate mass and volume fractions for the sludge in the fluffed state. Equation (6-2) is used to find the volume fraction. Sludge density is then the volume-weighted average of solid and liquid (supernatant) densities. Sludge-specific heat is the mass fractionweighted average of solid-and liquid- (supernatant) specific heat values. Thermal conductivity is calculated by the Maxwell model, as in Sathyanarayana (2000), and uses sludge liquid volume fraction as an input.

While the mixer pumps are operating, there is only one equation for the temperature rate-ofchange and all waste is said to be a convective layer. This equation reflects the overall energy balance at the waste boundaries and ignores interfacial heat transfer. Once the convective layer temperature rate-of-change is calculated, it is assigned to be sludge temperature rate-of-change, which must always be tracked. The individual terms for heat losses and sources are described in Appendix A for the bottom surface, and in the discussion below of supernatant temperature rateof-change.

Mixer pump heat is distributed uniformly throughout the waste. During mixing, the waste density is just the total mass waste divided by total initial volume. Waste heat capacity is assumed to be the liquid (supernatant) capacity and the solids heat capacity is ignored. While the mixer pumps are operating, thermal conductivity is irrelevant because there is no sludge layer.

Supernatant temperature can be described by a single value because convection ensures a uniform temperature distribution. The supernatant temperature rate-of-change includes the following sources and losses:

- Decay heat as calculated from the transient supernatant height,

- Heat transfer from the sludge top surface,

- Evaporation from the supernatant surface,

- Reflux of primary ventilation condensate,

- Conduction through the top and sides, and

- Annulus ventilation system.

Supernatant decay heat depends on the volume of the supernatant. The code assumes that the total waste height remains constant and that the height of the supernatant is just the height of the waste minus the height of the sludge. Sludge height during settling is given by equation (B-1).

The rate-of-change of supernatant temperature and/or sludge temperature proves to be insensitive to assumptions about the heat transfer coefficient between the sludge top surface and the supernatant. The sludge top surface temperature is always within a degree or so of the supernatant temperature. Heat transfer coefficient between the sludge and the supernatant is representative of natural convection of water overlying a hot surface: 


$$
h_{\text {sup }}=100\left[\mathrm{~T}\left(\mathrm{H}_{\mathrm{NCL}}, \mathrm{t}\right)-\mathrm{T}_{\mathrm{CL}}(\mathrm{t})\right]^{1 / 3} \frac{\mathrm{W}}{\mathrm{m}^{2}-\mathrm{K}}
$$

where $T\left(\mathrm{H}_{\mathrm{NCL}}, \mathrm{t}\right)$ is the temperature at the top of the sludge and $\mathrm{T}_{\mathrm{CL}}(\mathrm{t})$ is the supernatant temperature.

Evaporation from the supernatant is predicted by a simple model that assumes evaporation is only effective if primary ventilation is operating. If primary ventilation is operating, headspace properties are assumed to be that for pure air. Vapor suppression by dissolved salt means that vapor pressure is $85 \%$ that of pure water (Crea et al. 2000). Evaporation is expressed as:

$$
\mathrm{W}_{\mathrm{ev}}=\mathrm{h}_{\mathrm{m}}\left(\mathrm{Y}_{\mathrm{s}}-\mathrm{Y}_{\mathrm{atm}}\right)^{4 / 3}
$$

where $\mathrm{W}_{\mathrm{ev}}$ is the evaporation rate in $\mathrm{kg} / \mathrm{s}, \mathrm{h}_{\mathrm{m}}$ is a mass transfer coefficient, $\mathrm{Y}$ is vapor mass fraction, subscript $s$ denotes the supernatant surface, and subscript atm denotes headspace atmosphere. Vapor mass fraction at the surface, $Y_{s}$, is found from the steam partial pressure at the surface accounting for vapor suppression by salts. Mass transfer coefficient, $h_{m}$, is based on the heat-mass transfer analogy. Vapor mass fraction in the atmosphere is found by a Newton's method solution to the mass balance for the amount of steam in the headspace:

$$
\frac{Y_{a t m}}{1-Y_{a t m}}=\frac{h_{m}\left(Y_{s}-Y_{a t m}\right)^{4 / 3}}{\rho_{g} Q_{v}}
$$

where $\mathrm{Q}_{\mathrm{v}}$ is the primary ventilation volumetric flowrate and $\rho_{\mathrm{g}}$ is the gas density.

Condensate is returned to the supernatant with some user-defined split fraction and temperature. The usual assumption is that all the condensate returns to the supernatant.

Conduction through the soil overburden is simply one-dimensional, steady-state conduction through a slab with one end at the ambient air temperature and the other at the supernatant temperature. Sideward conduction is defined to be $33 \%$ of upward conduction, based on Kummerer (1994), and apportioned between sludge and supernatant based on height.

Annulus ventilation removes heat based on the supernatant temperature, the sideward heat transfer area of the DST (perimeter times supernatant height), the annulus ventilation inlet temperature, and some user-defined heat transfer coefficient.

\section{B.2 VALIDATION}

The coding was validated against the loss of ventilation results presented in Figure 3-6. This plot shows the following:

- The transient starts from a mixed waste temperature of $190^{\circ} \mathrm{F}\left(88^{\circ} \mathrm{C}\right)$, 
- The NCL maximum temperature reaches saturation after $50(119-69)$ days, and

- Supernatant temperature reaches $209^{\circ} \mathrm{F}$, or $98.3^{\circ} \mathrm{C}$, after $69(138-69)$ days.

For Tank 241-AZ-102, RETRIEVAL input was taken from Appendix B of Crea et al. (2000), and is as shown in Table B-1.

This input reproduces the GOTH run shown in Figure 3-6. Results are shown in Figure B-1. The first 34 days are simply to allow the waste temperatures to reach steady-state. The userdefined annulus ventilation heat transfer coefficient was chosen to keep the supernatant temperature constant at roughly $113^{\circ} \mathrm{F}$. A comparison of Figure B-l and Figure 3-6 shows that the RETRIEVAL code does a reasonable job of predicting the peak sludge temperature. Mixing then occurs between 34 and 69 days, at which time the mixer pumps and ventilation systems are shut off.

RETRIEVAL results show reasonable agreement with GOTH results shown in Figure 3-6:

- $\quad$ The transient starts from a mixed waste temperature of $193^{\circ} \mathrm{F}\left(89.7^{\circ} \mathrm{C}\right)$,

- The NCL maximum temperature reaches saturation $\left(254^{\circ} \mathrm{F}\right)$ after 42 $(111-69)$ days, and

- Supernatant temperature reaches $209^{\circ} \mathrm{F}$, or $98.3^{\circ} \mathrm{C}$, after $73(142-69)$ days.

The RETRIEVAL supernatant temperature curve is not in precise agreement with the GOTH curve because evaporative cooling is not accounted for in RETRIEVAL. After the mixer pumps are turned off, evaporative cooling will still be effective for a time.

This calculation was repeated with mixer pump shut off and ventilation failure occurring at various times other than 69 days. In all instances, the maximum sludge temperature rate-ofchange was about the same.

\section{B.3 SUCCESS CRITERIA RUN}

To determine if primary ventilation alone can prevent a bump, the previous case was revised to assume that primary ventilation does not fail at 69 days (time of mixer pump shut down) but annulus ventilation fails. Input is shown in Table B-2.

Results are shown in Figure B-2. The figure indicates that the sludge would still reach saturated conditions after about $55(124-69)$ days, but the supernatant would be highly sub-cooled. This would prevent bumps, but not lead to a stable state. Figure B-2 confirms that a valid, conservative success criterion is that both primary and annulus ventilation are required. 
Table B-1. RETRIEVAL Validation Input.

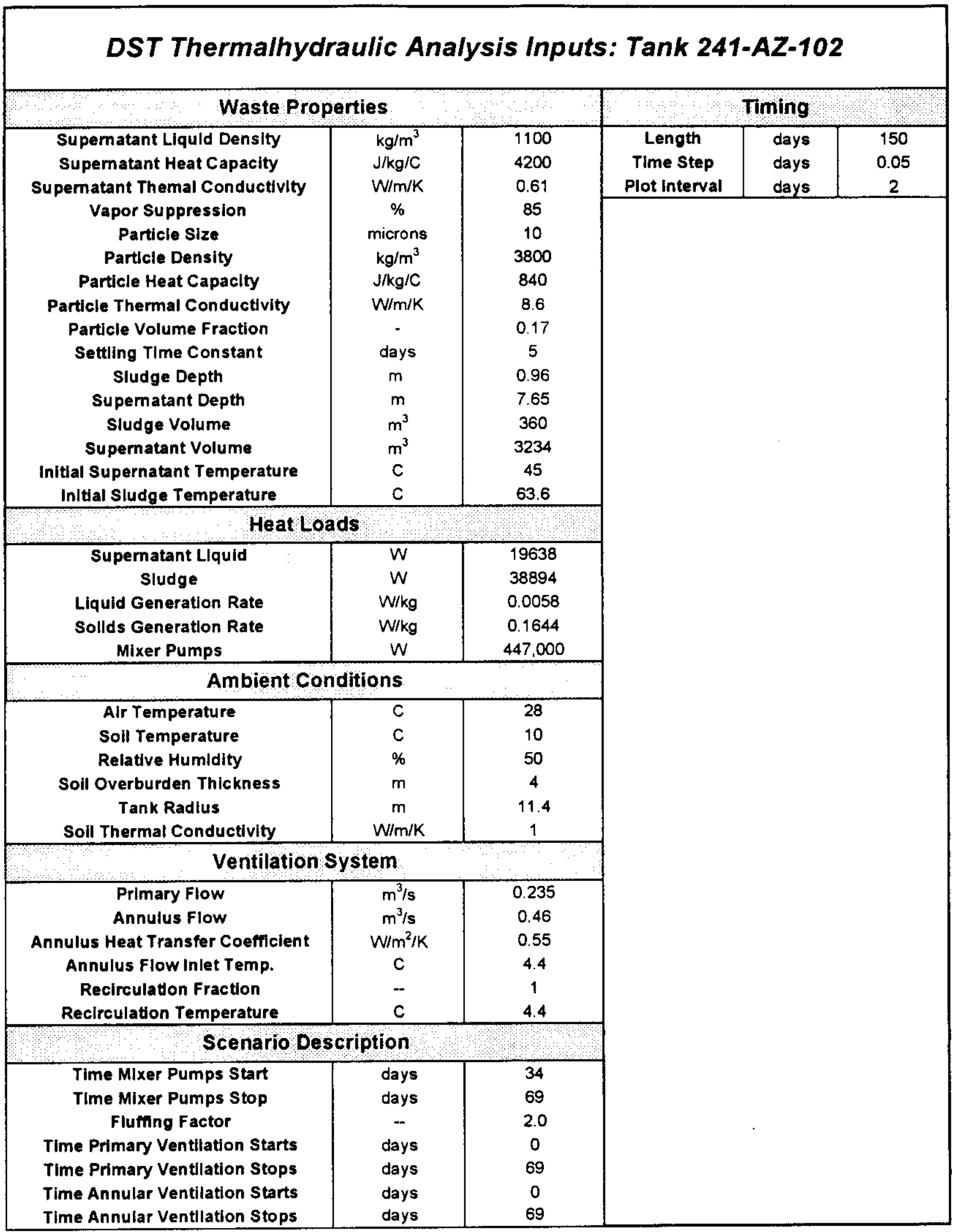


RPP-6654, REV. 0

Figure B-1. RETRIEVAL Validation Results.

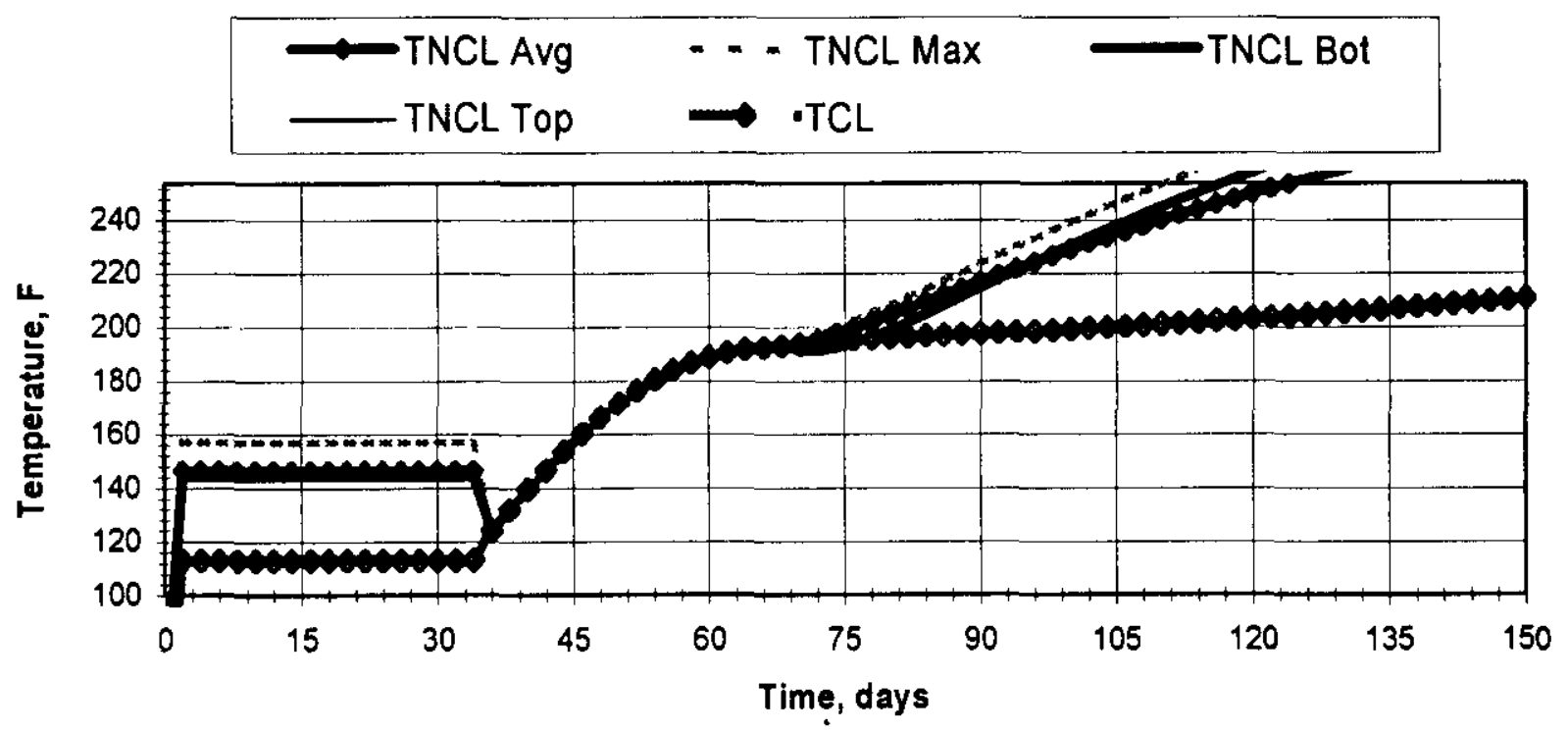


Table B-2. Inputs for Case with Primary Ventilation but No Annulus Ventilation.

DST Thermalhydraulic Analysis Inputs: Tank 241-AZ-102

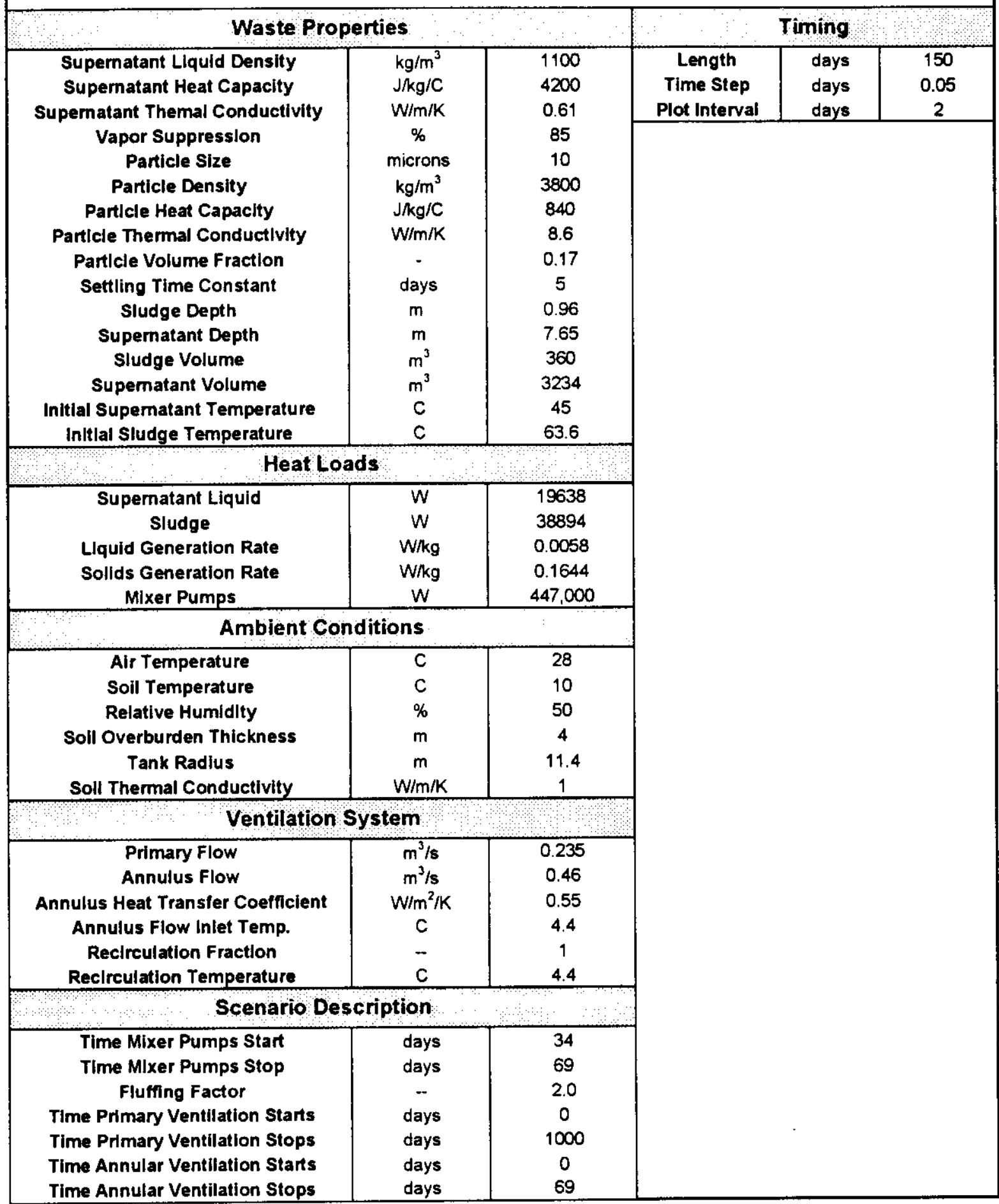


Figure B-2. Results of Case with Primary Ventilation but No Annulus Ventilation.

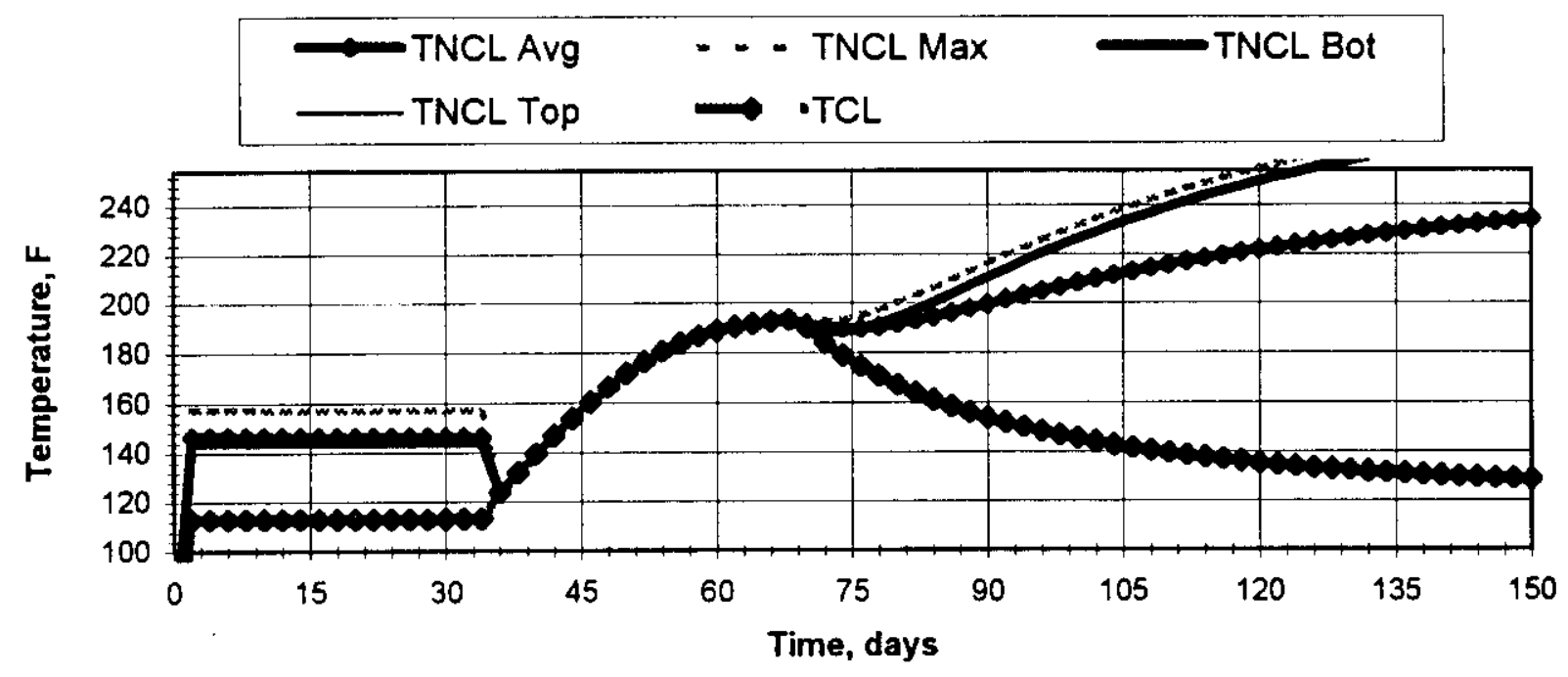


RPP-6654, REV. 0

\section{B.4 REFERENCES}

Crea, B. A., K. Sathyanarayana, and D. Ogden, 2000, Parametric Analyses of Heat Removal from High-Level Waste Tanks, RPP-5637, Rev. 0, CH2M HILL Hanford Group, Inc., Richland, WA.

Kummerer, M., 1994, Topical Report on Heat Removal Characteristics of Waste Storage Tanks, WHC-SD-WM-SARR-010, Rev. 0, Westinghouse Hanford Company, Richland, WA.

Sathyanarayana, K., 2000, Thermal Hydraulic Analysis of High Level Waste Tanks for Phase 1 Waste Feed Delivery, RPP-5386, Rev. 0, Fluor Hanford, Inc., Richland, WA. 
RPP-6654, REV. 0

This page intentionally left blank. 
RPP-6654, REV. 0

APPENDIX C

SPREADSHEETS FOR ACCIDENT FREQUENCY CALCULATION

\section{C.1 SPREADSHEET CALCULATIONS FOR FREQUENCY OF TANK BUMP CONDITIONS}

This spreadsheet evaluates retrieval tank bump conditions frequency, $F_{\mathrm{WFD}}$. See Section 5 of this report. Symbols are defined in the symbol table.

Differential equation for probability of tank bump conditions

$$
d F_{W F D}(t)=p_{f}(t) P_{n r}(t) d t
$$

Integrate over mixer operation time, $\mathrm{t}_{\mathrm{op}}$

$$
F_{W F D}=\int_{0}^{t_{\text {op }}} p_{f}(t) P_{n r}(t) d t
$$

Function Definitions: Ventilation System Failure and Probability of No Recovery

$$
\begin{aligned}
& p_{f}=\lambda_{p}+\lambda_{a n n} \\
& P_{n r}=\left(1-x_{r s}\right) \sum_{n=1}^{N} x_{n}\left[1-\log -\operatorname{normal}\left(t_{a}, \alpha_{n}, \beta_{n}\right)\right]
\end{aligned}
$$


RPP-6654, REV. 0

Time Available Function: Heatup rate $=1.2 \mathrm{~F} /$ day

$\begin{array}{ll}\text { If }(\mathrm{t}<35 \text { days }) & \mathrm{t}_{\mathrm{a}}=\frac{\left[240^{\circ} \mathrm{F}-\left(123+3.9 \mathrm{t}-0.055 \mathrm{t}^{2} \mathrm{~F}\right)\right]}{\alpha} \\ \text { else } & \mathrm{t}_{\mathrm{a}}=40 \text { days }\end{array}$

Long Form of the Equation

$F_{W F D}=\left[\lambda_{p}+\lambda_{\operatorname{man}}\right] \int_{0}^{t_{o p}}\left(1-x_{r s}\right) \sum_{n=1}^{N} x_{n}\left[1-\log -\right.$ normal $\left.\left(t_{a}, \alpha_{n}, \beta_{n}\right)\right] d t$

Definition of Exceedance Probability for CM Activity 1; log-normal is the cumulative log-normal distribution

Exceed. Prob $1=\left[1-\log\right.$-normal $\left.\left(t_{a}, \alpha_{1}, \beta_{1}\right)\right]$, etc. 
RPP-6654, REV. 0

Symbol Table

\begin{tabular}{|c|c|c|}
\hline Symbol & Definition & Value \\
\hline$\lambda_{0}+\lambda_{m n}$ & $\begin{array}{l}\text { Ventilation Failure } \\
\text { Rate }\end{array}$ & $0.0077 /$ day \\
\hline$x_{n}$ & $\begin{array}{l}\text { Restoration Activity } \\
\text { Fraction }\end{array}$ & 0.8 \\
\hline$x_{1}$ & \begin{tabular}{|l|} 
Corrective \\
Maintenance \\
Activity Fraction for \\
3TCNEL \\
\end{tabular} & 0.485 \\
\hline$x_{2}$ & $\begin{array}{l}\text { CM Activity } \\
\text { Fraction for STCIEL. }\end{array}$ & 0.030 \\
\hline$x_{3}$ & $\begin{array}{l}\text { CM Activity } \\
\text { Fraction for } \\
\text { STCNEL }\end{array}$ & 0.485 \\
\hline$\alpha_{1}$ & $\begin{array}{l}\text { Log-Mean of CM } \\
\text { Activity 3TCNEL }\end{array}$ & 5.08 \\
\hline$\alpha_{2}$ & $\begin{array}{l}\text { Log-Mean of CM } \\
\text { Activity STCTEL }\end{array}$ & 5.56 \\
\hline$\alpha_{1}$ & $\begin{array}{l}\text { Log-Mean of CM } \\
\text { Activity STCNEL }\end{array}$ & 4.89 \\
\hline$\beta_{4}$ & $\begin{array}{l}\text { Log-St Dev. of CM } \\
\text { Activity 3TCNER }\end{array}$ & 0.56 \\
\hline$\beta_{2}$ & $\begin{array}{l}\text { Log-SL. Dov. of CM } \\
\text { Activity STCIEI. }\end{array}$ & 0.56 \\
\hline$\beta_{1}$ & $\begin{array}{l}\text { Log-St Dev.of CM } \\
\text { Activity STCNEL }\end{array}$ & 0.56 \\
\hline
\end{tabular}

\begin{tabular}{|c|c|c|c|c|c|c|c|}
\hline \multicolumn{9}{|c|}{ Corrective Maintenance Distributions } \\
\hline CM Activity & 5TH & $95 T H$ & Log-Mean & Log St. Dev & $\begin{array}{c}\text { CM } \\
\text { Activlty } \\
\text { Fraction }\end{array}$ & CM No. & \\
\hline 3TCNEL & 64 & 400 & 5.08 & 0.56 & 0.485 & 1 & \\
5TCIEL & 102 & 638 & 5.56 & 0.56 & 0.03 & 2 & \\
5TCNEL & 53 & 331 & 4.89 & 0.56 & 0.485 & 3 & \\
\hline
\end{tabular}


RPP-6654, REV. 0

\begin{tabular}{|c|c|c|c|c|c|c|c|c|}
\hline & $\begin{array}{l}\text { Ventilation } \\
\text { Fallure Rate } \\
=P_{r}\end{array}$ & $\begin{array}{c}\text { Restoration } \\
\text { Activity } \\
\text { Fraction }\end{array}$ & & & & & & $\begin{array}{c}\text { Day that } F_{\text {wFD }} \\
>1 e-6\end{array}$ \\
\hline & 1/day & $\div$ & & & & & & 19 \\
\hline & $7.70 E-03$ & 0.8 & & & & & & \\
\hline $\begin{array}{c}\text { Mirer } \\
\text { Operation } \\
\text { Time, } t_{\text {op }}\end{array}$ & $\begin{array}{c}\text { Time } \\
\text { Available, } t,\end{array}$ & Exceed. Prob 1 & Exceed. Prob 2 & $\begin{array}{c}\text { Exceed. Prob } \\
3\end{array}$ & $\mathbf{P}_{\mathrm{nr}}$ & $\mathbf{p e}_{\boldsymbol{*}}^{*} \mathbf{P}_{\mathrm{ar}}$ & $\mathbf{d F}_{\mathbf{W F D}}$ & $F_{\text {wro }}$ \\
\hline days & days & & & & & & & \\
\hline 0 & 97.5 & $\frac{8.69 E-07}{1.17 E-06}$ & $\begin{array}{l}4.34 E-05 \\
55 E .05\end{array}$ & $\frac{1.52 E-07}{2.08 E-07}$ & $\begin{array}{l}3.60 E-07 \\
4.67 E-07\end{array}$ & $\begin{array}{l}2.77 \mathrm{E}-09 \\
3.59 E-09\end{array}$ & $\frac{0.00 E+\infty}{3.18 E-09}$ & $\frac{0.00 E+\infty}{3.18 E-08}$ \\
\hline 2 & 91.2 & $1.56 E-06$ & $7.09 E-05$ & $2.83 \mathrm{E}-07$ & $6.05 E-07$ & $4.66 \mathrm{E}-09$ & $4.12 E-09$ & $7.30 E-09$ \\
\hline 3 & 88.2 & $2.09 E-06$ & $9.02 E_{-05}^{-05}$ & $3.88 E-07$ & $7.82 E-07$ & 8.02E-09 & $5.34 E-09$ & $1.26 E-08$ \\
\hline 4 & 85.2 & $2.79 E-06$ & $1.15 E-04$ & 5.28E-07 & $1.01 E-06$ & $7.77 E .09$ & $6.85 E-06$ & $7.95 E-08$ \\
\hline 5 & 82.4 & $3.71 \mathrm{E}-06$ & $1.45 E-04$ & $7.16 E-07$ & $1,30 E-06$ & $100 E-08$ & $8.89 \mathrm{E}-09$ & $2.84 E \cdot 08$ \\
\hline 6 & 79.7 & $4.92 E-06$ & $1.83 E-04$ & $9.68 E \cdot 07$ & $1.67 E-06$ & $1.28 E-08$ & $1.14 E-08$ & $3.98 \mathrm{E}-08$ \\
\hline 7 & 770 & $6.50 E_{-06}$ & $2.30 E-04$ & $1,30 \mathrm{E}-06$ & 2.14E-06 & 7.64E-08 & $1.46 E-08$ & $5.45 E-08$ \\
\hline 8 & 74.4 & $855 E-66$ & $2.88 E \cdot 04$ & $1.75 E-06$ & $2.73 E-06$ & $2.10 E-08$ & $1.87 \mathrm{E}-08$ & $7.32 \mathrm{E}-08$ \\
\hline 9 & 72.0 & $1.12 \mathrm{E}-03$ & $3.59 \mathrm{E}-04$ & $2.34 E-06$ & $3.47 E-06$ & $2.67 \mathrm{E}-08$ & $2.39 E-08$ & $9.71 \mathrm{E}-0 \mathrm{~B}$ \\
\hline 76 & 69.6 & $1.46 E-05$ & $4.66 E-04$ & $3.11 \mathrm{E}-06$ & $1.40 E-06$ & $3.38 E-08$ & $3.03 E-08$ & $1.27 \mathrm{E} \cdot 07$ \\
\hline 14 & $67 \overline{3}$ & $1.90 \mathrm{E}-05$ & $3.32 E-04$ & $4.12 E-06$ & 335E- 06 & 4.27E-08 & $3.83 E-08$ & $1.66-07$ \\
\hline 12 & 65.1 & $2.43 E-03$ & 6.79E-04 & 5.42E- 06 & $6.97 \varepsilon-06$ & $3.37 E-08$ & $4.82 E-08$ & $2.14 E-07$ \\
\hline 13 & 63.0 & $3.14 E-05$ & $8.31 E-04$ & $7.09 E-06$ & $8.72 E-06$ & $6.71 \mathrm{i} .08$ & $6.04 E-08$ & $2.74 E-07$ \\
\hline 14 & 61.0 & $401 E-05$ & 1.01E-03 & $9.21 E .06$ & $1.08 E-03$ & $8.35 E-08$ & $7.53 E-08$ & $3.50 E-07$ \\
\hline 15 & 59.1 & $3.08 E-65$ & $1.22 \mathrm{E}=03$ & $1.19 E-05$ & $1.34 E-05$ & $1.03 E-07$ & 9.35E-08 & $4.43 E-07$ \\
\hline 16 & 57.2 & ह.3दE-03 & $1.47 E-03$ & $1.32 \mathrm{E}-06$ & $1.65 E-05$ & 1.27E-07 & 1.15E-07 & $5.58 E-07$ \\
\hline 17 & 55.5 & $798 \mathrm{BE}-05$ & $1.76 \mathrm{E}-03$ & $1.84 E-05$ & $2.02 E-05$ & $1.35 E-07$ & $1.41 \mathrm{E}-07$ & $7.00 E-07$ \\
\hline 18 & 53.9 & $9.89 \mathrm{E}-0 \mathrm{~S}$ & $2.09 E-03$ & $2.44 E-06$ & $2.45 E-05$ & $1.89 E-07$ & $1.72 E-07$ & $8.71 E-07$ \\
\hline 19 & 52.3 & $1.22 \mathrm{E}-04$ & $2.46 E-03$ & $3.05 E-05$ & 2.95E-05 & $2.27 E-07$ & $2.08 E-07$ & $1.08 E-06$ \\
\hline 20 & 50.8 & $1.48 E \cdot 04$ & $2.87 \mathrm{E}-03$ & $3.78 E-05$ & $3.53 \mathrm{E}-05$ & $2.72 \mathrm{E}-07$ & $2.49 \mathrm{E}-07$ & $1.33 \mathrm{E}-06$ \\
\hline 21 & 49.5 & $178 \mathrm{E}-04$ & $3.33 E-03$ & $4.63 E-05$ & $4.18 E-05$ & $3.22 E-07$ & $2.97 E-07$ & $1.63 E-06$ \\
\hline 22 & 48.2 & $2.13 E-04$ & $3.84 E-03$ & $5 . \overline{61 E}-05$ & $4.91 E-05$ & $3.78 E-07$ & $3.50 \mathrm{E}-07$ & $1.98 E-06$ \\
\hline 23 & 47.0 & $2.52 E-04$ & $4.38 E-03$ & $6.73 E-05$ & $5.72 E-05$ & $4.41 E-07$ & $4.09 E-07$ & $2.38 E-06$ \\
\hline 24 & 45.9 & $2.95 E-04$ & A.9SE-03 & $7.97 \mathrm{E}-05$ & $6.60 E-05$ & 3.08E.07 & $4.74 E-07$ & $2.86 E-06$ \\
\hline 25 & 44.9 & $3.41 \mathrm{E}-04$ & $5.54 E-03$ & $9.34 E-03$ & $7.53 E-05$ & $3.80 E-07$ & 3.44E-07 & $3.40 E \cdot 06$ \\
\hline 26 & 44.0 & $3.89 \mathrm{~g}-04$ & $6.15 E-03$ & $1.08 E-04$ & B.51E-05 & $6.55 E-07$ & $6.18 E-07$ & 1.02E.06 \\
\hline 27 & 43.2 & $4.39 E-04$ & $6.76 E .03$ & $1.23 k-04$ & 9.51E-O5 & $732 E-07$ & 6.94E-07 & 4.71E-06 \\
\hline 28 & 42.4 & $4.90 E-04$ & $7.36 E-03$ & $139 E-04$ & T.05E-04 & B.0SE-07 & $7.71 E-07$ & $5.49 E-06$ \\
\hline 29 & 41.8 & $3.39 E-04$ & $7.93 E-03$ & 1.34E-04 & $1.13 E-04$ & 8.84E-07 & 8.47E-07 & $6.33 E-06$ \\
\hline 30 & 41.3 & $3.85 E-04$ & $8.45 E-03$ & $1.68 \mathrm{E}-04$ & $1.24 E-04$ & $9.54 E-07$ & $9.19 E-07$ & $7.25 E-06$ \\
\hline 31 & 80.8 & $6.27 E=04$ & $8.92 E-03$ & $1.82 E-04$ & $1.32 E-04$ & $1.02 E-06$ & $9.85 E-07$ & $8.24 E-06$ \\
\hline 32 & 40.4 & $6.63 E-04$ & $9.31 \mathrm{E}-03$ & $1.93 E-04$ & $1.39 E-04$ & $1.07 E-06$ & $1.04 E-06$ & $9.28 E-06$ \\
\hline 33 & 40.2 & $6.92 E-04$ & $9.61 E-03$ & $2.02 E-04$ & $1.14 E-04$ & $1.11 E-06$ & $1.09 E-06$ & $1.04 E-05$ \\
\hline 34 & 40.0 & $7.092-04$ & $9.80 \mathrm{E}-63$ & $2.08 E-04$ & $1.48 E-04$ & 1.14E-06 & $1.12 \mathrm{E}-06$ & 1.15E-05 \\
\hline 35 & 40.0 & $7.09 E-04$ & $9.80 E-03$ & $2080-04$ & $1.48 E-04$ & 1.14E-06 & $1.14 E-06$ & $1.26 E-05$ \\
\hline
\end{tabular}

Values for times larger than 35 days are plotted below. 
RPP-6654, REV. 0

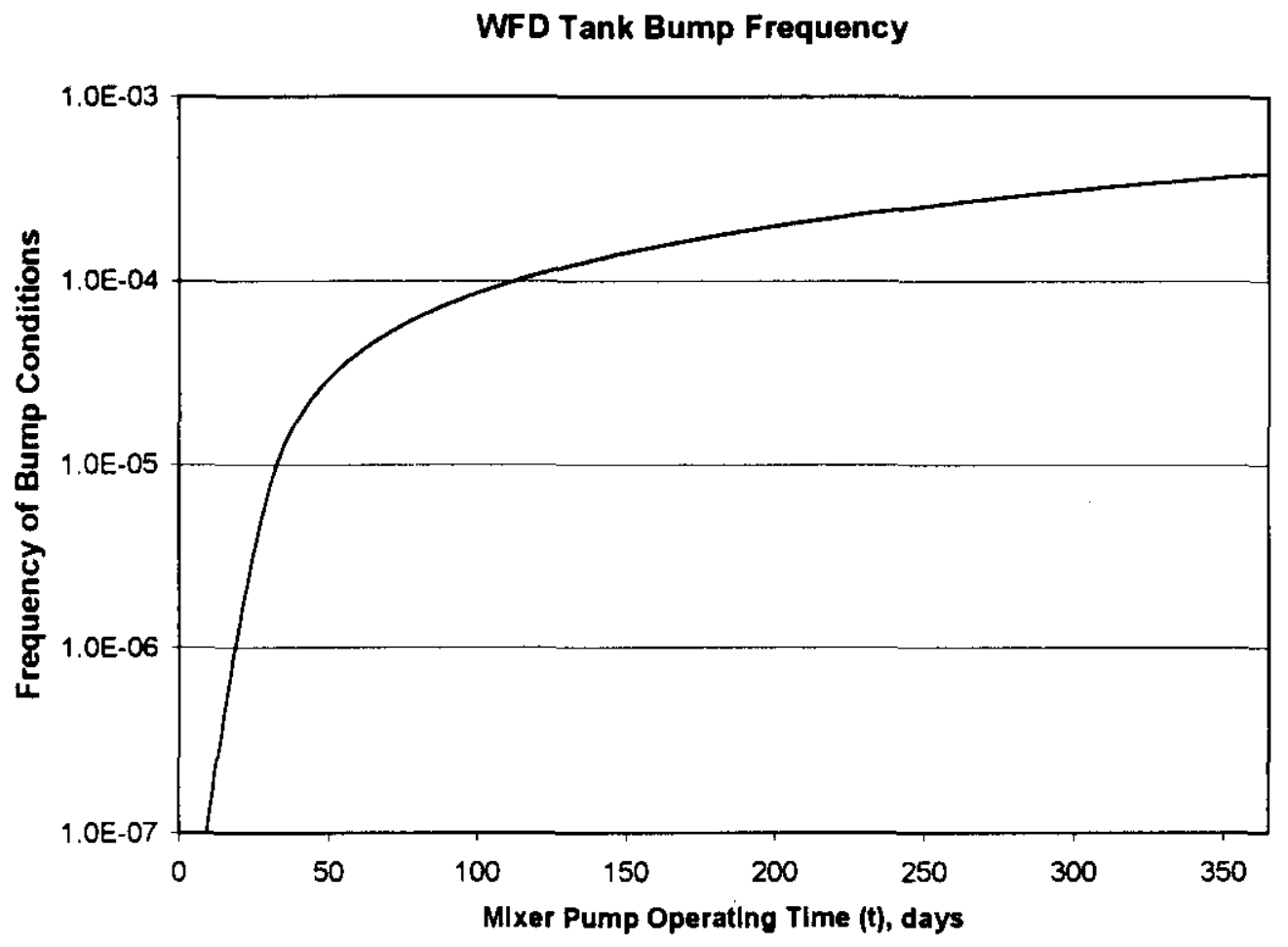




\section{C.2 UNCERTAINTY ANALYSIS FOR FREQUENCY OF TANK BUMP CONDITIONS}

\section{Crystal Ball Report}

Simulation started on $7 / 21 / 00$ at $13: 09: 58$

Simulation stopped on $7 / 21 / 00$ at $13: 12: 23$

Forecast: Days to Exceed 1E-6 Bump Frequency

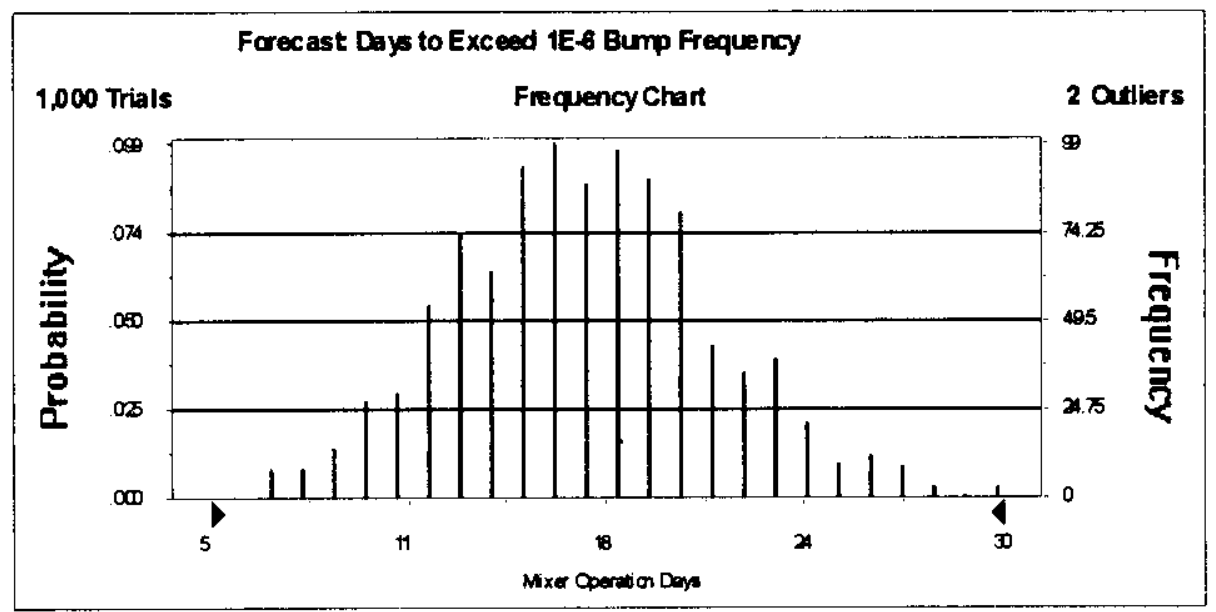

Percentiles:

\begin{tabular}{rr} 
Percentile & Mixer Operation Days \\
\hline $0.0 \%$ & 7 \\
$2.5 \%$ & 9 \\
$5.0 \%$ & 10 \\
$50.0 \%$ & 17 \\
$95.0 \%$ & 24 \\
$97.5 \%$ & 26 \\
$100.0 \%$ & 32
\end{tabular}

End of Forecast 


\section{Assumptions}

\section{Assumption: Relative Frequency of 5TCIEL}

Uniform distribution with parameters: Minimum

Maximum

Mean value in simulation was 0.05

Assumption: Recovery Fraction $=1-\mathrm{CM}$ Fraction

Uniform distribution with parameters:

$\begin{array}{ll}\text { Minimum } & 0.50 \\ \text { Maximum } & 0.80\end{array}$

Mean value in simulation was 0.65

Assumption: Ventilation Failure Rate, 1/hr

Lognormal distribution with parameters:
Mean
3.21E-04
Standard Dev.
3.07E-04

Selected range is from $0.00 E+0$ to + Infinity

Mean value in simulation was $3.14 \mathrm{E}-4$

End of Assumptions 
RPP-6654, REV. 0

This page intentionally left blank. 


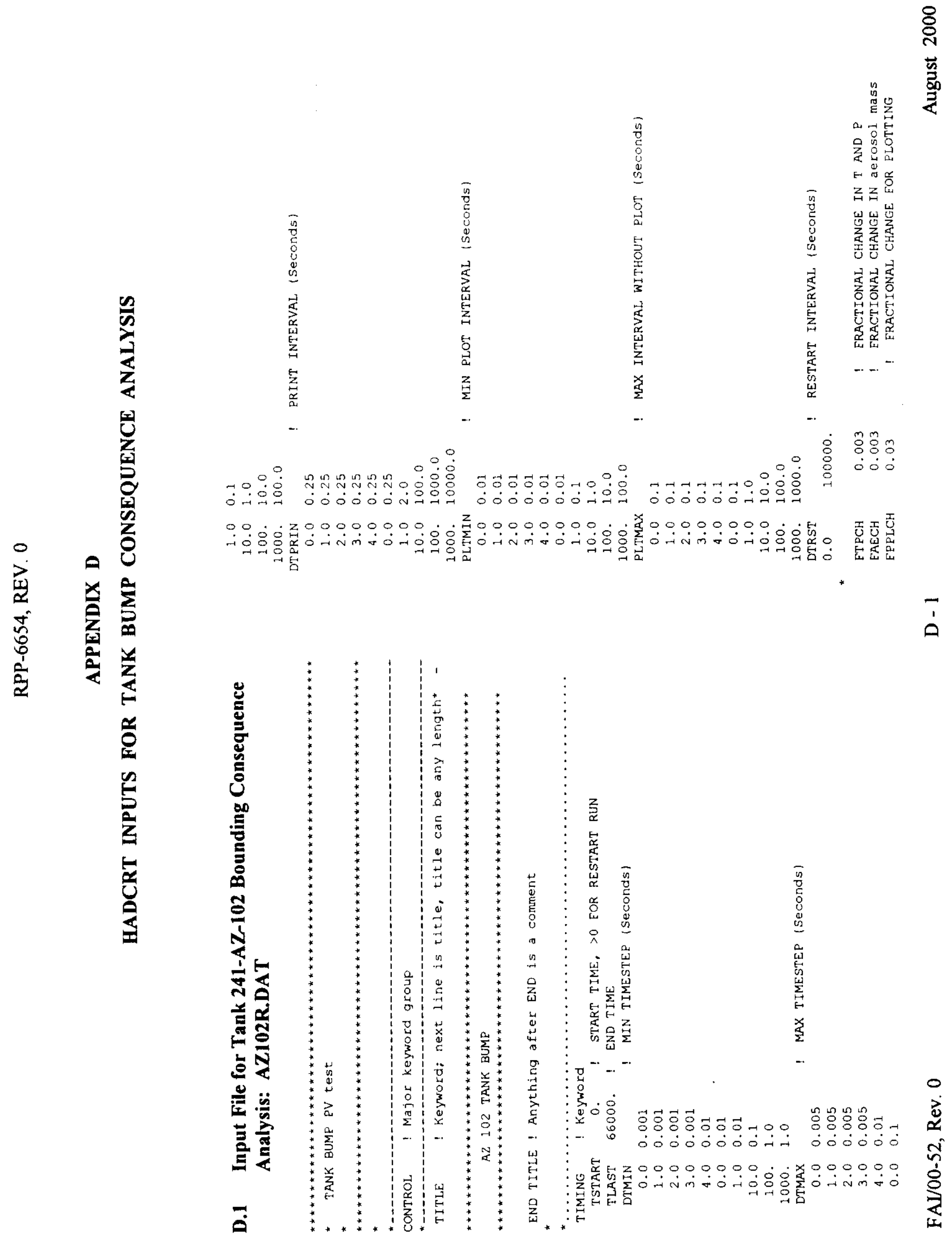




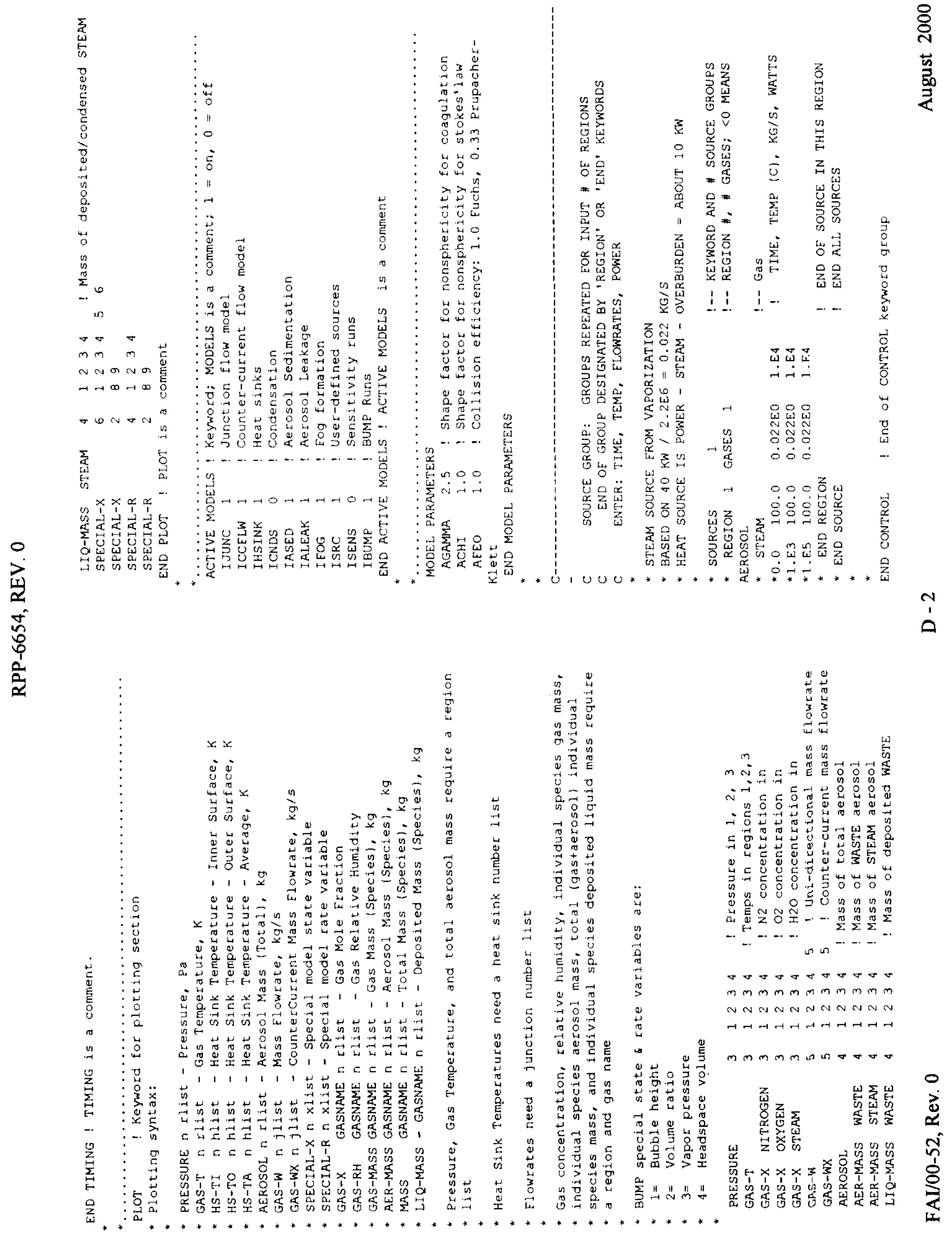



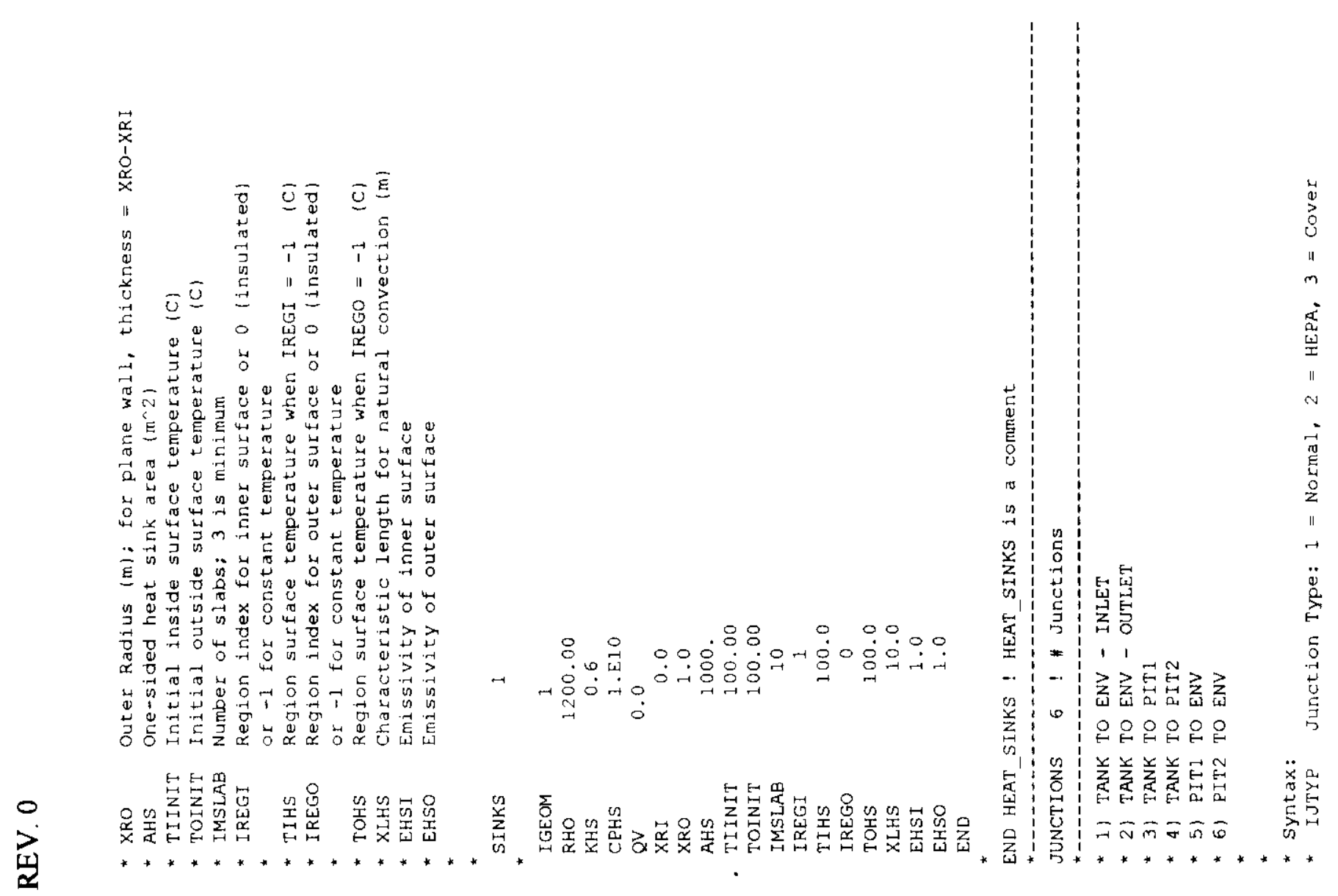

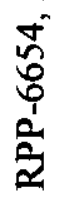

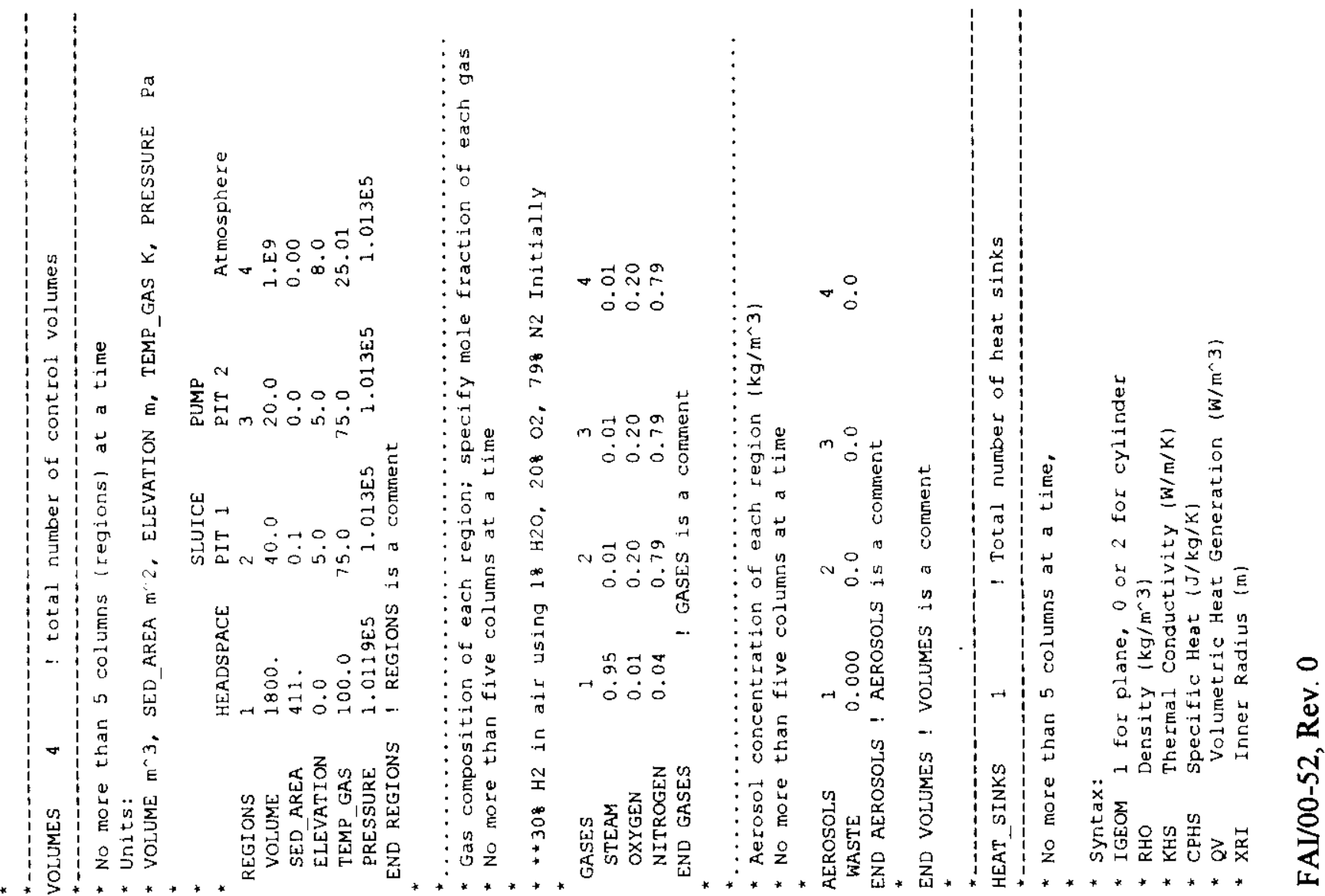




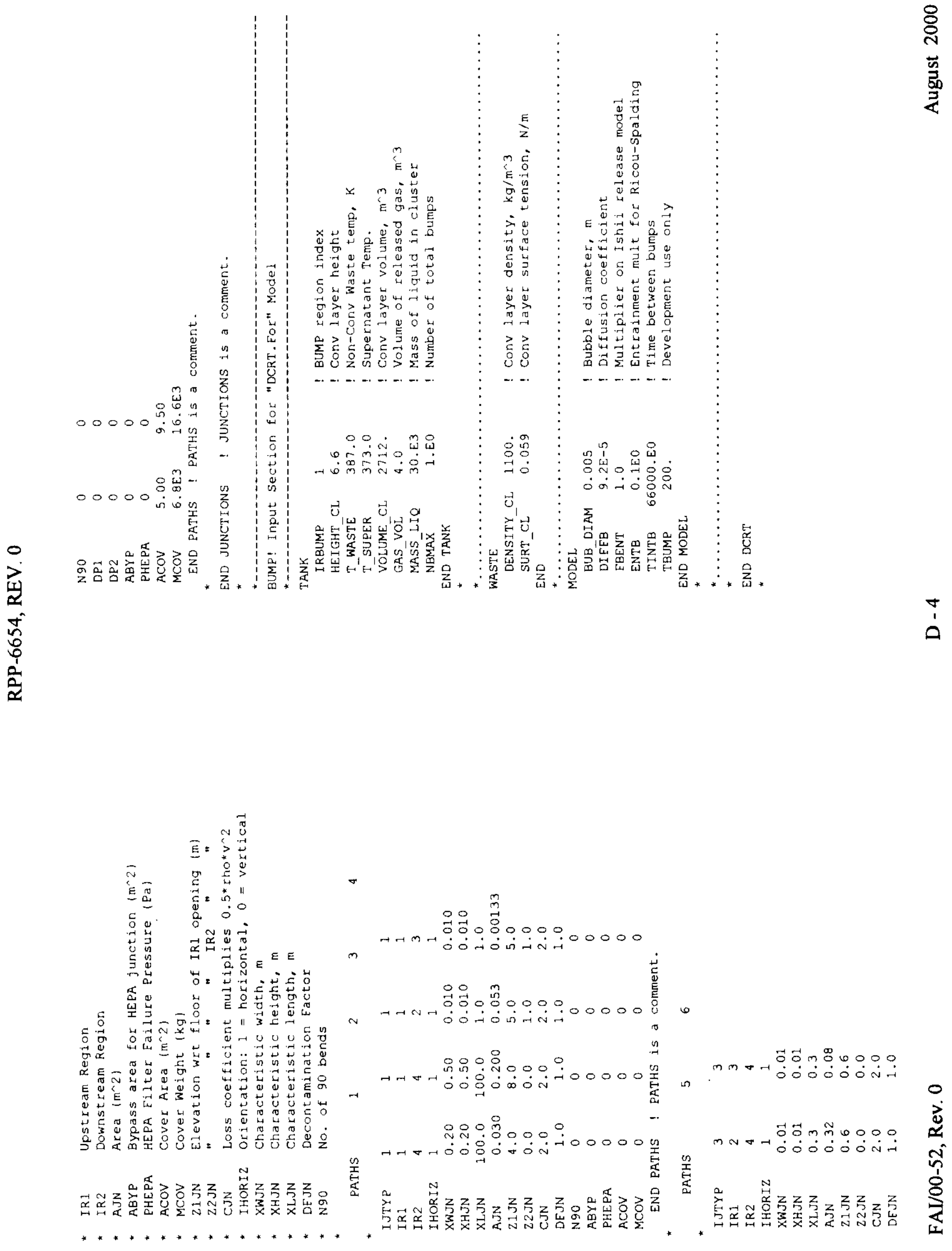




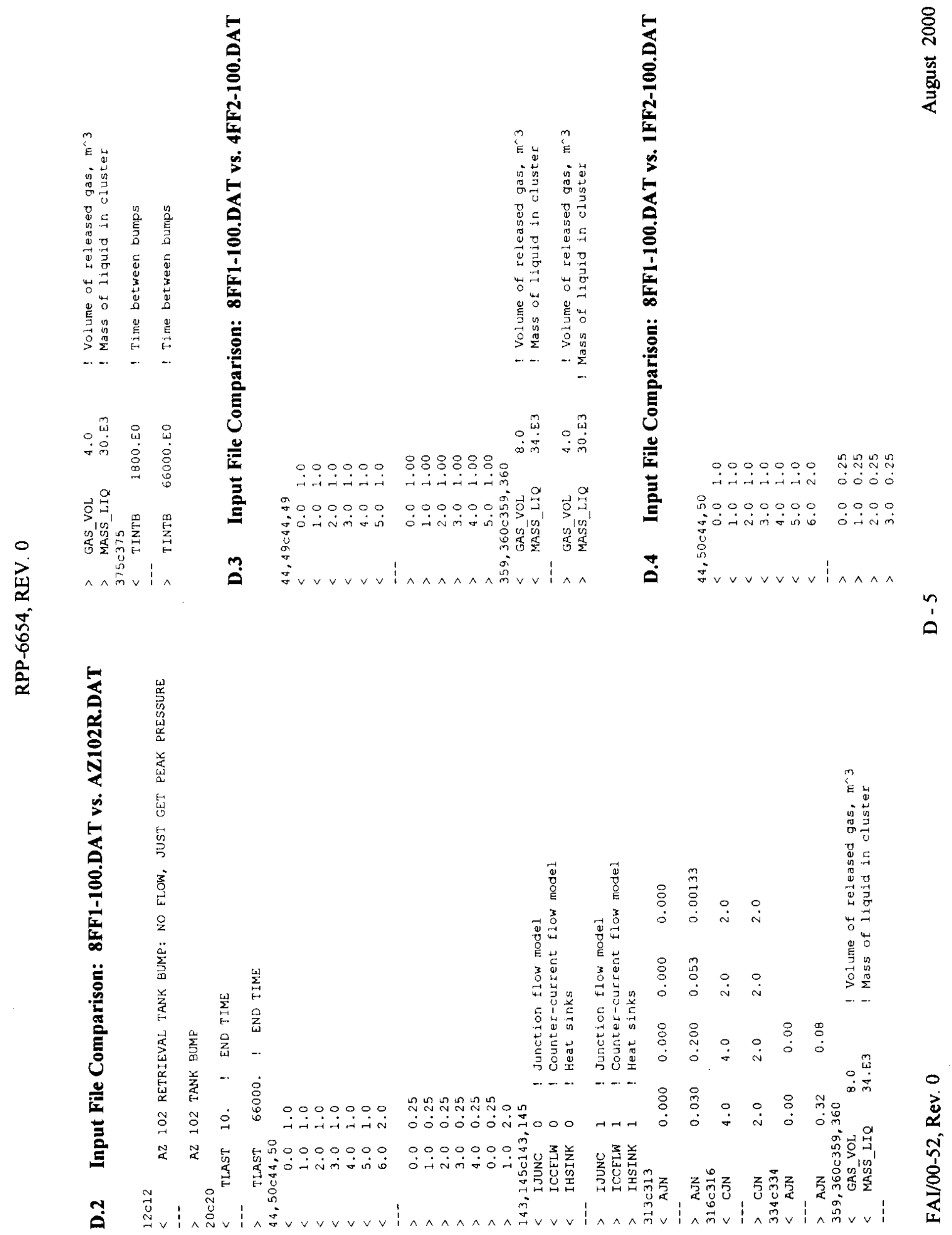




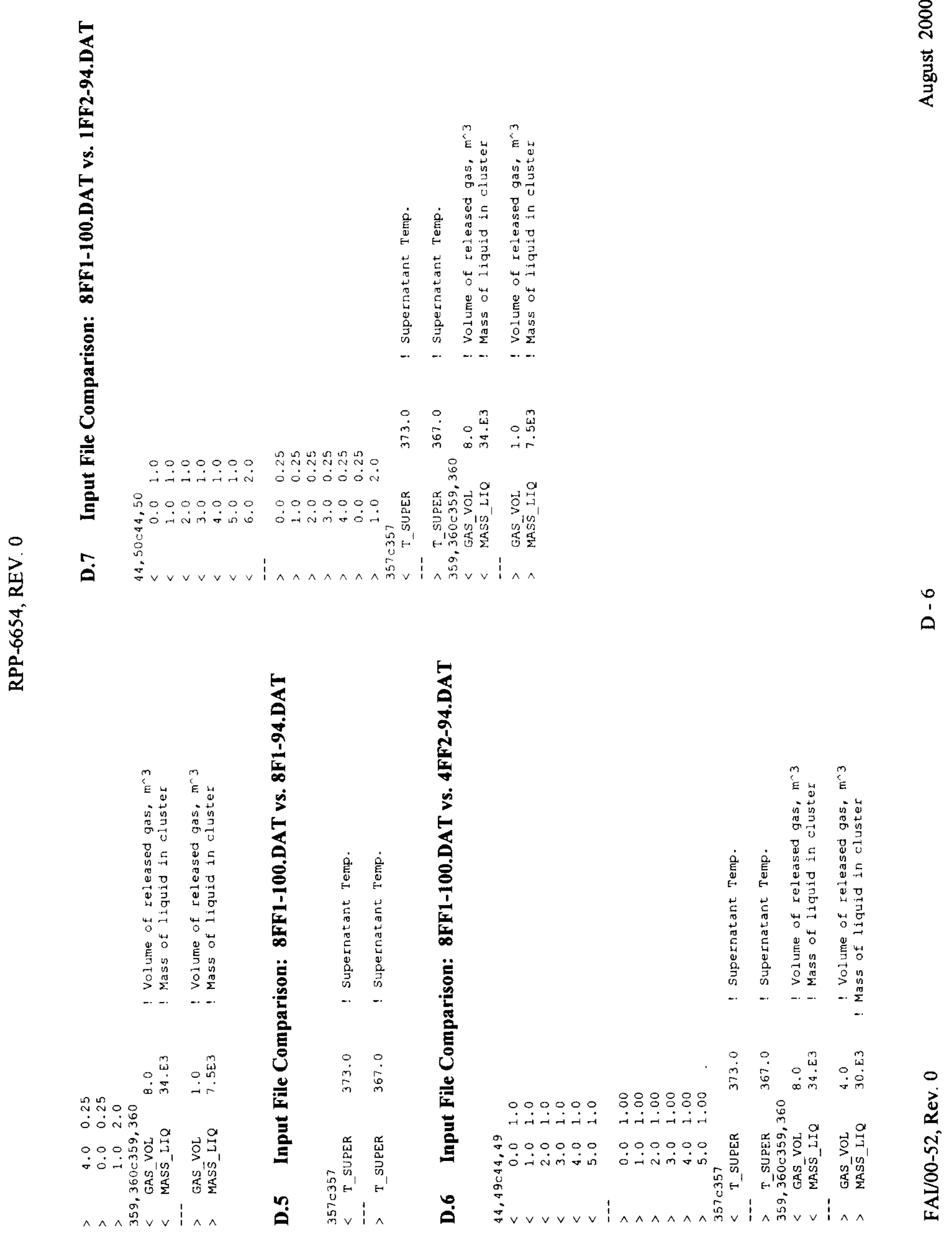


RPP-6654, REV. 0

\section{APPENDIX E \\ QUALITY ASSURANCE DOCUMENTS}

Included here are:

1. Calculation Note Cover Sheet.

2. Authorship and Reviewer Table.

3. Calculation Note Methodology Checklist. 
FAUSKE \& ASSOCIATES, INC.

CALCULATION NOTE COVER SHEET

\section{SECTION TO BE COMPLETED BY AUTHOR(S):}

Page E-2

Calc-Note Number _ FAI/00.52

Revision Number

0

Title _. Tank Bump Accident Potential and Consequences During Waste Retrieval

Project No. or

Project Nuclear Safety \& Licensing Shop Order

CHGOIC

Purpose: Extend the waste tank bump analysis to retrieval operations.

Results Summary: Physical models, criteria, frequency, and consequences are provided.

References of Resulting Reports, Letters, or Memoranda (Optional)

Author(s):

Name (Print or Type)

Boro Malinovic

Michael Epstein

Martin Plys
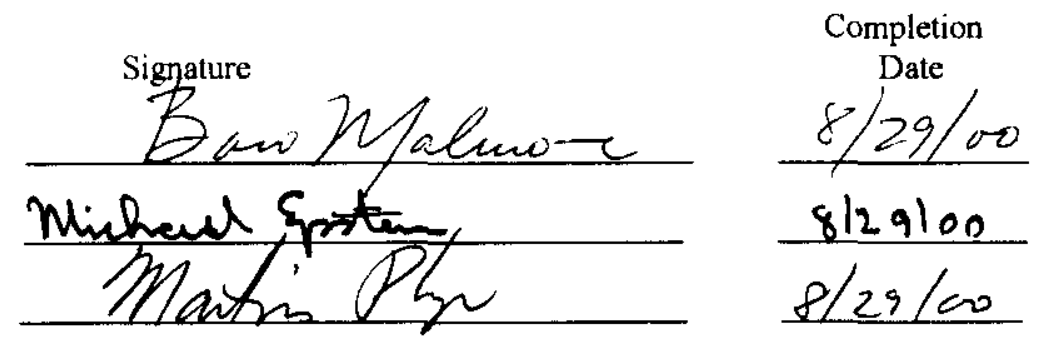

SECTION TO BE COMPLETED BY VERIFIER(S):

\section{Verifier(s)}

Name (Print or Type)

Boro Malinovic

Michael Epstein

Martin Plys

Method of Verification: Design Review

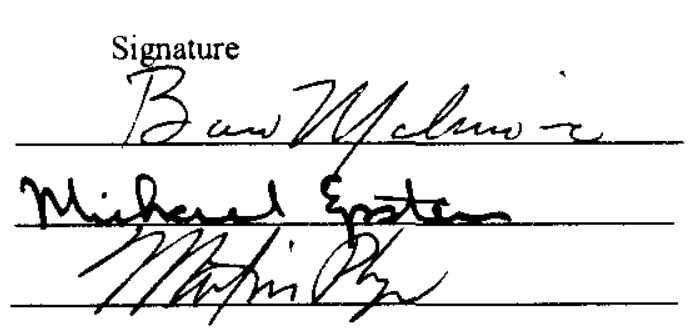

Independent Review or Alternate Calculations $\mathrm{X}$
Completion

Date

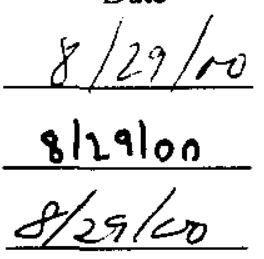

Other (specify)

\section{SECTION TO BE COMPLETED BY MANAGER:}

Responsible Manager:

Name (Print or Type)

Martin G. Plys

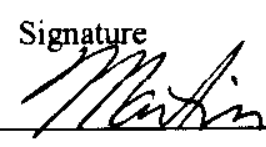

E - 2
Approval

Date

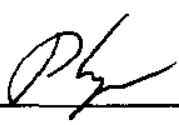
, Testing

FAI/00-52, Rev. 0

August 2000 
RPP-6654, REV. 0

\begin{tabular}{|c|c|c|}
\hline Section & Author & Reviewer \\
\hline 1 & Martin G. Plys & Boro Malinovic \\
2 & Boro Malinovic & Martin G. Plys \\
3 & Boro Malinovic & Martin G. Plys \\
4 & Michael Epstein & Boro Malinovic \\
5 & Boro Malinovic & Martin G. Plys \\
6 & Boro Malinovic & Michael Epstein \\
7 & Boro Malinovic & Martin G. Plys \\
App. A & Michael Epstein & Boro Malinovic \\
App. B & Boro Malinovic & Martin G. Plys \\
App. C & Boro Malinovic & Martin G. Plys \\
App. D & Boro Malinovic & Martin G. Plys \\
App. E & N/A & N/A \\
App. F & N/A & N/A \\
\hline
\end{tabular}




\section{CALCULATION NOTE METHODOLOGY CHECKLIST}

CHECKLIST TO BE COMPLETED BY AUTHOR(S)

1. Is the subject and/or the purpose of the design analysis clearly stated?

2. Are the required inputs and their sources provided?

YES • NO • N/A

3. Are the assumptions clearly identified and justified?

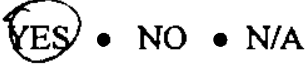

4. Are the methods and units clearly identified?

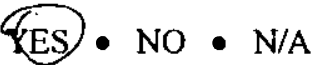

5. Have the limits of applicability been identified?

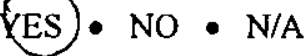

(Is the analysis for a 3 or 4 loop plant or for a single application.)

6. Are the results of literature searches, if conducted, or other background data provided?

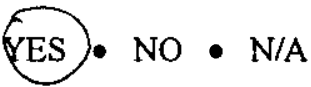

7. Are all the pages sequentially numbered and identified by the calculation note number?

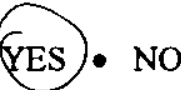

8. Is the project or shop order clearly identified?

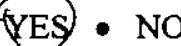

9. Has the required computer calculation information been provided?

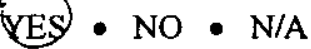

10. Were the computer codes used under configuration control?

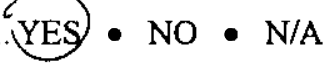

11. Were the computer code(s) used applicable for modeling the physical and/or computational problems identified? (Is the correct computer code being used for the intended purpose.)

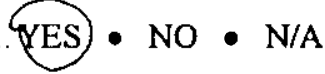

12. Are the results and conclusions clearly stated?

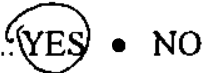

13. Are Open Items properly identified

14. Were approved Design Control practices followed without exception? (Approved Design Control practices refers to guidance documents within

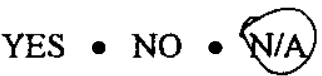
NSD that state how the work is to be performed, such as how to perform a LOCA analysis.)

15. Have all related contract requirements been met?

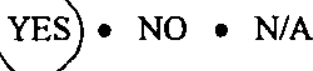

NOTE: If NO to any of the above, Page Number containing justification: 
RPP-6654, REV. 0

\section{APPENDIX F CHECKLISTS FOR TECHNICAL PEER REVIEW}




\title{
CHECKLIST FOR TECHNICAL PEER REVIEW
}

\author{
Document Reviewed: RPP-6654 draft, Tank Bump Accident Potential and Consequences \\ During Waste Retrieval
}

Scope of Review: Gas retention and release behavior and modeling; tank thermal behavior and modeling

Yes No NA

[x] [] [] Previous reviews are complete and cover the analysis, up to the scope of this review, with no gaps.

[x ] [] [ ] Problem is completely defined.

[x ] [ ] [ ] Accident scenarios are developed in a clear and logical manner.

[x] [ ] [] Necessary assumptions are explicitly stated and supported.

[] [] [x ] Computer codes and data files are documented.

[x] [] [] Data used in calculations are explicitly stated.

[x ] [] [] Data were checked for consistency with original source information as applicable.

[ ] [x] [ ] Mathematical derivations were checked including dimensional consistency of results. [most, but not all derivations were checked - CWS 8/22/00]

[x ] [ ] [ ] Models are appropriate and were used within their established range of validity or adequate justification was provided for use outside their established range of validity.

[ ] [ ] [ $\mathbf{x}]$ Spreadsheet results and all hand calculations were verified.

[] [] [ $\mathrm{x}$ ] Software input is correct and consistent with the document reviewed.

[] [] [x] Software output is consistent with the input and with the results reported in the document reviewed.

[] [ ] [x ] Limits/criteria/guidelines applied to the analysis results are appropriate and referenced. Limits/criteria/guidelines were checked against references.

[] [] [x] Safety margins are consistent with good engineering practices.

[x] [] [] Conclusions are consistent with analytical results and applicable limits.

[x ] [] [] Results and conclusions address all points in the purpose.

[] [] [x] The document was prepared in accordance with HNF-2353, Section 4.3, Attachment B, "Calculation Note Format and Preparation Instructions".

\section{[ x] [] [] Concurrence}

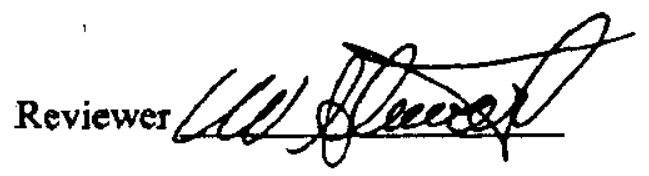

Date: $8 / 22 / 00$ 
RPP-6654, REV. 0

\section{CHECKLIST FOR TECHNICAL PEER REVIEW}

Document Reviewed: RPP-6654

Scope of Review: The review consisted participation in a series of several meeting in which FAI presented their work and a review of the subject report. Items identified as NA below were not included in this review.

Yes No NA

[] [] [ $\mathrm{x}$ ] Previous reviews are complete and cover the analysis, up to the scope of this review, with no gaps.

[x] [] [] Problem is completely defined.

[x] [] [] Accident scenarios are developed in a clear and logical manner.

[ $x$ ] [] [] Necessary assumptions are explicitly stated and supported.

[x] [] [] Computer codes and data files are documented.

[x] [] [] Data used in calculations are explicitly stated.

[] [] [x ] Data were checked for consistency with original source information as applicable.

[] [] [x ] Mathematical derivations were checked including dimensional consistency of results.

$[\mathrm{x}]^{1}[]$ [] Models are appropriate and were used within their established range of validity or adequate justification was provided for use outside their established range of validity.

[] [] [ $x$ ] Spreadsheet results and all hand calculations were verified.

[] [] [ $x$ ] Software input is correct and consistent with the document reviewed.

[1 [] [ $x$ ] Software output is consistent with the input and with the results reported in the document reviewed.

[x] [] [ ] Limits/criteria/guidelines applied to the analysis results are appropriate and referenced. Limits/criteria/guidelines were checked against references.

[] [] [ $x$ ] Safety margins are consistent with good engineering practices.

[x] [] [] Conclusions are consistent with analytical results and applicable limits.

[ $x$ ] [ ] [] Results and conclusions address all points in the purpose.

[] [] [x] The document was prepared in accordance with HNF-2353, Section 4.3, Attachment B, "Calculation Note Format and Preparation Instructions".

\section{[x] [1] [] Concurrence}

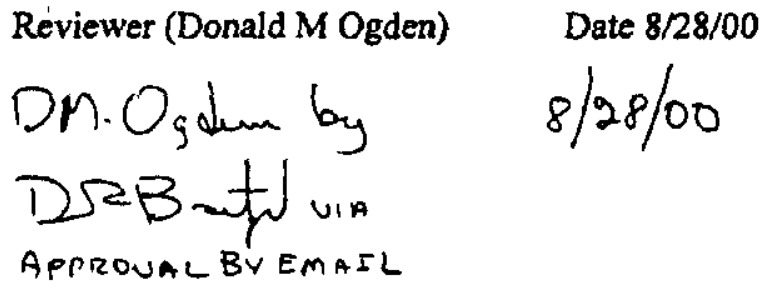

\footnotetext{
' Reviews conducted by John Marvin, Inc JMI for related document RPP-6213 identified some areas of concem relative to the applicability of the models. A consensus was not reached. The JMI RCR comments for RPP-6213 document the areas of disagreement. These issues also apply to RPP-6654.
} 
RPP-6654, REV. 0

This page intentionally left blank. 